\title{
SURVIVING HILLSBOROUGH
}

Sally Day

A thesis submitted in fulfilment of the requirements for the degree of Master of Arts in Criminology

Institute of Criminology

Victoria University of Wellington

October 2016 


\begin{abstract}
This thesis explores trajectories of survival in the long-term aftermath of the 1989 Hillsborough disaster. Despite the vast amount of literature on Hillsborough, there is little knowledge regarding the subjective experiences of survival in the political climate of denial, collusion and cover-up. Therefore, this thesis identifies how 'survivors' have understood and experienced their 'survival' from a major disaster and the subsequent injustices, and in this context considers what is required to 'survive'. Together with informal conversations with key informants, the researcher conducted nine qualitative semi-structured interviews with individuals who experienced the disaster in various capacities, in order to critically examine the factors that have assisted or inhibited individual attempts at survival. The findings determined that there are various pathways to survival however all are impacted by the wider official and collective response to 'survivors'. The findings demonstrate that the official expectation is that 'survivors' can and will navigate their own personal survival but the lived experience of survival determines that, in reality, 'survivors' need a continuous multi-faceted institutional and social response. Contextual factors unique to continuing a life after 'Hillsborough' are discussed. The concluding argument interprets that 'survival' is a continual process, and responses towards 'survivors' can either support quality of life or cause revictimisation.
\end{abstract}




\section{Acknowledgements}

Many people have supported me in different ways this year and although they don't all feature here, I am grateful to them all.

Steph, thank you for granting all my leave from work, for your understanding I will always be grateful. Ginny, a kindred spirit, I appreciate the many ways you have supported me during this year. The 'CBB' family, thank you for your encouragement and giving me time out with the littlen's at your place. My second home at no.4, thank you for supporting this project and for the education throughout my life.

Fellow $9^{\text {th }}$ floor students, Heidi, Hayley, Jordan, Julie, Anj, Charlotte, Sanna and Toni, you have helped me navigate university life and I am deeply grateful for our friendships. Hayley and Jordan, you have been an invaluable source of support! Heidi, thank you for all that you do for me, this would have been a very different journey without you, and so I am truly grateful that we have crossed paths in this life.

Jordan, Natalya \& Javi, and Heidi \& Charley, thank you all for kindly letting me stay at your homes whenever I couldn't face the commute home.

Paul, Thomas \& Nikki thank you for all the giggles, banter and sibling solidarity. Mum \& dad, I am immensely grateful to you both for instilling in me a strong sense of social justice, for teaching me to have courage in life, and for loving me even when I'm sure I wasn't very lovable during this time!

Julian, thank you for being so kind to introduce me to your friends: Angela, Paul and Jennifer Sneade. The Sneade's, I will always be grateful to you for warmly welcoming me into your Liverpudlian home and for showing me around the vibrant city.

Phil Scraton, I would like to acknowledge you for being so generous with your time and knowledge, and for putting me in touch with some exceptional people. 
To my dear supervisor Elizabeth Stanley, your warmth, compassion and dedication to social justice has encouraged me throughout this process. Lizzy, I am ever grateful for your patience, guidance, and knowledge which have supported me in producing this work. You have taught me so much over the years and I feel truly honoured to have had such a remarkable woman as my supervisor - thank you.

Most importantly, I would like to acknowledge each of my participants who took part in this project: Nick Braley, Peter Carney, Sheila Coleman, Paul Dunderdale, Dan Kay, Steve Kelly, Tim Knowles, Tony O'Keefe, and Adrian Tempany. Each of you gave up your time to share your journey, and I owe immense gratitude for the insight and understandings this gave me. Your stories of resolute courage, inner strength, and tenacity in the face of constant adversity and injustice deeply moved me. This work would not have been possible without your input - thank you all. 


\section{Abbreviations}

CCTV - Closed Circuit Television

FA - Football Association

HFSG - Hillsborough Family Support Group

HIP - Hillsborough Independent Panel

HJC - Hillsborough Justice Campaign

IPCC - Independent Police Complaints Commission

LFC - Liverpool Football Club

NFFC - Nottingham Forrest Football Fans

PTG - Post-Traumatic Growth

RIV - Recent Inquest Verdict

SYP - South Yorkshire Police

WMP - West Midlands Police 


\section{Walk On}

In 2003 Peter Carney, a survivor from Pen Three, was asked why the Hillsborough Justice Campaign walk every year on the anniversary, from the HJC shop to the memorial on Anfield Road. Peter wrote this in response, and reads it at the end of each walk.

We walk with hope in our hearts and friends at our side in a struggle to continue challenging the verdicts and opinions which contradict the living experiences of those who survived pens three and four, and those who were bereaved by the storm we have come to know as Hillsborough.

We Walk On to share companionship and show the challenge continues through Anne Williams' efforts to have the cause and verdicts on her son Kevin's death overturned. To show that survivors still suffer the ill effects of the disaster and challenge the legal lice who ripped us off when we needed their help.

We Walk On to continue our challenge to the Rancid rag, and their rugger rat mates, who spit in our face when all we ask for is the truth, the whole truth, and only the real truth be told about its role in the writing of the Hillsborough history.

We Walk On to show solidarity and share proper sunshine with those we know, who've had to face a similar struggle. Like the father arrested at Walton Hospital, while his infant child's body was taken to Alder Hey. Or the mother incarcerated at Styal while her babies lay helpless, as well as the woman whose loss, pain and suffering at the hands of independent experts has been ignored and inflated by a soulless system.

We Walk On to gather and gain support from each other; support from the likes of you here today and everyone else who takes the time out to listen; support from those who buy and wear our badges or stickers, those who call into our shop, read our books or wear our T shirts; those who play or watch our footy tournaments, attend or perform at our gatherings, read our website or buy at our auctions, make donations 
or wear our bands. And especially those that tell the tales of Hillsborough in a manner that is true to and reflects our struggle.

That's our support in the face of this storm we know as Hillsborough. We Walk On because we know with that support we can deal with and change the experience of Hillsborough. With that support we can get stronger about how we feel, clearer about what we see and surer about what we need to say or do.

We Walk On because we know we can change the experience, the verdicts, opinions, knowledge and understanding of Hillsborough. We can change the minds of FHM magazine, gain a retraction from Michael Moore and backlash the babblings of Boris.

We Walk On to run a base of our own, and with the help of friends like you, we can continue to show that our living experience is the real truth about Hillsborough. Through our actions and your support this can be seen to be so.

We Walk on because we can and while you hold our hand in the struggle through this storm we will never walk alone.

We Walk On because we can. 


\section{Contents}

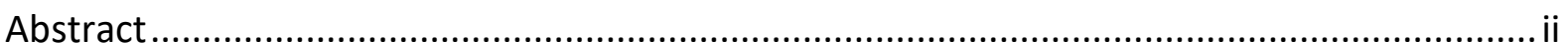

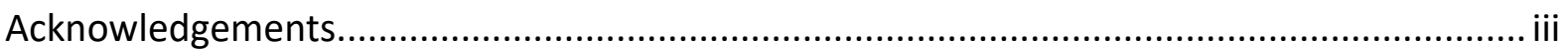

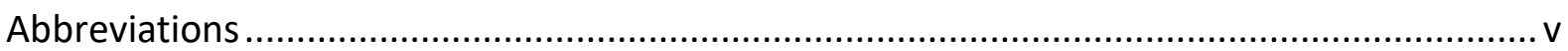

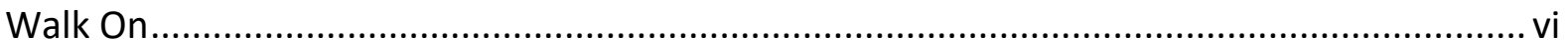

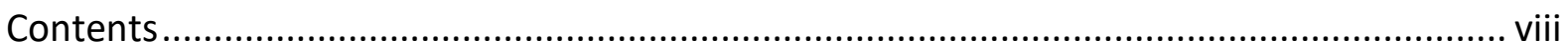

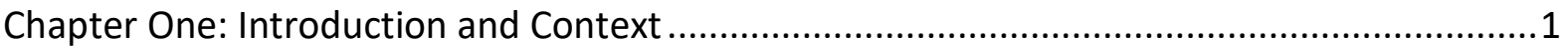

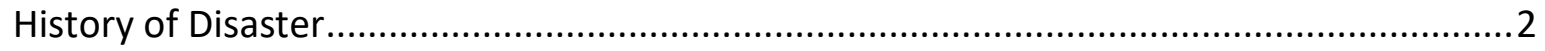

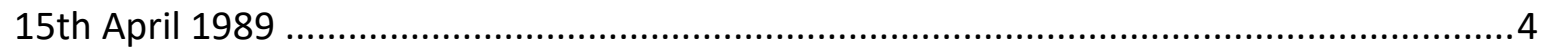

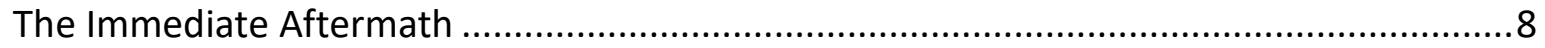

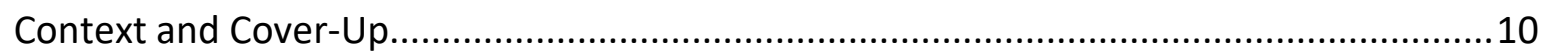

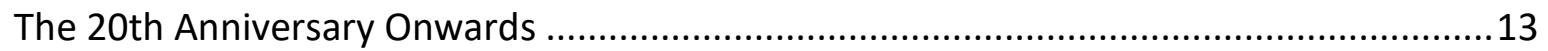

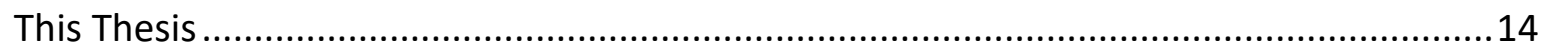

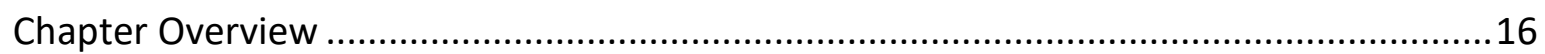

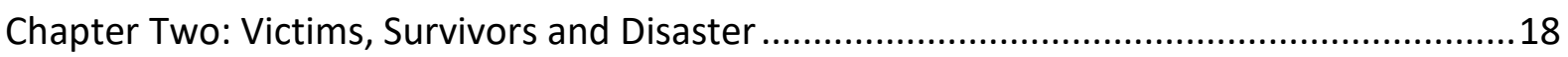

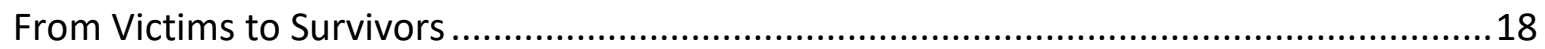

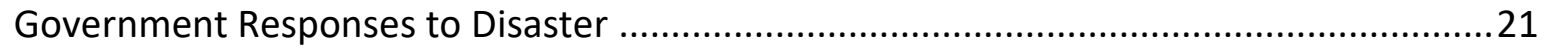

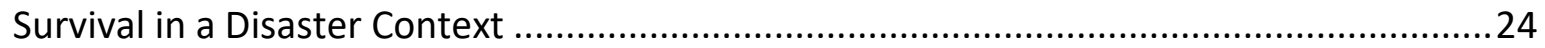

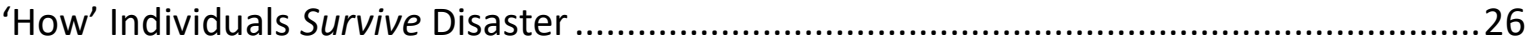

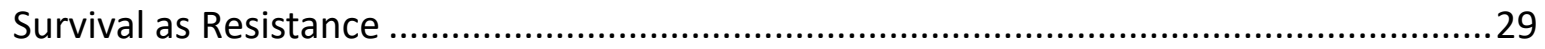

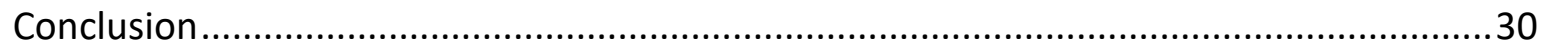

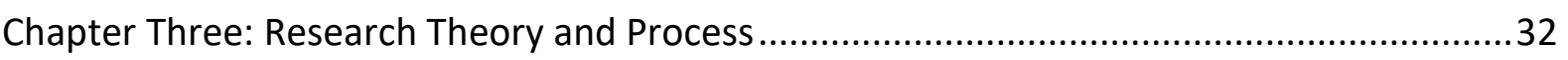

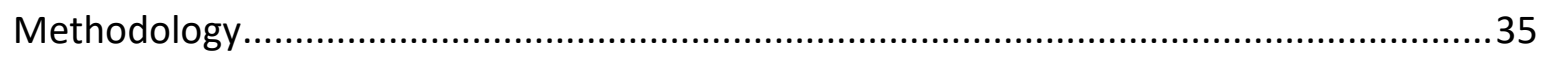

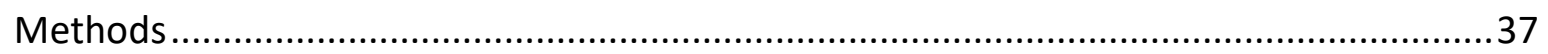

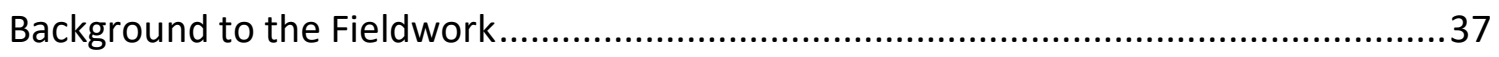




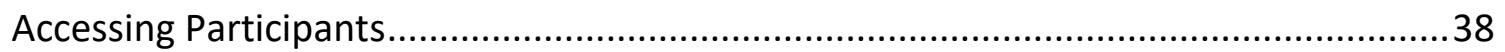

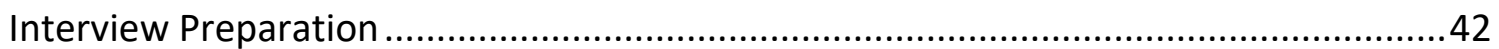

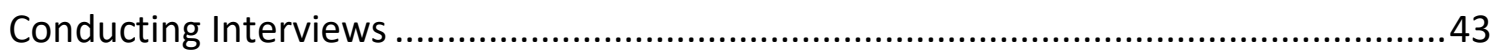

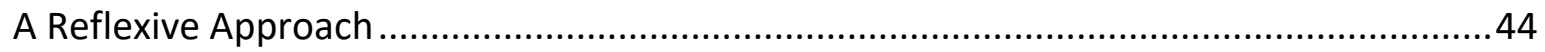

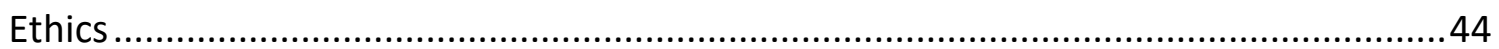

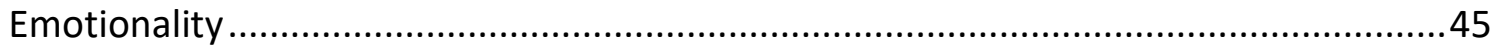

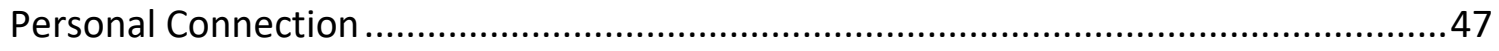

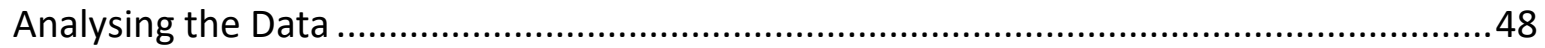

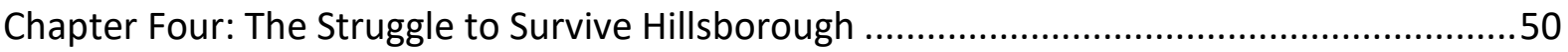

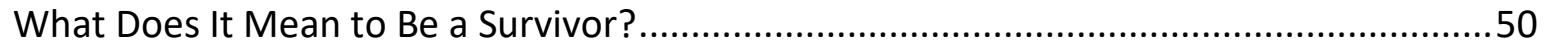

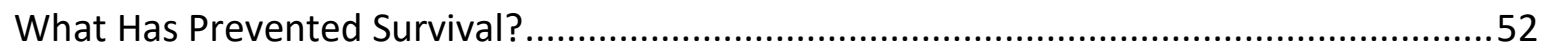

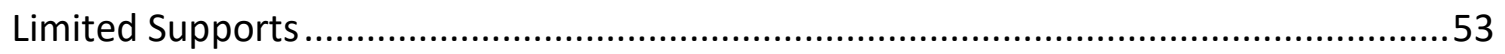

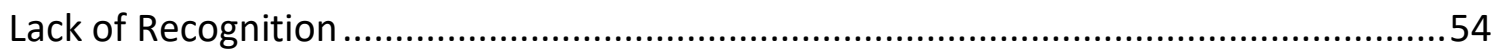

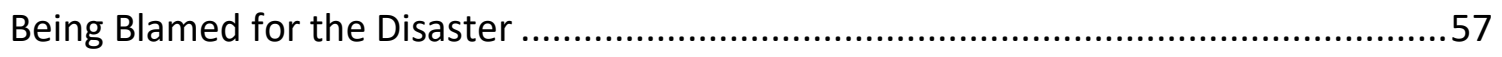

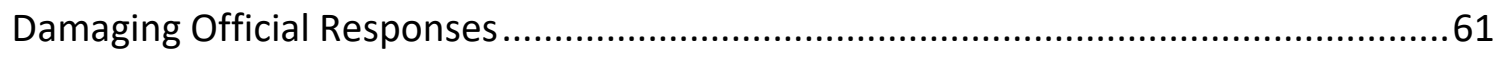

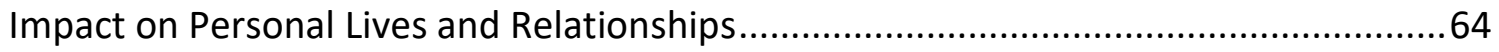

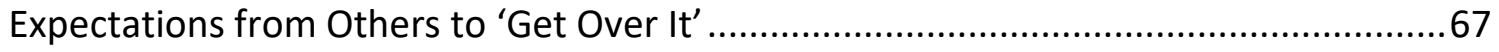

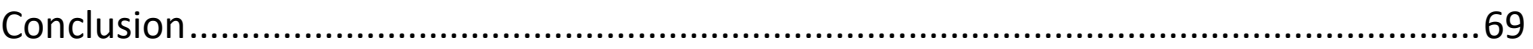

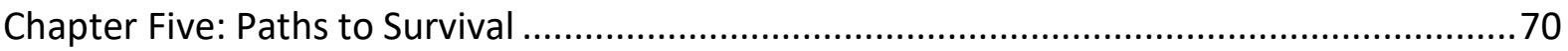

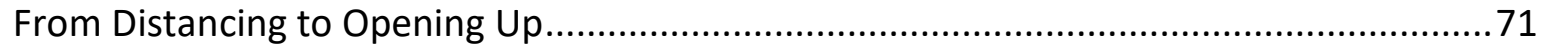

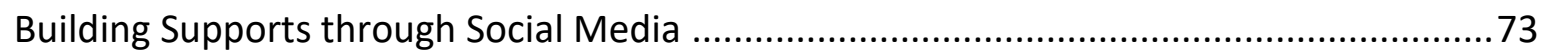

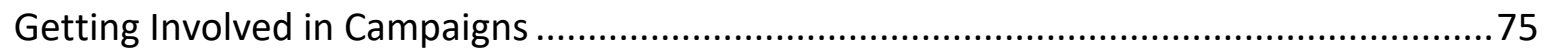

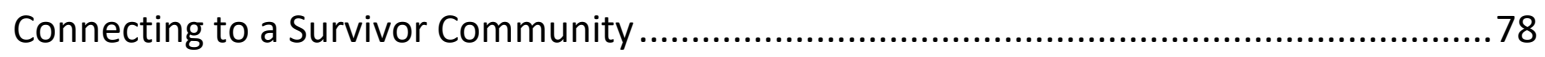

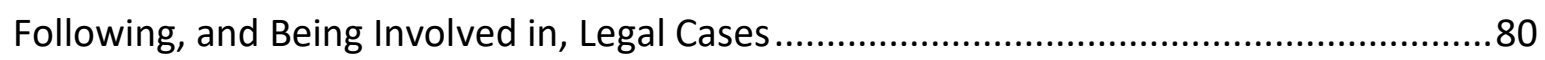

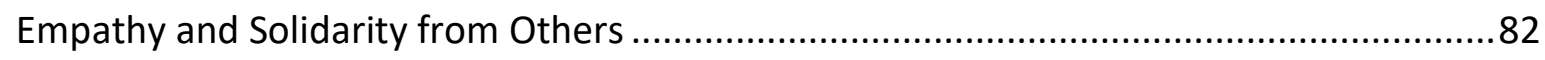

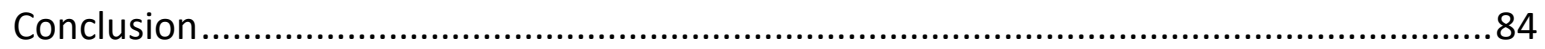


Chapter Six: Moving Beyond Hillsborough .85

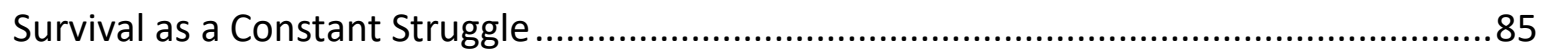

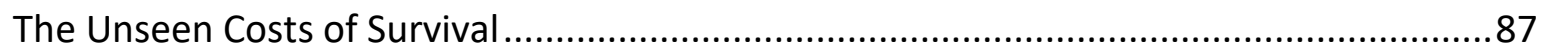

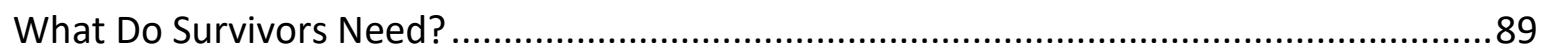

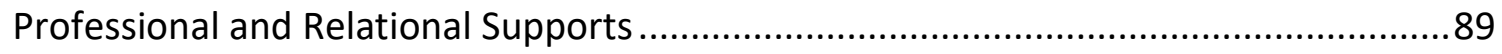

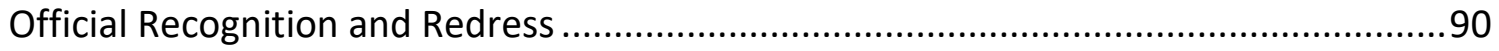

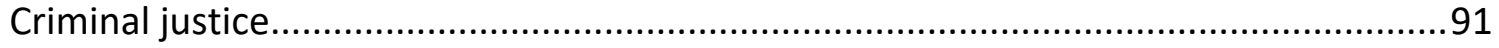

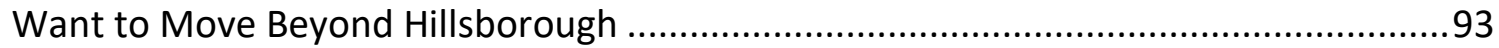

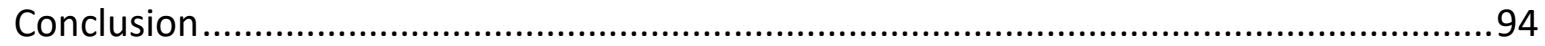

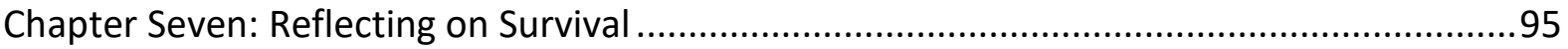

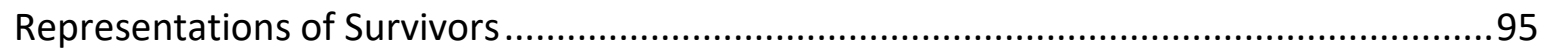

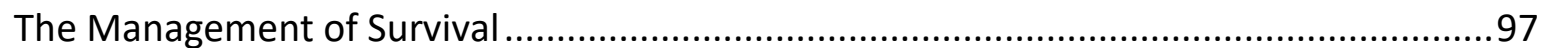

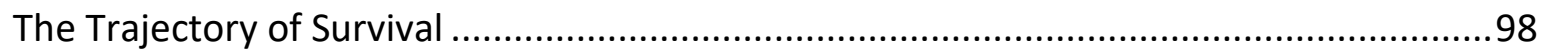

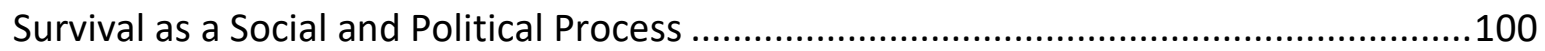

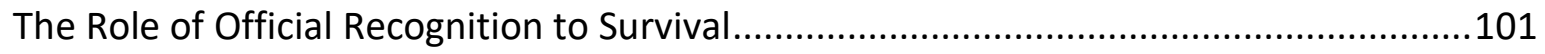

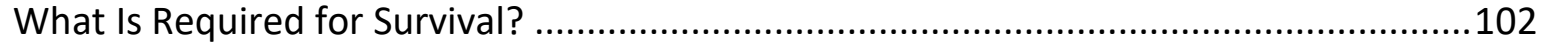

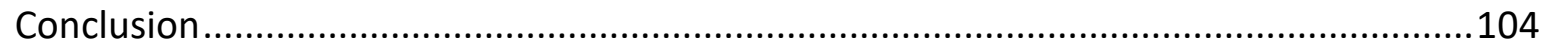

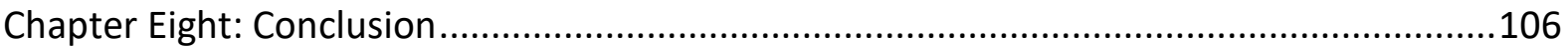

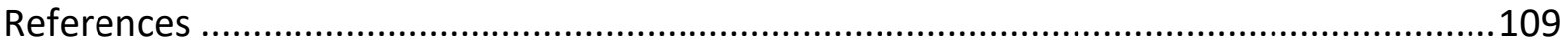

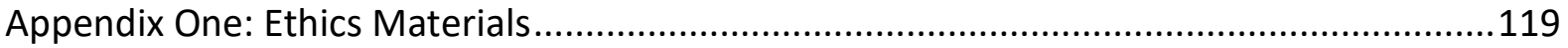

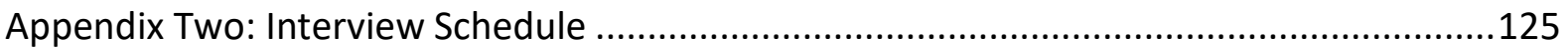




\section{Chapter One: Introduction and Context}

It has taken 8,551 dark days and a report consisting of 395 pages to finally expose to the world what we all knew from day one: the fans were not to blame (Aspinall, 2013: para. 14).

96 men, women and children were unlawfully killed at the Hillsborough football stadium on the $15^{\text {th }}$ of April 1989 (Hillsborough Inquest Verdict Ruling, 2016). While the behaviour of football fans attending the match played no part in causing or contributing to the 'disaster' 1 (Hillsborough Independent Panel Report, 2012; RIV, 2016), they were regarded as responsible, for many years. Official misinformation, misrepresentation, falsified evidence and a deliberately constructed incorrect narrative, had informed the world with this 'version' of the Hillsborough disaster. It took almost three decades for the true facts of the causes of the disaster and subsequent cover-up to be officially recognised and legally recorded. Many of the people who attended the match, their families and campaigners, realised the true nature of the disaster on the day and have discovered various aspects of the cover-up over the years. However, the 2012 Hillsborough Independent Panel Report (HIP Report) and the recent 2016 Inquest Verdict Rulings (RIV) officially exposed the factual causes of the disaster, what occurred on the day, and the extent of the sustained cover-up, including the role and responsibilities of the authorities involved2. Due to the longevity of the controversial issues regarding the official rulings on Hillsborough, throughout this thesis the term 'Hillsborough' is used to refer to the event on the day, but also to the long-term injustices that have ensued for survivors and bereaved families.

\footnotetext{
1 'Disaster' is a contentious term, as outlined in chapter two disasters are often the result of human actions or inactions. Throughout the remainder of this thesis the term is written without single quotation marks, however I acknowledge and support the wider debate regarding the definition and application of this term.

2 It is beyond the scope of this thesis to adequately discuss all the significant information related to Hillsborough. For detailed evidence and facts, see: the Hillsborough Project's publications, the HIP Report and the RIV court transcripts.
} 
This chapter provides an overview of the social and political context in which the Hillsborough disaster occurred. It illustrates the significance of the political climate at the time in creating circumstances and facilitating an environment ripe for disaster. The chapter demonstrates the historical inadequacies and failures of official systems, responsible for ensuring crowd safety at football matches, prior to the Hillsborough disaster. It gives an account of the events on the day of the disaster, in the immediate aftermath, and of the official responses during that time. From here, this chapter describes how state institutions and agencies colluded in their responses to orchestrate a systemic and sustained cover-up of the disaster. It presents an overview of the grassroots campaigning that lobbied against the official narrative and establishment rulings on Hillsborough, and their success in influencing events, which caused the formation of the HIP and outcome of the RIV. This chapter concludes by presenting a justification for the current study and outlines the subsequent chapters in this thesis.

\section{History of Disaster}

You don't expect to go to a football match and die (Nicol, 2004: 183).

There is no standard definition of 'disaster', which makes it difficult to accurately determine how many disasters have occurred at football matches. In the UK, the first recorded football disaster dates back to 1902, and from that point there is a thoroughly documented history of injuries and deaths of fans attending matches (Walker, 2005). The commodification of what was, historically and predominantly, a working class game created a culture of complacency in terms of adequate safety provisions (Moore, 2016; Tempany, 2016). The preoccupation with profit has been so extreme that the fallout has continuously put fans' lives at risk (Scraton, 2009). Fans attending matches place their trust in the competency of organisations in charge of monitoring all aspects of safety involved. However, those responsible for operating the running of football consistently neglected to provide adequate safety measures (Scraton, Jemphrey and Coleman, 1995).

Some stadiums have been host to more than one disaster, where the exact same circumstances have been left unaddressed and so have led to another disaster years later. The Ibrox stadium in Glasgow, for example, has experienced three disasters, totalling over 
770 injuries and 93 fatalities (Rangers Football Club, 2016). Two of the three disasters at Ibrox occurred in the same exit stairwell, which had a recorded history of repeated accidents (Walker, 2005). In the claims for damages awarded after the 1971 disaster, Sheriff James Irvine Smith found the disaster "was due to the fault and negligence of the defenders, Rangers F.C." (McArdle, 2016: para. 7). The tragedies at Ibrox can be found replicated at other stadiums (Scraton, Jemphrey and Coleman, 1995; Walker, 2005). There have been countless complaints by fans and authorities to the Football Association (FA) regarding the 'near' death situations at games (HIP Report, 2012) and numerous research reports, together with many recommendations, regarding the circumstances that are ingredients for disaster3.

The 1989 Hillsborough disaster was a foreseeable and preventable tragedy. Sheffield's Hillsborough football stadium had a well-documented history of inadequate safety issues, dating back to 1914 when a wall collapsed injuring 80 fans (HIP Report, 2012). Throughout the 1980 s, the stadium was the site for several crushing incidents. At a 1981 match between Tottenham Hotspurs and Wolverhampton Wanderers, the West Stand terrace exceeded capacity by over 300 people and the crushing was so severe that 38 Spurs fans were injured with broken bones (Tempany, 2016: 5). During this incident, police opened the perimeter gates, ensuring fans could exit the terrace and sit alongside the pitch (Tempany, 2016). Fans made written complaints to the FA and as a result the Hillsborough stadium was withdrawn from the FA Cup semi-final list as a viable venue (HIP Report, 2012). At this point, the ground did not comply with the minimum requirements of the Home Office Safety of Sports Grounds Act (1975) or Green Guide (1976) standards (HIP Report, 2012).

From 1981 to 1987, a series of modifications occurred at Hillsborough. Like many grounds, it became a mixture of newly installed fittings and old decrepit structures still in existence from 1899 (HIP Report, 2012). One significant modification was the introduction of lateral fences on the terracing, as recommended by the South Yorkshire Police (SYP) (HIP Report, 2012). These created three smaller pen enclosures with restricted access to the pitch through one

3 See the Moelwyn Hughes Burnden Park Report 1946, 1968 Harrington Report, the 1972 Wheatley Report that led to the Green Guide safety guidelines, and the 1977 McElhone Report (HIP, 2012). 
narrow locked gate at the front of each pen. Despite having an invalid safety certificate, the Sheffield County Council and SYP were satisfied with the modifications and Hillsborough was reinstated as an FA Cup semi-final venue in 1987 (HIP Report, 2012). The Independent Panel concluded in its 2012 report that "safety of the crowd admitted to the terrace was compromised at every level" (p6).

Further problems ensued. At a 1987 Leeds-Coventry match, Chief Superintendent Mole publicly acknowledged that police checks on arriving fans had delayed their entry into the ground, and had contributed to a crush at the Leppings Lane end of the ground (Scraton, 2009). He made the decision to delay kick off by fifteen minutes to ensure their safe entry (Tempany, 2016). The following year, Liverpool and Nottingham Forrest fans complained of severe crushing in central pens three and four; some fans collapsed and were passed above the heads of others down to the front (Scraton, 2009). However, fatalities were prevented when senior police officers placed officers in front of the entry tunnel to the West Stand terrace preventing any more people entering the pens (HIP Report, 2012).

The inadequacies of the layout and structure of the Hillsborough ground, and the failures of responsible institutions to adhere to legal safety requirements, had been consistent over a prolonged period of time. They provided the circumstances for the possibility of further disaster.

\section{5th April 1989}

Liverpool Football Club (LFC) was matched against Nottingham Forrest Football Club (NFFC) in the FA Cup semi-final (Scraton, 2004). Many fans travelled from Liverpool to Sheffield to attend the game at the Hillsborough stadium (Scraton, 2004). The SYP directed traffic on arrival into Sheffield; cars, coaches and buses were stopped and spot-searched for alcohol and pre-bought tickets. On leaving transport, fans were briefed and escorted by police to the ground (Scraton, 2004). LFC fans had a well-known reputation for good behaviour and police did not expect any trouble (Scraton, 2004). Police reported fans were in good spirits, and there was a good-humoured atmosphere as excitement for the match grew on the approach to the ground (Scraton, 2004). 
LFC had a larger following than NFFC. Yet, despite complaints from the previous year, the tickets allocated to NFFC fans significantly exceeded the amount allocated to LFC fans. The decision was made to allocate LFC fans the smaller Leppings Lane end of the ground, which had to process all fans for the entire North stand, West stand and Leppings Lane terrace (Scraton, 2009). The 23 turnstiles at the Leppings lane outer concourse, used to process 24,256 fans, were malfunctioning (L Taylor, 1990; HIP Report, 2012). Fans reported "very little police presence" and, unlike previous years, no stewarding services were provided by the FA or the SYP around the ground (Scraton, 2009: 53).

Three weeks before the game, Chief Superintendent David Duckenfield, who lacked professional experience at managing football crowds, was given the job of Match Commander (McMillan, 2009; Scraton, 2009). Duckenfield made the unconventional decision that fans, many who had never visited Hillsborough before, should find their own seating and standing level (McMillan, 2009; Scraton, 2009). This prevented police officers from monitoring entry into the pens. Insufficient and misleading signage around the ground left fans to assume one tunnel, which led into central pens three and four, was the main or only entry to the stands. Many fans who had attended in 1988 assumed that because the tunnel was open it meant there was room in the pens because, in 1988 , access to the tunnel was prevented when the pens were full (Scraton, 2009).

Although the majority of fans arrived early, there was a dangerous build-up at the Leppings Lane turnstiles (Scraton, 2004). The small queuing area, just like previous years, proved inadequate to hold the fans waiting to be processed, causing a dangerous crushing situation (McMillan, 2009; Scraton, 1999). Duckenfield made the decision to open exit gate $C$ but did not provide crowd safety control inside the grounds to manage the influx of fans (Scraton, 2009). This meant that police did not direct the flow of entering fans and no officers closed the tunnel once the pens were full (Scraton, 1999). This decision transferred the bottle-neck crush at the turnstiles directly inside the stadium, where fans were immediately met with the misleading signage above the tunnel that led to the central pens three and four. A mass of fans were funnelled down the one in six gradient tunnel, which breached the Green Guide's 
safety recommendations, literally unable to see that the pens were already full (Scraton, 2009).

Duckenfield remained adjacent to the central pens in the police control box (Scraton, 2004). The control box provided closed circuit television (CCTV) live streaming of the pens (McMillan, 2009; Scraton, 2004). However, the CCTV was not vital, as Duckenfield had "a commanding view of the pens below" (HIP Report, 2012: 37). Photos taken at 2:30pm demonstrate that pens three and four were overcrowded (Scraton, 2009). They were filled to three times their capacity before a safety barrier in pen three collapsed at approximately 3pm (Scraton, 1999). Police gave no immediate help, were slow to react, and their response was fatally inadequate (Scraton, 2004; Scraton, Jemphrey and Coleman, 1995).

The experience of the crushing in the pens amounted to unimaginable horrors. The immense pressure from the crushing has been described as like "a vice getting tighter and tighter and tighter" (Scraton, 2009: 63). Survivors have spoken about the helplessness they felt from being paralysed and knowing there was literally nothing they could do to save themselves or the people around them (Scraton, 2009). One survivor described it as "like watching a war scene in a movie but it wasn't a war: it was only a football match and those people should never have been killed" (McDougall, 2015: para. 5).

The crush was a harrowing ordeal forcing people to endure "pure pain and agony" (Derbyshire, 2012: para. 15). Initially there was widespread panic. Survivors spoke of fans screaming to the loved ones they had been separated from, screaming at others to stay alive, but eventually as time went on "people gave up screaming for help to save the air in their lungs" (Tempany, 2009: para. 10). Survivors watched fans vomiting uncontrollably on themselves, heard the cracking of bones, saw eyes bulging, tongues stuck out, people turning blue; "It was sheer horror" (Scraton, 2009: 61). One survivor said "somebody bit a chunk out of my shoulder because they must have been in agony" (Scraton, 2009: 61). As the crush went on those still alive began to realise they were surrounded by people "standing dead, bolt upright" (Tempany, 2009: para. 9). The fans at the front of the pens were so squashed their faces were disfigured and "distorted by the mesh" of the fences (Scraton, 2009: 61). One officer saw a young boy turning purple pressed up against the mesh. He held his hands and 
"told him to hang on", but the perimeter gate was still locked (Scraton, 2009: 68). Piles of fans were buried under one another when the safety barrier collapsed at the front of pen three, some dead, and some fighting to stay alive.

Even in this desperate situation there were valiant acts of humanity. Many fans courageously attempted to save lives (Scraton, 2009). People desperately tried to stop each other from falling down and going under the crush. Fans who had the movement of their arms were slapping others on the face to keep them awake (Nelson, 2016). In the West Stands, fans pulled people up, but their body parts were so entangled that it left many physically trapped (Scraton, 2009). Fans gave many a hand or foot up to the stands above; after saving the lives of others, some of these rescuers died inside the pens (Kavanagh, 2005; Scraton, 2009).

While this catastrophe unfolded, fans begged and pleaded with police officers, standing just a few feet away, to open the gates (Kavanagh, 2005). Survivors spoke about the frustration to see the perimeter gates so close, with officers standing idly by, while people had the life crushed out of them (Tempany, 2009). Some fans attempted to climb the spiked overhanging perimeter fence and were aggressively pushed back into the crush by officers on the other side (Kavanagh, 2005). Many survivors said they made eye contact with officers standing around the perimeter fencing and they screamed or mouthed for them to help (Tempany, 2009: para. 14), but they described officers as being "transfixed", stunned, "unresponsive", and looking straight through them (Scraton, 2009: 61: 70). At one point, the front perimeter gate sprung open from the pressure, but police pushed people back in and closed it shut (Scraton, 2009). Many thought "we've been left to die" (Tempany, 2009: para. 15).

Among the dead were family members, mothers, fathers, children, siblings, partners and childhood friends. Some who died in the crush had family members watching the disaster unfold from the side pens. One father said, "I was calling their names as well in the hope that you know they'd know we were there"; his two children both died in pen three (Hicks, 2016: para. 7). Some people were rendered unconscious and woke to find they had survived and their loved ones had not. These are but a few descriptions and examples of the many incidents 
from inside the pens4. The 96 who were crushed died a violent death, in horrific circumstances, at an annual sporting event.

\section{The Immediate Aftermath}

While the perimeter gates were eventually unlocked, senior police officers instructed their juniors to attend a pitch invasion, not an overcrowded crush (Scraton, 2004). With this misinformation, officers denied emergency services entry into the grounds, claiming crowd trouble was occurring and services were not needed (Scraton, 2009). At this point, fans, many of whom had just escaped death, began a spontaneous rescue response.

Some survivors went back into the pens to try to pull free those still fighting for their lives. Many began to pull at the fences from the other side, attempting to alleviate the pressure (Scraton, 2009). Individual officers joined in with rescue efforts and followed the fans' initiatives. Fans ripped down advertising hoardings from around the stadium, to carry the dead and injured the length of the pitch to the gymnasium (Scraton, 2009). Off duty doctors and nurses among the crowd attempted to organise triage and resuscitation efforts. As the fans and survivors led the rescue efforts, the majority of police officers, following orders from senior sergeants, formed a cordon along the pitch (Scraton, 2009).

The official emergency response was fatally inadequate. The serious lack of communication between the police and emergency services, the lack of direction from senior officers, and official actions that prevented services, led to a slow ineffective response (see the HIP Report). The chaos and carnage on the pitch was exacerbated by Match Commander Duckenfield's information to officers that the crush was caused by rioting fans (Scraton, 2009). Therefore, all the instructions from senior officers, and reactions, were informed by this mind-set. An example of the devastating consequences from this insufficient emergency response was that out of the fleet of ambulances to arrive, only three made it on to the pitch, and of the 96 who died only 14 made it to hospital (Scraton, 2009). It has since been found that approximately

\footnotetext{
4 For a more detailed account of the disaster, see the HIP Report.
} 
41-58 of the 96 had the potential to survive if they had received the required emergency care (HIP Report, 2012).

The chaos on the pitch was transferred to the gymnasium, which became a temporary mortuary. There was mass confusion in the gym, there was no first aid equipment or organised triage, and bodies came in so fast that officers could not cope (Scraton, 1999). Emotions ran high as many survivors, officers and medical personnel found themselves overwhelmed with no direction or leadership from senior officers. "Several officers were bewildered and crying" (Scraton, 2009: 78) and some friends and relatives of the dead were hysterical. Amid the chaos there were still survivors and others attempting resuscitation and trying to assist the "walking wounded", before the identification process began (Scraton, 2009: 78).

Duckenfield's initial lie, of fan-blame, set the precedent for the conduct and actions of the officers during the identification process. At a time that required a humanitarian response towards distraught families, officers were largely unprofessional, cavalier and inappropriate. There are numerous examples of unacceptable officer behaviour, including that: people were told their loved ones were alive when they were dead, and those actively searching for missing people were re-directed all over Sheffield between hospitals and the gymnasium, even when officers knew their loved one had died (Scraton, 2009). These incidents have been described as senior officers "playing for time" in order to coherently organise elements of the cover-up (Scraton, 2009: 99).

In the early hours of the next morning, people were eventually escorted back to the gymnasium and told to view a board full of unorganised, uncategorised, polaroid photographs of all the dead; family members collapsed at the sight and some broke down wailing (Gordon, 2014). Officers told family members that the dead "were the property of the coroner" (Scraton, 2009: 104), and they were not "allowed" to touch the dead (Jones, Gordon, 2014). In taking statements, officers took an accusatorial focus on the alcohol consumption of the dead; when a bereaved mother denied her son drank heavily an officer remarked "you'll be telling us he was a virgin next" (Fallon, Gordon, 2014). During this time, many of the survivors 
who had worked so hard to try and save lives, and some who had awoken from unconsciousness hours later, were left to walk away from Hillsborough (Tempany, 2009).

Duckenfield's decision to open exit gate $C$ combined with his failure to then close off the tunnel to pens three and four, have since been found to be the main causes of the crush inside the pens; which resulted in 96 deaths and the severe victimisation of countless others (HIP Report, 2012; LJ Taylor, 1990). These events, how they occurred and how they were responded to, were covered up for almost 24 years. The realities of the disaster and immediate aftermath, as previously outlined, were manipulated and distorted, primarily by those responsible (Scraton, 1999; Scraton, Jemphrey and Coleman, 1995). This caused no accountability and a denial of justice to the dead, bereaved and survivors for almost three decades (McMillan, 2009; Scraton, 1999). For survivors, it also led to their being blamed, almost entirely, for a disaster that was not of their making.

\section{Context and Cover-Up}

At the height of the disaster, the Chief Executive of the FA, Graham Kelly, approached Duckenfield for information. Duckenfield deliberately misled Kelly and said that Liverpool fans had arrived late, drunk, aggressive, without tickets, and had forced exit gate $\mathrm{C}$ open which caused a crush inside the pens (McMillan, 2009; Scraton, 2009). Kelly repeated this account to waiting media and it was broadcast around the world in a matter of minutes (Scraton, 2004). This fabricated version of events set an agenda of blame on Liverpool fans, which later influenced every inquiry and investigation that followed, amounting to numerous miscarriages of justice (HIP Report, 2012; Scraton, Jemphrey and Coleman, 1995).

In order to understand how the lies, denials, and misinterpretation of Hillsborough could be so widely accepted it has to be viewed within the social and political context of the 1980s. British Prime Minister of the time, Margaret Thatcher, pursued a vendetta against all football fans, naming them a "national malaise" (Scraton, 2009: 119; Moore, 2016). She sensationalised the idea of "football hooliganism" and contributed to negative stereotypes of football fans (Hughson and Spaaij, 2011: 285). This political agenda normalised a "them and us" mentality and firmly categorised football fans as an "enemy within" (Scraton, 1999: 280; 
White, 2011: para. 19). This constant narrative heavily influenced those outside the working class to regard football as "a slum sport played in slum stadiums increasingly watched by slum people, who deter decent folk from turning up" (Hume, 2016: para. 17).

It is also important to acknowledge that the Thatcher government maintained an extremely close relationship with the British police force (Chesshyre, 2012; Scraton, 2007), so much so that the Prime Minister led the police force to believe "that they have an inherent right to operate above the law" (Reade, 2012: para. 16). Their relationship has been described as creating an institutional complacency, a shift to hard-line policing tactics, and a "culture of impunity" (Reade, 2012: para. 20). The 1980s were marked with many ruthless confrontations between civilians and the police force such as the Poll Tax riots, the printer's dispute at Wapping, and the miner's strikes (Chesshyre, 2012; Moore, 2016). However, the actions of the SYP at the Orgreave miner's picket are considered to have contributed to the behaviour of senior officers at Hillsborough (Moore, 2016). Prime Minister Thatcher demanded the SYP force to break the Orgreave strike and adopt a more "vigorous interpretation of their duties" (Macintyre, 2014: para. 18). The subsequent violent 'Battle of Orgreave' has never been properly investigated, however this event is said to be deeply linked to Hillsborough - as MP Andy Burnham noted, "the full truth about Hillsborough won't be revealed until Orgreave is investigated" (Barlow, 2016: para. 1; Macintyre, 2014).

Negative perceptions, towards working class populations and football fans, set the precedent and agenda for the cover-up. This political climate influenced many decisions from numerous individuals and agencies, which directly enabled the creation of a cover-up (Chesshyre, 2012). For example: the Hillsborough coroner, Stefan Popper, made the unprecedented decision to take blood alcohol levels from all the dead including the children, the youngest of whom was only ten years old (Scraton, 1999). He also imposed a 3.15pm cut off time on all evidence, incorrectly declaring that the 96 would all have been dead by that time (Scraton, 1999). This ensured that vital evidence, on the response from emergency services and police, would be excluded from the inquests. Lord Justice Taylor's Inquiry into Hillsborough found that alcohol and 'hooliganism' played no part in the disaster. He saw the main cause as "the failure of police control" (U Taylor, 1990: 49), and he criticised senior officers who had unjustly initiated a vilification campaign towards Liverpool fans ( $\amalg$ Taylor, 1990: 31). Despite these findings, the 
mechanisms of the cover-up were so widespread and powerful that they caused the realities of the disaster to be suppressed and marginalised from mainstream acknowledgement (Scraton, 2009).

The cover-up was also enhanced by the actions of the West Midlands Police (WMP) force, who were brought in to manage the information and evidence within the SYP force (Scraton, 1999). The WMP hand-picked evidence and witnesses at the original official inquests, and also organised a system of "review and alteration" on witness statements taken after the disaster (Scraton, 1999: 293). WMP officers pressured and harassed officers in the SYP, survivors, bereaved, and other witnesses to supply them with a false narrative in the form of a witness statement (Scraton, 2009). People who refused to comply were either not called to court, did not have their evidence presented, or in many cases they had their statements 'edited'. It has since been discovered that 164 statements had "substantial" changes made (HIP Report, 2012: 321); this included the removal of criticism of police actions and of language that described the horror on the day. In some instances officers inserted fabricated criticism of the fans.

The SYP and WMP found ready support for their narrative from the mainstream media, and prominent official figures such as the Prime Minister's press secretary Bernard Ingham and local Conservative MP, Irvine Patnick, who publicly endorsed the lies and became 'reliable' sources for the media (Scraton, 2009). Many newspapers ran with the misinformation of the disaster, but the most offensive and extreme lies were produced four days after the disaster by 'The Sun' newspaper. Kelvin McKenzie, The Sun editor at the time, published a front-page story with the headline: 'The Truth', followed by numerous false allegations, such as Liverpool fans had pick-pocketed the dead, and assaulted and urinated on police officers giving CPR (Scraton, 2009). As the HIP Report (2012: 342) emphasised: "The allegations remained prominent and have since been repeated as factually accurate in academic texts, broadcast documentaries, political debate and popular discourse, including fiction writing". Many members of the police, media and politicians colluded to avoid any blame and accountability for those responsible and instead directed blame onto the Liverpool fans (Scraton, 2009). The original inquest, following this script, recorded the deaths at Hillsborough as 'accidental'. Once the lies were legitimately registered by the mass media and the original inquest verdict 
they took on a life of their own. They led to successive failures by the judicial and legal systems, and created a sustained systematic cover-up for nearly three decades.

\section{The 20th Anniversary Onwards}

There have been three official campaign groups involved in the fight for truth and justice over Hillsborough: (i) The Hillsborough Justice Campaign (HJC), initiated by bereaved family members and survivors; (ii) the Hillsborough Family Support Group (HFSG), formed of bereaved families; and, (iii) Hope for Hillsborough headed by bereaved mother Anne Williams and supported by many others. These three groups have pursued every legal avenue available, to uncover the facts of the disaster and to have the truth officially acknowledged and recorded. They have worked tirelessly to keep Hillsborough in the public eye and retain pressure on those in government to expose the cover-up. Their initiatives have gained a wider supporting community and, in 2009 , that community took a stand and very publicly demanded truth and justice over Hillsborough. At the Hillsborough disaster's 20th anniversary memorial service, Government minister, Andy Burnham, made an address to the 28,000 in attendance. Televised nationwide, Burnham's speech was rendered inaudible by powerful mass chants from the crowd of 'Justice for the 96' (Shennan, 2012; White, 2009). Moved by the emotion from the crowd, Burnham filed a 'Freedom of Information' request, in an attempt to publicly release all privately held documents related to the disaster (Shennan, 2012; White, 2009).

In 2010, an Independent Panel was formed to research and analyse these documents, in order to provide the maximum possible disclosure of material and contribute to further understanding of the tragedy (HIP Report, 2012). After two years of 'forensic' analysis, the panel released 395 pages reporting the 'truth' of the Hillsborough disaster. This report identified specific individuals and parties that deliberately attempted to conceal the realities of the disaster, including those who conspired to direct blame onto Liverpool fans (HIP Report, 2012). After the publication of the Panel's findings in 2012, the 'accidental death' verdict was quashed and a fresh inquest opened. 
The latest inquest became the longest jury case in British legal history (Hume, 2016). The jury of six women and three men answered fourteen questions relating to the disaster, and they unequivocally found that the fans were in no way to blame for the disaster, and that the 96 were unlawfully killed (RIV, 2016). After 27 years those affected by Hillsborough finally had an acceptable verdict in place. However, it proved bittersweet for many as the strain and struggle of having to fight for so many years had taken its toll and affected the quality of life of those involved (Coleman, 2009). The main regret expressed by bereaved and survivors was that many ardent campaigners had died before the recent verdict was reached (Coleman, 2009). Since the verdict, two criminal investigations have been launched: Operation Resolve and the IPCC investigation, both looking into individuals and organisations that may be held legally accountable for the disaster and subsequent cover-up. At the time of writing, these investigations are ongoing. Campaigners have expressed concern that because of the extent of the collusion any outcome that places the blame on individual senior officers would be a form of continuing the cover-up. To ignore other involved agencies represses the wider political context and societal systems that enabled the cover-up to sustain for almost three decades (Hume, 2016).

\section{This Thesis}

The survivors of the Hillsborough disaster are forgotten victims (Coleman, 2009a: para. 4).

In the past 27 years, public attention to the victims of Hillsborough has almost entirely focused on the 96 that died and their families. The strong establishment narrative set up the fans as the perpetrators who caused the disaster and, given the depth of collusion and coverup, that specific narrative was impenetrable over many years. Fans that were victimised by the experiences in the pens were immediately mislabelled as the guilty mob that killed the 96, and the sustained smear campaign effectively removed survivors' experiences from existence (Scraton, 2009: 120). Unlike victims of other disasters, the fans have had to try to survive in a climate where they have been unjustly blamed, by the majority, for causing the deaths of 96 men, women and children (Scraton, 2009). 
Campaigners have fought to ensure Hillsborough maintained a high profile, however the experience of survivors returning from Hillsborough to continue their lives with the impact of that near-death experience is largely unknown. Similarly, the experience of continued miscarriages of justice and effect of prolonged denials, on this group of victims, has not been substantively addressed (Davis and Scraton, 1999). The public focus on the 96 that died and their families is entirely appropriate; however there remain thousands of people impacted by the disaster who also survived the pens that day (Davis and Scraton, 1999). Their perspectives and experiences have remained largely absent from official and public view (Davis and Scraton, 1999).

The denigration of fans, alongside the silencing of survivors' experiences, has meant that many survivors have been left without societal or official acknowledgement and supports. This thesis seeks to work against these conditions, by focusing on the impacts and aftermath of the disaster from survivors' perspectives. This research does not examine experiences on the day (as shown above, can be found elsewhere). Instead, it aims to explore their experiences in the years after the disaster. Specifically, the thesis examines the different survival trajectories taken by individuals, and considers the factors that have enabled or impeded a sense of survival in the wake of Hillsborough. The questions informing this research include:

- What does it mean to be a 'survivor'?

- What has prevented survival?

- How have survivors 'survived'?

- What has been the role of others in the survival process?

- What are the costs of survival?

- What do survivors require in order to 'survive'?

This focus will demonstrate how fans have continued a 'life after Hillsborough', and illustrate what 'survival' means to them. Survivors' stories highlight the potential of ongoing trauma and re-victimisation, either from specific encounters or from the official denial of the truth (Hughson and Spaaij, 2011; Scraton, 2007). By acknowledging these experiences, the thesis 
will increase understanding about experiences of victimisation and survival, and will challenge misinformed perceptions about survivors' realities (Scraton, 1999, 2007). For the remainder of this thesis when specifically discussing the survivors of the Hillsborough disaster, the term 'survivor' refers to individuals who survived the crush in pens three and four, but also to those groups who identify as having survived the 'experience' of Hillsborough. As this chapter has illustrated, aspects of 'Hillsborough' have caused further victimisation affecting a wider range of individuals in various capacities, and therefore creating a diverse cohort of 'survivors'.

\section{Chapter Overview}

The following chapter two introduces the mainstream conceptions of victim and survivor identities and their relationship to theories of 'survival'. It critically develops these understandings specifically within a disaster context and explores the problematic implications associated with traditional misrepresentations of these concepts. The dominant themes of stereotyping victims and survivors, victim hierarchy, politicisation of victimisation, victim-blaming and survival as a continuum are presented and discussed. This chapter also gives an overview of government responses to disasters and considers what 'survival' might mean in a disaster context. It also considers existing theories on survival trajectories, for example promotion of individual resiliency, psychological survival, post-traumatic growth and survival as a form of resistance towards victimisation.

Chapter three explains the primary research process, including the methodological approach taken in this thesis. Alongside significant discussions with key informants, the thesis is based on nine in-depth interviews with two key informants and seven individuals who have 'survived' Hillsborough in some way. In approaching these individuals, I employed a critical methodological approach. This chapter outlines the justifications for this stance, and it discusses the various aspects of carrying out this research in another country. This includes consideration of: preparation for fieldwork, accessing participants, conducting interviews, ethical considerations, employing a reflexive approach, acknowledging emotionality, and method of analysis. 
The findings are discussed over chapters four, five and six, and each chapter is organised according to resulting dominant themes. These chapters identify how 'survivors' have understood and experienced their 'survival' from Hillsborough within a long-term climate of denial, collusion and cover-up. Chapter four discusses factors that have prevented or undermined personal attempts at survival, while chapter five illustrates the trajectories or pathways to survival in the aftermath of the disaster. Chapter Six discusses the implications of moving beyond 'Hillsborough' and what various factors are required to 'survive'.

Chapter seven presents a discussion of the findings. It reflects on this research in relation to the literature reviewed in chapter two. In doing so, it critically examines the personal, social, political, and institutional factors that affect individual attempts at survival. This chapter shows that 'survival' is a continual process, and responses towards 'survivors' can either support quality of life or cause re-victimisation. While there are various pathways to survival, all 'survivors' are impacted by the official and collective response to them. This thesis concludes that 'survivors' need a continuous multi-faceted institutional and social response to assist their progress to 'well-being'.

Chapter eight presents a summary of the main themes identified throughout the thesis and the dominant findings discussed in previous chapters. This chapter re-states the critical analyses developed in relation to the research questions and findings, the social and political context, and the wider literature concerning 'survival'. This section concludes with an overview of the thesis and states that future official responses to the 'Hillsborough community' must be committed to the principles of care and social justice. 


\section{Chapter Two: Victims, Survivors and Disaster}

Well-being is influenced greatly by the context of the larger freedoms within which people live (UNDP, 2014: 83).

This chapter outlines traditional notions of victims and survivors to provide an overview of the historical relationship between these two identities, in order to critically evaluate the impact these labels have on the concept of survival. The concept of survival is then developed, specifically within a disaster context, in a review of 'survival' and 'disaster' research. After a major disaster the governing institutions inform mainstream response strategies and so literature addressing how official responses affect personal survival is presented. Much survival literature revolves around the dominant themes of: stereotyping victims and survivors, victim hierarchy, politicisation of victimisation, victim-blaming and survival as a continuum. In response, this chapter also critically analyses these themes in terms of their relevance and appropriateness to survival trajectories from disasters. The chapter concludes by reviewing the various survival trajectories that are officially encouraged post-disaster. It critically analyses the expectations of pathways to survival and evaluates the implications of prescribing specific survival trajectories. Overall, this chapter provides an overview of the concept of survival, of personal and official responses to disaster, and of survival from major disasters.

\section{From Victims to Survivors}

Traditional definitions of victims have often been constructed in relation to a prior interpretation of what is defined as crime (Walklate, 2007). Historically, criminologists investigated criminals and criminal acts, whilst neglecting to comprehensively investigate the victims of those acts (Howarth and Rock, 2000; Jordan, 2013). This approach led to categorising certain experiences as true or real victimisation, causing other types of experiences to be unrecognised (Orgad, 2009). In turn, the social construction of a 'victim' and the application of this label has been produced in relation to 'traditional' notions of crime 
- focusing on victims of mainly "predatory offences" and highly individualised, visible "street crime', such as burglary or assault (Dignan, 2005: 17; Quinney, 1972; Walklate, 2007).

The traditional representation of a 'victim' has structured mainstream public understandings with a set of specifically prescribed victim characteristics (Profitt, 1996; Walklate, 2007). Christie (1986: 17) defines the process of assigning victim status as the social construction of "the ideal victim". This process discriminates against certain types of victimisation by constructing polarised stereotypes of 'deserving' and 'undeserving' victims (Christie, 1986; Croall, 2007; Profitt, 1996). 'Deserving' victims are expected to be upstanding moral citizens, passive, helpless, powerless and preferably victims of conventional crime (Christie, 1986; Jordan, 2013; Orgad, 2009). This process ultimately creates what is perceived to be a 'legitimate' victim who is worthy of the victim status and the societal response that it generates, such as compassion and empathy (Orgad, 2009; Walklate, 2007).

The construction of a hierarchy of victims is a top-down process where those in positions of power assign the 'victim' label according to their criteria and discretion (Christie, 1986; Quinney, 1972). This hierarchy sets "normative standards" and individuals who do not conform to those standards can often be regarded as being somehow to blame for their victimisation (Nissim-Sabat, 2009: 13; Croall, 2007; Orgad, 2009). In this sense, victimisation can be politicised to serve political agendas, often further discriminating against minority groups because of their social standing. Scholars have identified that this has impacted negatively on groups such as the homeless, problematic drug users, and sex workers, to name a few (Dignan, 2005; Orgad, 2009).

The victim-survivor relationship is often presented as a linear process, from one identity to the other, and so misrepresentations of victimisation also create misrepresentations of survival (Dignan, 2005; Kelly, 1988). The term 'survivor' has specific connotations within much mainstream literature; it is often presented as a desirable state, associated with active resistance to victimisation, and often assumes transcendence from a traumatised victim to an empowered survivor (Jordan, 2013; Orgad, 2009; Profitt, 1996). However, within wider feminist research, survival trajectories are presented as non-linear, often involving a complex 
journey which is in direct opposition to common representations (Jordan, 2013; Kelly, 1988; Profitt, 1996; Walklate, 2007).

Critical feminist scholars, mainly in a domestic violence context, have argued for mainstream representations of victims, survivors, and the nature of 'surviving' to be broadened. This argument emerged as a response to traditional understandings of victimisation, which situated 'crime' inside the parameters of the law, and scholars argued in reality there was a spectrum or continuum of victimising experiences which were not specified in current laws (Jordan, 2013; Kelly, 1998; Quinney, 1972). Profitt (1996: 25) argued "the conceptualizations of 'battered women' as 'victims' and 'survivors' found in the literature provide an inadequate basis for challenging the social conditions that enable systemic male violence against women". Profitt (1996) developed her argument and acknowledged the constructions of these identities simplified and limited understandings of the diverse experiences of victimisation and also diverse responses to them. These labels also diverted attention away from the wider social and political structures that create climates for certain types of victimisation to occur, essentially protecting certain criminal acts (Jordan, 2013; Quinney, 1972). In resistance to the traditional classifications of the victim/survivor labels, feminist writers have developed the sense of survival as a continuum, to create opportunities to see and respond to a variety of victimisation (Jordan, 2013; Kelly, 1988). Conceptualising 'survival' as existing on a continuum gives victims/survivors the power to identify and articulate the multi-dimensional aspects of survival (Kelly, 1998). For example, it gives victims/survivors the freedom to acknowledge dual-states, such as being in a more traumatised state at one point in time to moving to a less traumatised state and vice versa, depending on a variety of contributing factors.

The representation of victims and survivors is a key element for this thesis. Dominant perceptions of victims and survivors - who they are, what they have experienced, and how they should act in the wake of victimisation - supply a context for societal responses to victims of disasters (Christie, 1986). Representations are important in understanding why specific responses are mobilised, and how these responses affect personal attempts at long-term survival. The concept of 'victim-blaming', or the notion of what a real victim is, is based on set criteria, and the role of those in positions of power in society in orchestrating these processes, 
are all major themes which also emerge when viewing victims of disaster. In a disaster context, the main responder to victims is the state and therefore state agencies and institutions play a vital role in supporting personal survival efforts.

\section{Government Responses to Disaster}

In a certain sense, all disasters are man-made (Friedman and Thompson, 2003: 251).

Recent research has demonstrated that disasters are rarely 'natural', especially as the decisions made by officials pre- and post-disaster can cause extensive and unnecessary damage (Green, 2005; Urbatsch, 2016). Official responses to any type of disaster are rooted in deep social and political pre-existing structures (Green, 2005). All states have the discretionary power to dictate pre- and post-disaster initiatives and this significantly affects the outcomes of disasters for the rest of society (Green, 2005; Hartley, 2002; Olson, 2000; Verchick, 2012). In this way, decisions made from a 'top-down' approach can exacerbate and reinforce pre-existing social inequalities and maintain existing power structures (Green, 2005; Spring, 2011; Urbatsch, 2016).

During and in the aftermath of disasters, existing social inequalities can be reinforced and power structures maintained by the direct decisions made by the state. For example, researching the 1999 Marmara Turkey earthquake, Green (2008: 163) found that the devastation in the aftermath was magnified due to "state organizational deviance", which resulted in the violation of human rights, and differentially impacted the vulnerable migrant population. Green (2008) argues systemic corruption, state collusion with official agencies, and the failure or omission of states to follow legal procedures, amounted to state organisational deviance in this disaster. Another example of a damaging top-down response relates to Hurricane Katrina (Faust and Kauzlarich, 2008). The survivors of Hurricane Katrina received no state compensation, even though this is a common official response in the wake of disasters, and there remains evidence that the disastrous impact of the floods were caused by known defects in the design and construction of the levee flood barriers (Faust and Kauzlarich, 2008; Verchick, 2012). New Orleans communities were marginalised prior to the Katrina disaster and this situation was worsened in the long-term aftermath as the state failed 
to initiate appropriate disaster response strategies (Hooks and Miller, 2006). Faust and Kauzlarich (2008: 99) argue that Katrina survivors were "the least socially powerful actors and are often blamed for their suffering" while state institutions that might have prevented the floods or protected those affected "have tended to deny the extent of harm they cause[d]".

Governments are charged with a "duty of care" and they are expected to respond appropriately to disasters, attempting to minimise damage and aid in recovery (Friedman and Thompson, 2003: 279; Verchick, 2012: 28). However, governments repeatedly fail to address pre-existing conditions, which inevitably leads to preventable and foreseeable disasters. In this context, disastrous outcomes are the direct result of government omissions or inaction (Faust and Kauzlarich, 2008; Green, 2005, 2008). Studies have shown that governments and official institutions can regularly fail to enforce safety regulations, they remain apathetic towards safety and emergency procedures, and instead prioritise organisational goals and economic growth (Faust and Kauzlarich, 2008; Hartley, 2002; Shaw, 2012). For some authors, 'man-made' disasters are catastrophes that have emerged from the "wilful avoidance" of actions that are expected via safety codes and regulations (Green, 2005: 538; Faust and Kauzlarich, 2008; Hartley, 2002).

The above research illustrates the detrimental impact that state actions can have for survivors of disasters and indicates that certain communities will be made vulnerable to the risk of experiencing disaster (Olson, 2000; Spring, 2011). Critical scholars have defined the role of social inequality in a disaster context as the "socialization of disaster", as they predict that particular groups will be over-represented in experiencing disaster, and also in suffering disproportionately in the aftermath (Verchick, 2012: 29; Green, 2008; Hartley, 2002; Spring, 2011). There is a "political economy of risk", where vulnerable populations can experience discrimination via official disaster responses that act to undermine their survival (Hartley, 2002: 30; Faust and Kauzlarich, 2008; Green, 2005).

This frames the "social vulnerability" of certain groups within society, often minority groups, who may receive negative differential treatment from government responses based on their structural location in relation to gender, class, and race (Verchick, 2012: 38; Green, 2008; Hooks and Miller, 2006; Olson, 2000). Structural discrimination can become embedded in 
practices and policies and therefore work in a covert and often invisible manner to disadvantage vulnerable groups within society (Edwards and Imrie, 2008; Stanley, 2009). Researchers have claimed government responses to disasters have, at times, been "almost deliberately, ineffective for the most vulnerable and marginalized" (Hooks and Miller, 2006: 25; Green, 2008). Governments and their institutions have often made unprecedented, arbitrary decisions post-disaster that have resulted in directly inhibiting the survival of marginalised populations (Friedman and Thompson, 2003; Green, 2005; Hooks and Miller, 2006).

The decisions made in the aftermath of disasters, by government agencies and institutions, can create further victimisation. In these circumstances, victims of the initial disaster have to survive the disaster as well as the way the state handles and responds to the disaster (Faust and Kauzlarich, 2008; Olson, 2000; Spring, 2011). In this context, authors like Penny Green (2005: 529; 2008) have framed disasters as "state crimes", due to the systemic corruption which can generate precursors for disaster and post-disaster cover-ups (see also Faust and Kauzlarich, 2008). The harm generated from state actions or omissions during times of disaster creates economic, social and political damage, and therefore can detrimentally affect personal attempts at long-term survival (Faust and Kauzlarich, 2008; Olson, 2000; Verchick, 2012).

Scholars have also frequently identified that governments can search for "scapegoats" on which to apportion blame in the aftermath of a disaster, to avoid government departments or their corporate allies being held accountable (Friedman and Thompson, 2003: 284; Verchick, 2012: 37; Urbatsch, 2016). Governments have used their discretion to block public inquiries into disasters, also as a means to deflect accountability in their own construction of "the blame game" (Olson, 2000: 266; Davis and Scraton, 1999; Hartley, 2002). Those in positions of power are also able to manipulate traditional constructions of 'victims' in order to preserve their own legitimacy (Verchick, 2012). This is achieved when a group of victims do not possess enough traditional 'characteristics' and so can be denied the status of 'victim' (Verchick, 2012). By employing scapegoat tactics, states are able to convincingly deflect allegations and project them onto vulnerable populations (Hartley, 2002) - victims of disasters can quickly be redesignated as 'threats' or 'offenders'. Official institutions and agencies are 
rarely, if ever, called to account for their illegitimate/unlawful actions pre- and post-disaster. Rare situations that eventuate in court proceedings often do not result in any formal or official sanctions and charges are often dismissed (Faust and Kauzlarich, 2008; Friedman and Thompson, 2003; Hooks and Miller, 2006). Instead, state agencies and institutions often act to secure and preserve their own interests. This knowledge is essential when viewing the information, recommendations and supports given to survivors of disaster.

\section{Survival in a Disaster Context}

Contemporary governments promote resiliency as a means to secure wellbeing in the wake of disasters (Taylor, 2011). Conceptions of resiliency and wellbeing are often developed together in academic literature and policy documents (Manyena et al., 2011). There is now a mainstream understanding that in order to return to a state of wellbeing, or to gain a higher level of wellbeing, individuals must endeavour to be resilient (Taylor, 2011). Most literature does not discuss specific survival strategies, however it is implied that by being resilient, whatever that entails, individuals will effectively survive and will therefore be able to gain a positive quality of life (Manyena et al., 2011).

Traditionally, authors have interpreted resiliency as the ability of individuals and/or communities to 'bounce back' to a pre-disaster state in the fastest possible time and with minimal or no help (Manyena et al. 2011; McGreavy, 2015). Researchers have categorised people as being 'successfully' resilient if they withstand negative effects and recover in a timely fashion, compared to those categorised as not 'coping' and so are not 'being' resilient (Shaw, 2012). Resiliency is frequently viewed as an outcome from successfully employing socially acceptable survival mechanisms (Leichenko, McDermott and Bezborodko, 2015; Shaw, 2012).

Authors who oppose this stance argue that an over-emphasis on self-help and selfresponsibility detracts from issues at a societal level that affect wellbeing and quality of life at a personal level (Alatartseva and Barysheva, 2015; Taylor, 2011). That is, the

preoccupations with individual actions de-contextualise social conditions, which can significantly affect the outcome of individual efforts (Spring, 2011). In a post-disaster context, 
the individualised focus suggests that individuals, regardless of contextual circumstances, are able to achieve and maintain a positive quality of life from their own initiatives (Alatartseva and Barysheva, 2015).

Governing institutions, by emphasising traditional conceptions of resiliency, have "concentrated on individual remedies for social maladies" (Prilleltensky and Prilleltensky, 2005: 91). Critical scholars have suggested that governments focus on self-help to serve neoliberal political agendas and to avoid accountability, and this can cause individuals to become complacent or submissive with societal systems which act in oppressive ways (Alatartseva and Barysheva, 2015; Prilleltensky, 2008). This situation has influenced the positioning of 'resiliency' as the dominant focus in post-disaster recovery and survival literature (Freidman and Thompson, 2003; Olson, 2000). The dominant conception of resiliency constructs an image that recovery from disaster is a linear, inevitable, and straightforward course (McGreavy, 2015).

Official endorsements of resiliency encourage individuals to regain control and reject vulnerability after disasters (Leichenko, McDermott and Bezborodko, 2015). In this context, survivors from disasters can be expected to fulfil the stereotyped notions of 'survival' (previously outlined) behaving in a manner which reflects 'moving on' from the traumatic event (Manyena et al. 2011; McGreavy, 2015; Olson, 2000). Resiliency is framed as the major indicator of positive survival and regaining a positive quality of life post-disaster (Prilleltensky and Prilleltensky, 2005). In this context resiliency can act as a mechanism of regulation, encouraging conformity to this officially sanctioned response to disaster, which can be used to return society to the status quo (Prilleltensky, 2008; Spring, 2011).

In summary, traditional conceptions of resiliency presents an insufficient response to disasters. Resiliency is often too narrowly defined and applied, and therefore is not capable to respond to the many incidents survivors have to 'survive' post-disaster. This work acknowledges the dangers of employing a resiliency approach as a 'blanket' disaster response, as it has been found to be used as a mechanism for maintaining unequal power structures, at the cost of supporting survival efforts (Spring, 2011). Widening the definition of resiliency develops the concept to acknowledge and recognise the varied complexities of the 
lived experience of surviving disaster. A more critically conscious version of resiliency would discourage official expectations of post-disaster survival, and replace them with mechanisms that allow communities and individuals to identify and enact what survival mechanisms will work for them (Shaw, 2012). This critical conception develops the idea of "becoming resilient differently", which encompasses the many reactions survivors may have as they are 'surviving' or becoming 'resilient' (McGreavy, 2015: 116; Newburn, 1993). Resiliency is presented in a way which assumes a set survival trajectory returning to a pre-disaster state, and as the previous discussion on victims/survivors and critical resiliency literature suggests, 'survival' in reality does not reflect this (McGreavy, 2015).

\section{'How' Individuals Survive Disaster}

The disaster literature is extensive, and the vast majority of research has focused on analysing disaster preparedness and concentrated on the psychological impacts for survivors (Newburn, 1993). For example, one significant study encompassed 60,000 individual survivors of various disasters and, although there were elements of analysing the personal and official responses, the main focus measured the impact disasters had on individual mental health (Norris, Friedman and Watson, 2002). Similarly, most other researchers have exposed the detrimental psychological effects, which have acted as barriers to positive survival, such as: "effects on mental functioning" and "psychological distress" in the short and long-term aftermath of disasters (Lindy and Titchener, 1983: 85; Solomon and Thompson, 1995: 199). In longitudinal qualitative studies, elements of resilience, well-being, quality of life and survival have been included, however these themes are often framed within the context of researching psychiatric disorders such as Post-Traumatic Stress Disorder (Hull, Alexander and Klein, 2002; Morgan et al., 2003; van der Velden et al., 2013). Within the literature, knowledge on survival mechanisms and trajectories does exist, but there is a lack of sufficient information regarding the logistics of navigating individual survival. Despite the vast body of literature, there remains a "lack of direct research evidence" on the trajectories of survival that might be able to inform appropriate and realistic official strategies to aid personal and social survival in the long-term aftermath of a disaster (Hobfoll et al., 2007: 284). 
One survival trajectory prominent in mainstream literature relates to Post-Traumatic Growth (PTG). PTG is a conceptual development from notions of resiliency, which allows a state of personal resiliency to co-exist with the negative effects from experiencing disaster (Hobfoll et al., 2007). PTG refers to the development of additional strengths and competencies that contribute to creating a fulfilling and meaningful life post-disaster (NSW Health, 2012). Within PTG literature, there is a shift in the representation of resiliency to occurring as a 'process' rather than an outcome (NSW Health, 2012; Shaw, 2012). This suggests that individuals possess a "fundamental human motivation" to positively adapt to adverse experiences and to create and maintain wellbeing (NSW Health, 2012: 39).

The critical development in PTG literature is that it presents the possibility that experiencing disaster could allow for positive as well as negative effects to occur. This highlights an alternative survival trajectory, where survivors continue their lives attempting to understand and adapt to changes in ways that could attribute to thriving post-disaster_(Newburn, 1993). That is, surviving a disaster could act as a catalyst for positive transformation (Tedeschi, 1999). This corresponds with survivor literature that reports a common victim response to trauma is the belief they can overcome other adverse experiences, because they have survived (Tedeschi, 1999). Research has found that positive self-perceptions contribute to psychological wellbeing and this, in turn, causes increased self-efficacy and adaptive coping strategies in times of future adversity (Tedeschi, 1999). In relation to the notion of resiliency this outlines a different 'way' of being resilient, as individuals are able to acknowledge their pain and process it in a way that identifies their vulnerability but simultaneously their strength (Tedeschi, 1999).

However, the connection between being resilient in order to attempt PTG, as a means to attain wellbeing or a positive quality of life, has also faced criticism. PTG also presents an individualised model of 'wellbeing' by prescribing socially defined ideals, which are to be aspired to, in order to achieve wellbeing (Taylor, 2011). Edwards and Imrie (2008: 338) have described this situation as a "politics of happiness", where individuals seek to fulfil the societally constructed ideals of what is commonly defined as 'wellbeing'. Examples of these ideals include certain types of employment, a certain level of health, and engagement in community activity (Taylor, 2011). This sets up a 'happiness' agenda "reinforcing particular 
social norms" and framing those norms as the type of happiness that should be aspired to; this can consequently stigmatise individuals who are not seen to be 'growing' or 'transforming' post-disaster (Taylor, 2011: 786). This narrow conception of resiliency and PTG does not allow survivors of disaster the freedom to respond in other ways and this prevents opportunities for people to maintain autonomy over their own responses to disaster.

The expectation and assumption that PTG will occur and resiliency will manifest in a certain way can act as a barrier to survivors seeking help, and thus can act to undermine their survival (Brown and Alcoe, 2010). Reactions and changes post-disaster can be polarised - for example, some survivors will lose their spiritual faith while others may find a new spiritual faith - and reactions like these can have a ripple effect in altering various dimensions of everyday life (Newburn, 1993). These changes can cause discord as well as solidarity, they can lead to disconnections between victims and their friends or relatives and this creates yet another element that disaster victims must navigate (Newburn, 1993). It is these varied responses and diverse survival trajectories in the long-term aftermath of disasters that have not been substantively addressed in the literature. Instead of fostering an environment of tolerance and acceptance towards diverse survival trajectories, the narrow application of PTG and resilience creates an expectation that if people enact their survival in a 'certain' way then they will ascertain 'wellbeing' (Alatartseva and Barysheva, 2015). These concepts in practice have the potential to create a competitive, discriminatory environment, where individuals who may take alternative trajectories are marginalised (Alatartseva and Barysheva, 2015; Taylor, 2011).

In summary, dominant representations of personal survival do not substantially incorporate the complex realities of survivors' journeys. What appears to be lacking is a comprehensive account of disaster survivors' lived experiences. The reality is that 'recovery' is not a prescribed set of actions to be taken in order to 'achieve' resilience and gain wellbeing. Rather, in order to gain wellbeing, post-disaster requirements need to be met by official interventions that create a suitable environment for individuals to realistically embody resilience and be able to have a positive quality of life (Taylor, 2011). 


\section{Survival as Resistance}

Critical literature identifies that the promotion of certain themes and official responses, such as the traditional focus on notions of resiliency, could be a guise for 'putting up with' the 'way things are' (Manyena et al., 2011; Shaw, 2012). As detailed above, mainstream approaches, often centred on a neo-liberal individualised focus, can act to maintain the status quo as they fail to identify responsibilities of official institutions in assisting and supporting grassroots survival efforts (Leichenko, McDermott and Bezborodko, 2015). Focusing resiliency on the individual responsibility to achieve a state pre-disaster acts as a means to reinforce dominant power institutions, who are in turn absolved of addressing the causes of disaster or of providing additional post-disaster supports (Manyena et al. 2011; Shaw, 2012). This 'top down' approach encourages people to take it upon themselves to be resilient, and the opportunity to question the systems that respond to disasters is removed (Shaw, 2012). This prevents an opportunity to understand wider societal structures that may have contributed to the disaster or caused detrimental barriers to 'surviving' (Brown and Alcoe, 2010; Prilleltensky, 2008). When society's gaze is set on the individual's capabilities to live up to the expectation of being resilient, this inevitably decontextualises the disaster and prevents any social transformation of the structures and processes that actually lead to victimisation (Shaw, 2012).

Critical resilience literature "suggest that resiliency approaches can reinforce unequal power relationships" (Leichenko, McDermott and Bezborodko, 2015: 4). Freire's (1972) concept of 'conscientization' is useful here (Freire, 2005). He explains that it is only when the oppressed can achieve 'conscientization' that resistance to oppression can begin. It is this process of 'conscientization' that enables oppressed groups to not only identify the societal power structures affecting them, but also to become empowered by the awareness of their own ability to overcome and resist them (Freire, 2005; Prilleltensky, 2008). Research on empowerment shows people will not engage in emancipatory action until they have developed a level of 'conscientization' regarding their situation (Prilleltensky, 2008). This idea suggests conscientization can emancipate survivors from impositions of oppression and create a trajectory of "freedom to" liberation; an example could be political or social action (Prilleltensky, 2008: 128; Freire, 2005). 
Developing Freire's concept of 'conscientization' in regards to resiliency suggests that a critical resiliency could be an individual awareness that official responses are not always positive and may, in fact, further victimise survivors of disaster. Therefore, 'conscientization' is the process of survivors realising that their employment of 'resiliency' may involve being resilient towards unjust or oppressive agency and institutional responses to disaster (Tedeschi, 1999). This understanding would suggest that individuals become more resilient when they challenge societal systems and processes that act to disempower them, instead of adjusting and learning how to cope within those systems (Prilleltensky and Prilleltensky, 2005). This is demonstrated in studies that report on individuals who become agents of social change, empowered to transform discriminatory practices within society, often via grassroots campaigning (Manyena et al., 2011; McGreavy, 2015; Prilleltensky, 2008).

There are a myriad of ways to respond to traumatic events such as disaster and being resilient during the survival journey is not embodied in only one way (Tedeschi, 1999). Survivors will experience paradoxes in themselves, at times feeling they are resilient or having achieved PTG and, at other junctures, feeling traumatised or struggling to cope (Tedeschi, 1999). "Small things can make a positive difference" in developing positive survival from trauma, such as support from family and friends, or holding down a job (Shaw, 2012: 287; Newburn, 1993). Traditional notions of resiliency do not take into consideration the multifaceted factors that are equally necessary and contribute to the whole wellbeing of an individual. Thus, a critical consciousness of resilience and survival is required.

\section{Conclusion}

This chapter has illustrated the limits and inadequacies of the traditional conceptualisations of the victim/survivor identities. It has shown how superficial and stereotyped representations create misunderstandings towards the diverse nature of 'survival'. This chapter also demonstrated the relationship between the misrepresentations of victim/survivor concepts and official responses to disaster, by highlighting the problematic consequences from a lack of accurate understandings of victims/survivors, such as: victim blaming and denial of victimisation. It demonstrated how government responses, or lack of 
responses, to disaster can undermine personal survival, and in some instances amount to systematic 'criminal' harms. Top-down responses can serve political agendas and deflect official blame, while an expectation is built - through notions of resiliency and PTG - that survivors will learn to 'survive' by working on themselves.

It is clear that a more comprehensive theory of survival is required, one that conceptualises the process of survival from disaster as existing along a continuum. The realities of survival that have been developed in this chapter, are that: survivors will experience the same disaster differently and therefore will have diverse needs and therefore may follow diverse survival trajectories; there are various types of survival trajectories and survivors can shift along the continuum between them at different junctures in time; and survivors also have to 'survive' incidents during the aftermath of disaster, including the unhelpful and inappropriate official responses.

Overall, there is a gap between the mainstream representation of survivors' experiences and their perspectives of their survival journeys. The rest of this thesis, therefore, considers the impacts of the various individual, social, political and institutional factors which influence personal survival efforts. Given that state responses can have a profound effect on personal attempts at survival, particularly as official processes have the capacity to inhibit or support survival, this thesis explores how the longevity of the official denial in the aftermath of Hillsborough, and how the various facets of the official 'cover up', have directly affected survivors' quality of life. In relation to the existing literature, this study focuses on gaining knowledge regarding the 'experiences' of survival in order to reveal necessary requirements to continuing a 'life after Hillsborough'. 


\section{Chapter Three: Research Theory and Process}

The question is not whether we will take sides, since we inevitably will, but rather whose side are we on? (Becker, 1967: 239).

In all research there are innate unavoidable biases (Becker, 1967). At each stage in the research process the decisions made by the researcher will inevitably affect the research outcome. Even the initial stages of identifying something as an 'issue' holds a bias, as the researcher interprets that the 'issue' is important and deserving of investigation (Crotty, 1998). Researchers cannot strip themselves of their human qualities nor can they compartmentalise the factors that affect their world view such as race, gender, class, social history, political affiliations or life experiences, to name but a few (Crotty, 1998). Therefore, we have to acknowledge the influences to our intellectual inquiries (Crotty, 1998).

Becker (1967) explains that, as we cannot conduct research from a neutral standpoint, we must justify and explain the acknowledged vantage point. Researchers use specific theories, methodologies and methods in order to secure academic rigour in conducting the investigation and avoiding distortions in their results (Becker, 1967). Selected methodologies and methods must be the most appropriate to support the purpose of the research and ensure the production of credible data (Crotty, 1998). Therefore, as researchers we invite others to view our research in the understanding that it has been chosen, conducted, and produced from the 'values stance' of the researcher and the discipline (Becker, 1967; Crotty, 1998).

This research has been conducted from a critical criminological perspective. This theoretical perspective creates the overarching framework for the research, and it acknowledges the set of assumptions, principles, and values underlying the entire project and how it has been conducted (Crotty, 1998; Scraton, 2002). Critical criminology assumes that some forms of knowledge have been brought into existence to serve hegemonic interests, supporting particular power structures that create oppression and other forms of injustice (Crotty, 1998; Ugwudike, 2015). This stance is based on the assumption that ruling elites control systems 
that produce and register knowledge and therefore "the ideas of the ruling class are, in every age, the ruling ideas" (Marx, 1961: 93 as cited in Crotty, 1998: 121). Those in 'ruling' positions have the power to classify themselves, their ideologies, and their constructions of reality as the legitimate or 'right way' to be (Scraton, 2002). Critical criminology attempts to expose and resist relations of power in society that create and maintain a status quo of inequality that exploits the most vulnerable populations (McLaughlin, 2010; Scraton, 2002; Stanley, 2012). This discipline is informed by a commitment to social justice and aims to challenge oppressive social structures, in a bid to create a more humane society (Friedrichs, 2009; McLaughlin, 2010; Stanley, 2012).

Critical criminology also employs a widened definition of what constitutes 'crime'. With a distinct focus on violations of human rights and social harm, critical criminologists are often especially interested in crimes of the state or "crimes of the powerful" (Cohen, 1993: 98; McLaughlin, 2010). This discipline examines 'who' has the power to define notions of crime and what are the implications of that (Ugwudike, 2015). Mainstream constructions of crime are considered to be predominantly a strategy of the powerful, serving a calculated political purpose to ensure their criminal activities are not recognised (Christie, 1986; Muncie, 2000). Therefore, conventional notions of crime are in fact deliberate constructions, which enable a privileged group of people with concentrated power to hold political control over the social order (Foucault, 1982; Muncie, 2000). Critical criminology challenges the engrained and 'taken for granted' belief in our social fabric which presumes state legitimacy and integrity (Schwendinger and Schwendinger, 1970; Ugwudike, 2015).

Critical criminologists are also deeply interested in how legitimate institutions and systems such as the judicial system and the police force - are operated, and in whose interests (McLaughlin, 2010: 155; Schwendinger and Schwendinger 1970; Ugwudike, 2015). Powerful state agencies have the ability to 'manage' social systems and ideological platforms to serve their own interests and, in doing so, create an environment of normalised discrimination against the non-powerful (McLaughlin, 2010; Muncie, 2000). A critical perspective has the ability to 'see' these ideological constructions, and the political management of crime, "by recognising the legal transgressions routinely employed by those wielding political and economic power and their ability to deny or conceal the harms they unleash under the 
protection of the law" (Muncie, 2000: 3). Those in various positions of power are well placed to silence any opposition and to secure impunity for their criminality (Coleman, 2015; Muncie, 2000; Schwendinger and Schwendinger 1970).

In critical criminology, a further "concern is to demonstrate how the application of the criminal label is not simply a matter of controlling 'criminality' but of containing political opposition and resistance" (McLaughlin, 2010: 163). Critical criminology takes the stance that crimes of the powerful cannot be understood by traditional conceptions of crime and so a human rights and social harm 'lens' is required (Friedrichs, 2009; Ugwudike, 2015). By employing a social justice agenda, critical criminology can analyse the differentials placed on human life that are dependent on social status within the hierarchy of power (Muncie, 2000; Schwendinger and Schwendinger, 1970).

This framework is suitable when analysing the Hillsborough disaster due to the specific social and political context the disaster occurred in. At every point of contact between those affected by Hillsborough and the establishment, the impact of the corruption of power can be seen (Scraton, 2009). Those individuals and institutions holding a disproportionately powerful position within the social hierarchy had the opportunity to abuse their power to preserve their interests over the victims of Hillsborough and they did this with no sanctions or repercussions (Scraton, 2002). As outlined above, the disaster was primarily caused by police officers who hold one of the most stereotypically respected, trusted, and legitimate positions of power in society. The realities of the disaster were denied, reconstructed, and fabricated by a range of powerful actors and institutions that colluded together to create and sustain a cover-up. Those in power were able to assert and officially register their 'version' of events in society by manipulating and exploiting existing credible systems, such as the mass media and the judicial system. Therefore, the issues surrounding Hillsborough are deeply connected to the structural hierarchy of power relations in society and the ability for those at the top of that hierarchy to abuse their power in order to attain and preserve their interests (Scraton, 2002). 


\section{Methodology}

Critical social research sets an oppositional agenda. It seeks out, records and champions the 'view from below', ensuring the voices and experiences of those marginalised by institutionalised state practices are heard and represented (Scraton, 2007: 10).

Methodology provides the explanation for taking a specific research design in a social research project and it is the concept that governs the choice of methods (Crotty, 1998). Therefore, reflecting the work of Scraton (2007) and Stanley (2012), this research project has been led by a critical methodology that considers six tenets to the research agenda and process:

(i) That it allows analysis of how institutional, social and ideological structures operate to create disadvantage and inequalities within society, and how these impact on diverse populations;

(ii) That the research considers how determining contexts, such as those related to class, underpin opportunities for state protection or justice;

(iii) That the thesis presents the connections between these structural or social relations of power and the personal experiences of Hillsborough survivors;

(iv) That the research will trace how knowledge about Hillsborough victimisation has been formed, how it came to be accepted and subject to challenge;

(v) That the thesis will provide alternative understandings, by exposing the 'view from below';

(vi) That, in doing so, the work will consider ideas for change, to improve conditions and experiences for those at the centre of this work.

These tenants are crucial for researching aspects of Hillsborough, as prior to the recent HIP report and the 2016 Inquest verdict, multiple official interventions (including the Home Office inquiry, inquests, criminal investigation, civil litigation, judicial review, judicial scrutiny, and a private prosecution) failed to produce the facts of the disaster or to hold those responsible accountable (Scraton, 2009a; Scraton, Jemphrey and Coleman, 1995). Individuals and 
institutions holding significant positions of power within the British establishment abused their power to serve their own interests over the needs and rights of the victims of the disaster; sacrificing the principles of social justice for almost three decades (McMillan, 2009; Scraton, 2009a). Employing a critical inquiry enables me, as the researcher, the opportunity to analyse how power-relations operate across society and how these structures impact on certain populations, particularly survivors from Hillsborough.

Authoritarian regimes create "suitable enemies" out of groups that do not conform or protest against the status quo, thus reconstructing them as "problem populations", thereby legitimising the use of arbitrary treatment against them (Christie, 1986a: 42; Scraton, 2007: 5). This has been identified in Howard Becker's (1963) depiction of the 'outsider', Jock Young's explanation of 'othering' (Walklate, 2015) and what Gareth Peirce (2010) describes as constructing 'suspect communities', to name a few examples. These ideas and constructions all explain how those in power employ official mechanisms to ensure the "marginalization of identifiable groups" (Scraton, 2009a: 156; Coleman, 2015). Victimisation by the state towards these groups can take many forms; unjust, oppressive power manifests itself in violent and discriminatory ways in 'everyday' mechanisms, ideologies and structures in society (Foucault, 1982; McLaughlin, 2010). In the case of Hillsborough, those in positions of power were able to use these mechanisms to dominate the public narrative, ensuring it represented their "version of the events" (Cohen, 1993: 113; Freire, 2005).

A critical methodology may unearth the impact of state victimisation within the oppressive "culture of silence" created by a state (Freire, 2005: 30; Stanley, 2012). As Peirce (2010: para. 22) noted, "secrecy kills justice: it has the effect of burying understanding"; this methodology seeks to expose the experiences of those surviving within an environment of political intolerance towards working-class and football supporting communities. This methodology attempts to "break the silence", creating the opportunity to challenge normalised oppressive structures and practises (Scraton, 2007: 9; Stanley, 2012: 241). In hearing survivors' voices, society can develop understanding about experiences of suppression and marginalisation (Freire, 2005). Speaking out can humanise previously demonised groups, asserting disapproval for their poor treatment (Belknap, 2015; Coleman, 2015; Scraton, 2007), and it can create an alternate narrative of Hillsborough. Registering the survivors "view from below" 
will gain a deeper understanding of the "insider" perspective on the impacts of survival from state crime and cover-up (Scraton, 2009a: 10; Stanley, 2012: 233; Belknap, 2015: 8). This approach also embodies the ethos of "speaking truth to power" in exposing violations of the state and calling states to account (Scraton, 2007: 14). Emancipatory knowledge is the main focus of critical inquiry because it creates the foundations for a socially just understanding of issues in society (Schwendinger and Schwendinger, 1970).

\section{Methods}

Alternative discourses are rooted in challenging the purposeful, propagandist constructions of what is published as 'official history' and embedded in 'official discourse' (Scraton, 2007: 4).

Qualitative research aims to draw out the meanings that people attribute to their experiences, to gain knowledge from their "frame of reference", avoid generalisations and develop a deep, rich understanding of personal experiences (Johnson, 2009: 193). Critical qualitative research "aims to prevent misunderstanding, empower new ways of seeing and emancipate, by disruption of the status quo" (Thomas, 1993 in McCabe and Holmes, 2009: 1523). These qualities are particularly useful in the context of exploring survival journeys (Grbich, 2013). Qualitative inquiry legitimises participants as a central source of information and, in doing so, the research process has emancipatory potential (Grbich, 2013). By exploring how individuals view their world, this study can more accurately reflect their lived reality (Grbich, 2013; Scraton, 2007).

\section{Background to the Fieldwork}

In the spirit of qualitative social research I thought it necessary to conduct face-to-face interactions with participants, out of respect for them and due to the sensitive and traumatic nature of their experiences. I made a decision to travel to Liverpool (England) from Wellington (New Zealand) to conduct interviews, rather than set-up Skype or phone-call conversations. Long before this research was undertaken I had set-up a savings account and had put money 
aside from working extra shifts in preparation for the travel. Once enrolled, I applied for and was granted a \$2000NZD Faculty grant, from the Faculty of Humanities and Social Sciences, at Victoria University, which paid for most of my return flight from NZ to the UK.

I was privileged to stay with a lovely family in Liverpool for the four weeks I was there. Their house was situated a few streets away from a train station and a five minute journey into the centre of Liverpool. It was also a short walk from 'Lark Lane', a well-known area of cafés, where I ended up conducting a few interviews. I undertook nine interviews in total, and two of these were with key informants. I conducted five interviews in Liverpool, and then travelled a few hours south to Crawley where I stayed with long-time family friends. I conducted one interview in Crawley and travelled from there directly into London to conduct two further interviews. For my last interview I took three trains to Suffolk, journeying three hours each way.

\section{Accessing Participants}

Due to the sensitive nature of the topic I was conscious not to contact people who may be negatively affected by the confrontation of this research. This was a difficult process, as I had no significant links with survivors and, of course, I live very far away. My main method of finding potential participants relied upon 'snowballing', which "allows the researcher to enter into networks of individuals and identify respondents that they might not otherwise be able to identify" (Lamont and White, 2005: 12). I initially contacted Sheila Coleman and Phil Scraton via their social media profiles and emails as potential 'key informants'. Sheila and Phil did not personally experience the disaster but both have made significant contributions in the fight for truth and justice. They have participated in countless interviews and projects regarding Hillsborough and so I knew that in terms of their 'emotional safety' it would be entirely appropriate to contact them.

A 'key informant' in social research represents an individual who has extensive involvement and experience with the proposed topic of investigation (Fetterman, 2008). They possess an acute vantage point of cultural information and are able to provide insights on the people belonging to the community of interest (Fetterman, 2008). Sheila Coleman presented an ideal 
'key informant' as her involvement with survivors from the Hillsborough disaster has spanned twenty seven years. Sheila originally became involved as a volunteer assisting the Hillsborough Disaster Working Party. She was employed as a researcher on the Hillsborough Project, commissioned by Liverpool City Council and Edge Hill University, and has been the spokesperson for the $\mathrm{HJC}$ and has continued to personally support survivors and family members (Coleman, 2012).

Prior to my research I had read many works by Phil Scraton and so was aware of his long-term involvement with Hillsborough. Phil was the director of the Hillsborough Project. His book 'Hillsborough: The Truth', first published in 1999, provides a comprehensive account of the disaster and its immediate aftermath with a distinct focus on the failures of the authorities involved and aspects of the cover-up. It was re-published in 2009 with additional chapters updating the events of the private prosecutions against senior officers Duckenfield and Murray, and then again in 2016 with updated chapters on the HIP report and fresh inquest verdict. Phil assisted in the formation of the HIP panel, he led the research, and was the primary author of the 2012 report. He has been involved in supporting survivors and family members in a personal capacity mainly with the HFSG since the disaster occurred. Although Phil has primarily been involved with the bereaved families, he has worked with many Hillsborough survivors over the years, and has extensive knowledge on issues of survival.

Researchers have sometimes critiqued 'snowballing' for not being able to produce a variety of respondents, as typically 'snowballing' leads to participants who belong to the same networks (Lamont and White, 2005). However, through 'snowballing' I was introduced to survivors, campaigners, rescuers on the day, bereaved family members and survivors who were also bereaved. Although this altered my initial focus (of sole attention on survivors) in a 'categorical' way, it also added to the depth and richness of the data, as it offered varied perspectives on 'survival' from the same disaster. It provided more complex and comprehensive knowledge of notions of 'survival', including different trajectories of survival, and what is 'needed' in order to effectively 'survive' from a major disaster.

Lamont and White (2005: 12) suggest that 'snowballed' participants: 
...tend to be more honest and willing to divulge personal information to researchers who have been validated by someone they know, enabling the researcher both to gather more accurate data and speak to individuals who otherwise may have declined to participate in research with a complete stranger.

This was an accurate reflection of my experiences. I found that, in initial discussions, interviewed people were initially guarded with themselves and protective over others. Armstrong (2012: 4) and Berger (2015: 228) have discussed their research experiences in negotiating access to specific populations via formal 'gatekeepers'. I similarly found that people involved with Hillsborough took on the role of 'gatekeeper' due to their immense dedication and care for those affected. Prior to meeting me, people were clear in verbalising their scepticism about putting me in touch with other potential participants. People voiced their concerns in a very respectful way, often explaining they had their trust betrayed in the past. For example, one participant had a journalist give out his contact details to the media after explicitly asking for them to be kept private. A few participants requested I get in touch when I had arrived in Liverpool before they would commit to a formal interview. I acknowledged and respected their concerns and was aware of articulating my sincerity and transparently presenting this project. I ensured I kept up communications, whilst respecting their boundaries and attempting to not in any way make them feel pressured to participate.

It is unsurprising given the history of persecution against Hillsborough survivors that people were wary of an 'outside' researcher attempting to gain access to their 'Hillsborough' community. When I embarked on my journey to the UK I had potentially organised one interview with Sheila and the rest were unconfirmed. Some people I contacted did not reply and others, while initially supportive of the project, did not return contact when I arrived in Liverpool. A few people who were very helpful, and clearly supported the research, never directly answered my question of whether they would like to be interviewed. To all of these individuals, I expressed my gratitude for their help; due to the sensitive nature of the topic I fully understood why some people may not reply or want to be involved.

The other person I contacted before I left NZ was Adrian Tempany. I had read Adrian's 2009 article for The Guardian, which told of his experiences surviving pen three and which explicitly 
discussed the implications of survival (Tempany, 2009). I contacted Adrian via his public Twitter account and after many exchanges Adrian put me in touch with Nick Braley and Tim Knowles, both survivors from pen three. By coincidence I had already come across Nick's Twitter page which publicly stated he was a survivor and had sent him a message prior to being associated with Adrian. Tim, Nick and Adrian agreed to an interview.

Whilst in Liverpool I attended two events that were related to Hillsborough: the book launch for Kevin Sampson's 'Hillsborough Voices', and a charity 'Run for the 96' at Stanley Park.

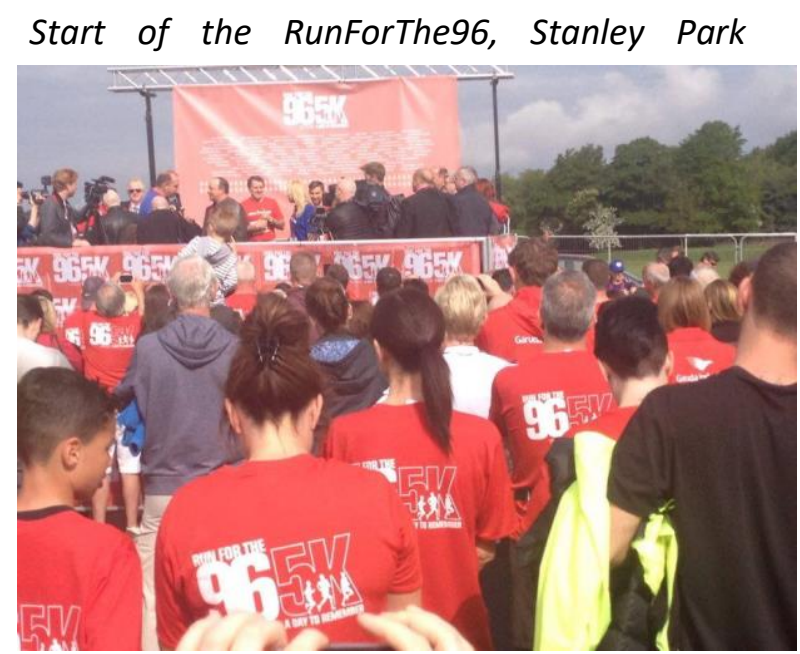

Chatting with Steve and Dan after they had just completed the run

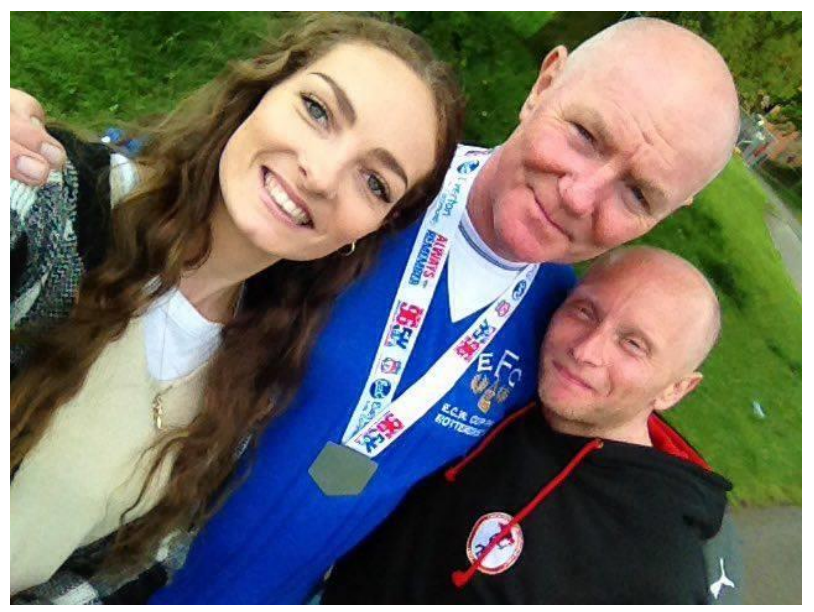

From researching Hillsborough over a prolonged period of time I have watched many documentaries, presentations and interviews online. At the end of the charity run, I recognised Steve Kelly, whose brother Michael Kelly was killed in pen three, from an interview I had seen on YouTube. I approached Steve and his friend, just to introduce myself and congratulate them on completing the run. Steve was surprised I had recognised him and had travelled from NZ for my project and, after our chat, he gave me his contact details and said he would like to be involved in the research. Steve introduced me to Dan Kay, a journalist for the Liverpool Echo and ghost writer for Anne Williams's latest book 'With Hope in

5 Anne's 15 year old son Kevin was killed in pen 3 at Hillsborough. Anne was a member of the HJC, she formed the 'Hope for Hillsborough' charity and was a committed Hillsborough campaigner who dedicated her life to challenging the original inquest verdicts and the '3.15pm cut-off' decision on all evidence. Anne presented her case to four Attorney Generals and took it to the European Court of Human Rights. Anne passed away on the 18th April 2013. 
her Heart'. Dan also gave me his contact details and said he would be happy to be involved.

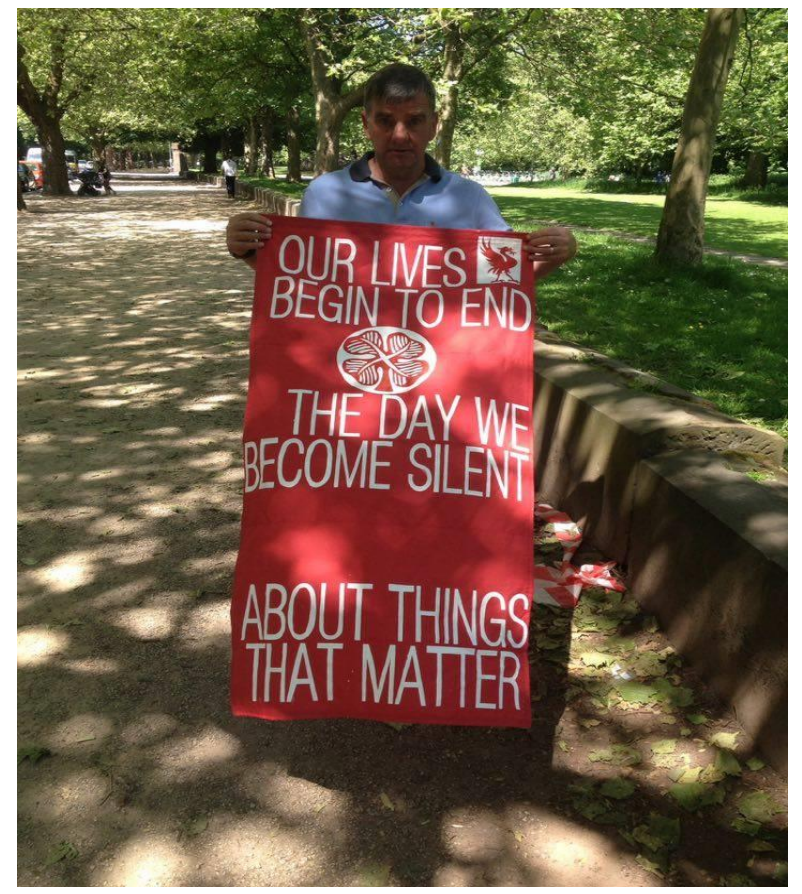

Peter Carney displaying his most recent 'justice' banner, after our interview
After meeting Phil Scraton, he put me in contact with Paul Dunderdale and Peter Carney. Paul is a survivor from pen three and also a bereaved family member, his to-be brother-in-law Graham Roberts died at Hillsborough, and Paul has remained close with Graham's family and the HFSG. Peter is a survivor from pen three and was actively involved in campaigning with the HJC. After interviewing Peter, he put me in touch with Tony O'Keefe who was an off-duty fireman and rescuer on the day, Tony was one of the rescuers who helped Kevin Williams and remained very close with Anne up until her death.

Most participants, after I had interviewed them and spent some time with them, offered to connect me to other people, but regrettably as I had pre-booked my return flight and organised my last interviews down in London (with Tim and Adrian) and Suffolk (with Nick) I ran out of time to return to Liverpool. In total, nine interviewees feature in this thesis: Nick Braley, Peter Carney, Sheila Coleman, Paul Dunderdale, Dan Kay, Steve Kelly, Tim Knowles, Tony O'Keefe and Adrian Tempany. The Key informant interviews are with Sheila and Dan. In addition, the wisdom of Phil Scraton is evident across many aspects of the following chapters. Interview Preparation

A main characteristic of qualitative research is that it is not strictly standardised, and can allow great flexibility in how research data is collected (Grbich, 2013). One intention of this research has been that it might develop new ways of thinking about survival. Before the interviews, I read very widely (across academic, media, campaigning and institutional sources) and spent significant periods watching interviews and documentaries on Hillsborough. I researched the 
history of the HJC and HFSG and watched/read every interview I could find with Sheila Coleman and Phil Scraton. This background research enabled me to identify 'gaps' relating to aspects of 'survival' which had little or no attention given to them. This process ensured I had thoroughly prepared for each interview, and allowed me to identify alternative avenues of knowledge which I could explore with participants during interviews.

Before the interviews, I developed an interview guide (see appendix two) to help me focus my research. However, in practice, the interviews were semi-structured and gave many opportunities for participants to direct and control the conversation (McCabe and Holmes, 2009; Pillow 2003). Semi-structured interviewing allows a more natural progression of freeflowing uninterrupted speech, which creates an environment free from the dictatorial constraints of questioning (Crotty, 1998). This process grants the storyteller the power to define their experiences, the meanings they attribute to them, and their perceived impacts (Johnson, 2009; McCabe and Holmes, 2009; Stanley, 2012). By using these interview techniques it gave the participants the freedom to discuss their knowledge as in depth as they felt comfortable doing, and enabled opportunities to discover multiple layers of experience (McCabe and Holmes, 2009; Pillow 2003). A few participants commented that I had asked them questions they had never been asked before and that I had asked insightful questions.

\section{Conducting Interviews}

In any interview, it is important to establish and maintain a level of rapport with participants to assist in constructing a relaxed and comfortable environment to share their experiences (Dickson-Sift et al., 2009; Watts, 2008). This is even more important when the interviews cover traumatic or sensitive topics. During the research, I was consistently making a considered effort to make the 'right' choices in terms of ensuring participant's emotional safety. I approached each interview with a preparedness to listen without judgement, to be receptive and empathetic to the information I was told, accepting the validity of participant's experiences (Armstrong, 2012: 3; Watts, 2008).

I conducted interviews anywhere that people suggested - in homes, a public park, a work office, but most were outside cafés or in pub gardens. I didn't conduct the one-two hour 
interview and then leave; instead, I spent time with people and, in some instances, I spent all day with participants before the actual 'interview' took place. I found that although my specific focus was on long-term survival everyone wanted to share their experiences of the day and immediate aftermath. This added significant context to my knowledge and it allowed me to gain an intimate understanding that you can't gain from reading the literature. I felt that because of the time I had spent with people when it came to conducting the official 'interview' a comfortable atmosphere had organically occurred.

\section{A Reflexive Approach}

Reflexivity is a methodological tool used to validate and legitimise research practises by acknowledging the "politics of the gaze" from the researcher (Pillow, 2003: 175; Berger, 2015). Being reflexive requires the researcher to be "critically conscious" and vigilant about their practices and behaviours throughout the entire research process (Pillow, 2003: 178). It is a type of "scientific rigor" attempting to make transparent how researchers identify and frame the knowledge they produce (Pillow, 2003: 186; Berger, 2015). Reflexivity involves remaining aware of your position as a researcher and constantly reviewing how we carry out the research in an ethical and compassionate way (Berger, 2015; Pillow, 2003). It is a critical endeavour to enhance understanding of the research process and therefore strengthen the findings (Berger, 2015; Johnson, 2009; McCabe and Holmes, 2009). As part of this reflexive approach, the concerns of ethics, emotionality, and personal connection took a continual presence in this research.

\section{Ethics}

This research had ethics approval from Victoria University of Wellington (\# 0000022632) however, ethics progresses through every aspect of research, especially in sensitive topics. A key element of the ethical dilemma in this research related to how I connected with interviewees, and how I might ensure that the research would not exploit them. 
In an attempt to conduct research ethically the researcher must respond by deliberately and constantly acting against unequal power relations (McCabe and Holmes, 2009; Stanley, 2012). I am an 'outsider' to the Hillsborough community, but not a stranger to the topic (Berger, 2015). I have approached the research as, what Stanley (2012: 237) calls, an "involved outsider". As a researcher I took the stance that the experiences of survival from the participant's point of view are a vital part of the wider Hillsborough story.

Armstrong (2012: 6) observed that her participants would "not allow themselves to be disempowered", and I similarly found this to be the case when conducting interviews. Initially it was clear that each participant tried to 'figure me out' and gauge my sincerity. As I come from a working class background and associate with a left-wing politics, similar to most of my participants, I found this common ground appeared to influence them to be more open about their experiences. However, I was also given the impression that they were aware of potentially being 'exploited' and they had judged my 'research agenda' prior to deciding to speak with me.

My ethical approach guided my interview technique, as I took the decision to take a less active role during interviews. I guided the focus, via my prepared questions on elements of survival, but I did not 'dig' or 'push' participants in any way. I was attentive to their barriers on what they did not want to speak about.

\section{Emotionality}

A fundamental aspect of our humanness is our capacity to feel and to show emotion (Gilbert, 2001a from Dickson-Swift, James, Kippen and Liamputtong, 2009: 61)

Social research has been dominated by two main schools of thought when it comes to 'emotionality'. One prioritises notions of professionalism and objectivity and therefore rejects an embracement of emotion in order to avoid contaminating research findings (Dickson-swift et al., 2009). The other acknowledges that emotions can provide a critical analytical resource gaining a greater understanding of participants and the research process (Copp, 2008). I found in my fieldwork the reality was a mixture of the two perspectives. 
As a researcher interviewing sensitive topics you can be confronted with emotionally disturbing information, but you must employ a type of 'detachment' to be able to conduct the interview and process the information you are given. This technique has been described as a constant "management of self" (Dickson-swift et al., 2009: 69). As the facilitator you have to be able to ask the next question, keep the flow of conversation going and be constantly aware of the participant and how they are coping. It is your ethical responsibility as the researcher to behave appropriately and ensure participant's welfare (Copp, 2008; Rager, 2005). During interviews I was constantly self-reflecting to ensure I responded in ways that remained respectful and above all else placed the participant's needs first (Berger, 2015; Copp 2008).

However, "emotions act as a 'doorway' to the inner terrain of people" and therefore can offer deeper layers of understanding to people's experiences and the meaning they attach to them (Watts, 2008: 8). It is normal to 'feel' when hearing stories of prolonged suffering and by being aware of your emotional reactions it can assist in your analysis of the data (Rager, 2005). Some researchers consider becoming emotional as an essential component of connecting with participants, allowing them to "capture the essence" of their stories (Berger, 2015: 230; Pillow, 2003: 184). Emotions can put 'outside' researchers in touch with deeper insights (Dickson-swift et al., 2009). As a researcher it would be unethical to ignore emotional reactions, in terms of ensuring personal safety, as a professional researcher you need to acknowledge them and manage them in an appropriate way (Rager, 2005).

I was highly anxious, before, during and after conducting all of my interviews (Dickson-swift et al., 2009; also Watts, 2008). After my first interview, with a survivor who was also a bereaved family member, I cried walking 'home', but I made a conscious and successful effort to hold in my emotions during the interview. Researchers have reported feeling overwhelmed by the confrontation of participant's lived experiences. In my last interview I was completely unaware that I had tears rolling down my face, until the interviewee commented that I was about to 'start him off' too. In that situation sharing my emotions seemed to actually lighten the mood, as we both laughed and he continued sharing his stories in a relaxed manner. While this was the only occasion in which I cried, I found that it was appropriate for me to openly 
show signs of empathy and concern during interviews, and I feel it often led to participants revealing more information. However, I remained conscious of ensuring I responded respectfully and in a way that minimised my presence during the interview (Watts, 2008).

\section{Personal Connection}

Watts (2008) discusses how it can be emotional for researchers to leave participants and questions whether researchers ever really do 'leave' their research. I experienced mixed emotions when leaving the UK. After making connections with participants, spending time in Liverpool and traveling around the south of England, the over-50hour journey back to New Zealand was an anti-climax.

Beyond the data, respondents had given me many significant memories and tokens. Paul gave me photos of his friend Graham Roberts, who was killed at Hillsborough, and his personal inquest ticket. Peter showed me the latest in a long line of 'truth and justice' banners he had made. Phil gifted me a HFSG wrist band. My family friends had saved a newspaper from the day of the recent inquest verdict and also recorded the most recent Hillsborough documentary for me. Tim had typed up his experiences of surviving the crush at Hillsborough to help me understand his situation. Tony and Paul both gave me their personal inquest folders to take away and read. Steve gave me a huge reel of HJC stickers. All of my participants were immensely helpful and generous, and I felt a strong connection with all of them (Armstrong, 2012). Steve and I both became emotional saying goodbye. Hearing people's experiences of victimisation made me aware of the suffering they had endured for decades, and by studying survival it also made me highly aware of those who did not survive.

On my return to NZ, respondents still occupy my thoughts. I ruminate on whether I always said the 'right' thing and whether I could have conducted an interview in a 'better' way (Armstrong, 2012). As I made connections with people, they are no longer 'anonymous', and I want to do "justice" to their stories (Rager, 2005: 427). These personal connections put pressure on the thesis, however they also made the research worth doing (McCabe and Holmes, 2009; Watts, 2008). 


\section{Analysing the Data}

Over 27 years there has been so many experiences of 'survival', I cannot compile a comprehensive account of them all. I used thematic analysis as my method for analysing the data from the interviews, as dominant themes emerged to reveal collective interpretations of experience and various layers of interpretation (Grbich, 2013).

I spent several weeks transcribing each interview verbatim. Once completed, I sent the transcripts to the participants that requested a copy. This allowed them to review the information they disclosed and gave them an opportunity to request any sections be removed. All participants were happy with the original transcripts and consented to me using all the information. From here, I made separate word documents with bullet points of every point, idea, incident and experience related to notions of 'survival' from each interview. I then grouped the relevant bullet points under the questions that led my research (see appendix two). Under each question I again separated each bullet point into distinct themes and then made another word document to assess which participants raised the same themes or distinctly different themes.

\section{Example:}

Research question: 1. what does it mean to be a survivor of Hillsborough? Point in \# interview: Survivor felt they had never been labelled or seen as a 'victim' only considered in terms of blame for the deaths of the 96 . Theme: Representation

I then created documents in which each theme was connected to quotes from every transcript, and then I assessed which quotes best 'represented' each theme. Via this process I became so familiar with the data that during the write-up process I had quotes, other than ones I had selected, constantly popping up in my head (Berger, 2015). Making connections with participants enabled me to be able to "capture the essence" of them and their stories (Berger, 2015: 230; Pillow, 2003: 184). "Writing is a way of framing reality" and, as the following chapters of primary research findings indicate, it can be emancipatory in the sense 
that registering participants' 'truths' is a way to resist establishment narratives (Pillow, 2003: 187; McCabe and Holmes, 2009). 


\section{Chapter Four: The Struggle to Survive Hillsborough}

The Hillsborough survivors is a club nobody chose to belong to (Paul).

This chapter considers the definition of the term 'survivor'. Participants developed the concept of 'survivor' from their lived experience, identifying that 'survival' did not end at the Hillsborough stadium. They also identified that, as a direct result from official responses in the immediate and long-term aftermath of the disaster, many cohorts of victims/survivors were created. This understanding supports the literature, discussed in chapter two, whereby victimising experiences in the aftermath of disasters creates many 'types' of survivors. This chapter then proceeds to outline and discuss the themes exposed from the research question: 'What has prevented survival?' Six main factors are discussed: limited supports; lack of recognition; victim-blaming and social stigma; the impact of official responses; the personal impact of surviving; and social expectations to move on from trauma. All of these factors demonstrate how survivors try to navigate their survival to overcome these incidents, structures and processes.

\section{What Does It Mean to Be a Survivor?}

Well the survivor's side is a strange one, because the majority of them wish to remain anonymous...I wish more people would come forward and speak about the issues that they've had since Hillsborough, because that way we can help them...and... avoid it in the future (Steve).

Every interviewee thought that only a fraction of those affected by Hillsborough has come forward to share their experiences. Participants emphasised that thousands of survivors left the ground that day and no-one knows how they survived, or even if they have. Sheila explained that some people only identified as survivors many years after the event:

You really don't know they're survivors, because they don't tell you, and it's only over many years where people...have at some point revealed that they are survivors. 
Others corroborated this observation, as their disclosure came at different points in their survival journey. The information available to understand what it means to be a survivor of Hillsborough, therefore, comes from a minority of individuals who openly acknowledge their involvement and survival.

There are different perspectives on what defines a Hillsborough survivor however most participants felt that the label 'survivor' could only be applied to people whose life was in danger on the day:

I have a very clear definition of what a survivor is and it's someone whose life was threatened by being in pen three or four, or outside gate ' $C$ ', at Hillsborough that day. Anybody else is an eye witness or an observer, but I have a quite clear idea of what it is that I survived and it was that life-threatening experience of being in pen three or four (Peter).

However, every participant acknowledged that the number of people who 'survived', who are still dealing with the victimisation and trauma of Hillsborough, is immeasurable. They also saw that various aspects of Hillsborough have created different types of victims and therefore various layers of survival. They often defined this complex situation by explaining there are many people who have "survived the experience" of Hillsborough (Paul: emphasis added), including observers, witnesses, rescuers, LFC fans, the entire city of Liverpool, campaigners, and generations of families and friends.

Every interviewee identified elements of the sustained cover-up as fundamentally connected to people's experiences of 'surviving' Hillsborough. They were at pains to point out that the propaganda campaign against the fans was a main barrier to survivors coming forward. Nick described this:

... when you talk about the people smeared by the police lies, well that's 24,000 Liverpool fans, because everyone who went through the Leppings Lane end was smeared by those lies and accused of effectively being a murderer. 
Participants acknowledged that direct consequences from the cover-up have created a highly complicated situation regarding survival. Many explained that the cover-up produced a ripple effect, creating more victims.

For interviewees, the survivors of Hillsborough are those who survived the crush outside gate $\mathrm{C}$ or in pens three and four. However, due to the nature of the disaster and the longevity of the cover-up, the number of 'victims' who have had 'to survive' Hillsborough is far higher. Participants identified that survivors' experiences cannot be generalised, because their experiences on the day and in the aftermath are so diverse. People survived variations of the same event and because of that each person's survival journey will have a different trajectory; their needs will be different and each 'need' will have a different importance to each person. However, as the following sections show, there are some barriers to survival and needs of survival which appeared to be commonly important for everyone.

\section{What Has Prevented Survival?}

A... always said 'you know you're fighting against the establishment, from the government right up to Thatcher'...I've said this to S..., A's daughter, 'I dunno how your mum carries on'. In the end, I think it killed her (Tony).

Interviewees demonstrated a unified understanding that someone can be 'alive' but not 'surviving'. They told stories that conveyed how a positive quality of life was fundamentally linked to positive survival, and that incidents that were detrimental to quality of life prevented survival. Interviewees acknowledged they suffered what would be considered expected responses from experiencing disaster, such as trauma and bereavement, however these conditions were often worsened by the inadequate and damaging responses they received from others. For example, Sheila identified that:

The help for survivors has always been woefully inadequate...if you read anything about post-traumatic stress, the sooner you're dealt with the better, that is in terms of 
your chances of recovery. Can you imagine, 27 years on, someone saying they need help for the first time, can you imagine the damage done?

The consensus among participants was that Hillsborough survivors have been largely ignored or regularly blamed for the disaster and deaths of the 96. Subsequently, there have been many responses that have, intentionally or not, acted as obstacles to survival. This chapter presents six main concerns that emerged from this research in relation to factors which have inhibited, undermined or prevented survival: limited supports, the lack of recognition, being blamed, harmful official responses, damaged personal relationships, and bystander expectations to 'get over it'.

\section{Limited Supports}

Everyone discussed the negative impact from the lack of official support, such as the ongoing inadequacy of professional help or counselling. Most participants acknowledged the main help offered from the state took the form of the 'Hillsborough Centre' in Anfield Road Liverpool, a place where survivors could be supported by social workers. However, many perceived the Centre as an arm of the state and only a minority of survivors accessed it. The participants who used the Centre explained they were very distrustful of the social workers, who at times had attempted to control their support groups or the way they expressed their trauma. The Centre, set up to attend to the needs of the thousands who survived the crush, disbanded after two years. Since then, any professional help has been independently paid for by individuals or developed from fundraising within the campaign groups (HJC and HFSG).

Interviewees thought that those affected by Hillsborough had nowhere to go to gather or receive support. They felt officially abandoned, left to deal with the trauma of the disaster and aftermath alone. Many identified that the cover-up, and the "smears" (Nick) and "poisonous" narratives (Adrian), created obstacles for people to get official support. Adrian went to his doctor when he was struggling and was told "Well, it looks like Liverpool fans were to blame doesn't it?". He described this encounter, directly caused from the official narrative, as exacerbating his trauma. Sheila explained that because of the denial of support, people had to rely on "their own survival skills" to progress. Many participants acknowledged that 
official supports were an important, and for some a vital requirement, for survival. As Paul explained, "how many times do you get knocked down before you actually stay down?". Peter described how the victim-blaming from officials, in some instances, exacerbated survivor guilt and acted as a barrier for survivors accessing professional supports:

I think survivors generally have struggled. They've had two big dilemmas, one is that they're not the most important people - the most important people are those that have been killed and their families and so they're secondary. And, along that thread of consciousness, is the thing about being lucky to be alive...And the other side of it is the malicious attacks on survivors...you know blaming the victim.

The overwhelming response from participants was that the actions of state authorities had, in general, detrimentally affected survival for those affected by Hillsborough. The fact that the majority of people have survived anonymously highlights the inadequacy of state agencies, whose job and responsibility it is to provide aftercare for victims of disasters. The assertion from participants that specific help was needed and was denied to them, raises questions concerning the difference in the quality of life those survivors might have had if they had received formal help in the immediate aftermath. The majority of survivors have remained anonymous and participants acknowledged that most survivors' experiences remain unknown. Given the context of victim-blaming, established by the state, survivors' suffering was prolonged and many have never accessed formal or informal supports. This has caused a mass societal lack of recognition of their trauma.

Lack of Recognition

Interviewees saw that the lack of recognition of survivor's experiences has created many barriers to survival. As a group, survivors have not been, and continue to not be, sufficiently represented. Tim explained:

I've been irritated over the years, because the term 'survivor' has rarely been used to apply to us, we've generally been described as the 'fans', this anonymous mob. 'Fan' 
is short for fanatic, which suits the police narrative of events but, no, I very nearly died in an incident, which killed 96 people so therefore I am a survivor.

The lack of recognition further removes the idea that survivors could also be victims and this devalues their experience of surviving the crush that killed 96 others. Many participants raised Tim's point and felt that they had never been labelled or seen as victims, and so had never been treated or responded to by the state and associated agencies as victims:

...in any other incident they'd be a victim, but they're a survivor and with that is the connotation they're lucky and...the guilt, well: 'we're lucky we're alive, I don't have the right to say anything, I'm alive'. And the shame, a lot couldn't face looking at a bereaved mother or father and they'd ask for forgiveness, that's very very hard that (Sheila).

The lack of official recognition was regularly internalised by survivors and this exacerbated their personal suffering. Participants repeatedly brought up that many groups: the survivors, fans, bereaved, rescuers and even campaigners, have not been sufficiently and accurately represented, and this has led to their experiences not being recognised. Paul explained an ongoing consequence from the lack of recognition:

There's still people today that deny the holocaust, there is still people today - 'that didn't happen' - well in 20 years' time there'll still be people saying Hillsborough was all drunken fans cos that's what they choose to believe.

People acknowledged that the continued smear campaign against the survivors contributed to the lack of societal recognition of their experiences and this had a major impact on survivors' sense of self. Peter explained (emphasis added): "I made a banner...the week after and it says on the banner 'to the victims of Hillsborough' at the bottom it says 'you'll never walk alone', and when I re-done it 20 years later it now says 'we never walk alone'"; this highlights the barriers the smear campaign caused impeding people's personal lack of recognition of their own experiences. 
A major cost generated from the lack of recognition of survivors is that they have felt that they have never really had their voice heard, recognised, or listened to and no-one has ever officially taken their perspective into account. Post HIP and RIV, more survivors are coming forward and speaking publicly, but there has been an acknowledgment that there is still a lack of attention towards survivors. As Tony expressed: "sometimes you wanna say your piece but there's no-one there to say it to". Survivors felt that it will take a long time for the misinformation and misrepresentation to be corrected with information from the survivors themselves; Peter acknowledged this point:

There's 3,300 people in them pens and they haven't all had the opportunity before and maybe some of them would like the opportunity to do it, so let them have a say, let them have the space, you get better understanding then.

Participants explained the negative effects of being confronted with misinformation in their daily lives. A few got into physical fights with people who did not identify them as victims, and who repeated the official allegations and slurs against them. Interviewees explained that they had been "demonised" and "dehumanised" (Tim). As a group, they are a major part of the 'Hillsborough story', but their part is rarely known, which compounds the lack of understanding towards their trauma and the personal costs of surviving a major disaster.

As a result of the lack of recognition and the misrepresentation of survivors, many victims from Hillsborough have never received assistance for their trauma. Sheila told many stories where she had come into contact with survivors who suffered immensely because their problems were not recognised as being directly related to Hillsborough. In one case, she explained:

...he was never the same when he come back from Hillsborough, this lad ended up with severe mental health problems, being sectioned, being put away ...now this fella, he was 15 or 16, he's spent most of his time in an institution since then, but never labelled as a Hillsborough survivor, how horrendous is that, horrendous, and multiply that, that's not isolated. 
In the case of Hillsborough, the lack of official recognition led to survivors not being accurately represented and this consequently misinformed the general public of the realities of the disaster and its aftermath. Not being accurately represented can present opportunities for states to employ mechanisms to deflect blame for their accountability before, during, and after the disaster. As the next section demonstrates, the ripple effect from the initial official responses can register a false narrative in history and initiate further preventions to personal survival.

\section{Being Blamed for the Disaster}

Participants continually highlighted the damaging effects of being blamed for the disaster and the deaths of the 96. Expressing a deep frustration, many emphasised their continued anger towards the smear campaign against the fans. Tony alluded to the constant attempts by many to resist and challenge the wrongful attribution of blame: "every door gets slammed in your face and...you've gotta fight against the authorities all the time".

Participants explained conditions such as survivor guilt and PTSD were exacerbated by the societal blame, as survivors internalised the smears and that accentuated their suffering over many years; one survivor described it as "torturous" (Paul). Participants explained the reason the stigma was so damaging was that it was so wrong. Steve described the reality as:

The fans were the heroes, they were jumping back in the pens, they were trying their very very best to pull things down with their bare hands... we should be honouring them, we do as families, but the authorities need to.

Some participants acknowledged the "irrational" (Peter) nature of their trauma. They explained they knew the truth, and didn't believe the lies, but the narrative against them was so strong and so widely accepted that it caused them to doubt themselves. They subsequently recognised that their mental health had been deeply affected, in many negative ways over the years. As Sheila recounted: 
They knew they were right and they knew they were telling the truth, but it shows the impact when there's an established version of events that everyone is reading. It's like you're walking around with a label on you, as soon as you open your mouth as a scouser, 'yeah, you're one of them'.

Participants identified that many disasters occurred through the 1980s and 1990s, however no other group of survivors were blamed. Every interviewee discussed the damage caused by the media and everyone specifically named 'The Sun' tabloid for its "appalling slur" on survivors (Nick). Some participants can no longer look at newspapers and Tony explained his reactions to the pain caused by 'The Sun': "anytime I seen it on the fire station I would just rip it up in front of someone and I set fire to a couple". The slurs also developed through statements from the police. For example, a few years after the disaster, a policeman told Nick that "95 dead, a good days work"6. Tim identified the implications when victimisation is turned into victim-blaming:

Survivors of other disasters do not have the huge amount of extra baggage of being blamed for causing what nearly killed us and what did kill 96 others...It seems that we're only ever mentioned in context of being blamed and that's the result of the dehumanisation...Even after the inquest verdict, when we had been finally cleared, there has been precious little media interest in survivors... We are not an anonymous mob, we are human beings who went through a traumatic experience beyond the comprehension of virtually anyone and then we were falsely blamed on top of that (Tim).

Many institutions were involved in the "public vilification" (Adrian) campaign against the fans and the social "stigma" (Adrian) this engrained in society, the police force, the mass media, and even the FA. People spoke about the filtering down of denial and lack of accountability from top official institutions, which became immersed in daily life situations and constructed

\footnotetext{
6 The official $96^{\text {th }}$ victim, 18-year-old Tony Bland, was left in a persistent vegetative state after suffering injuries in the crush in pen 3 at Hillsborough, his life support was turned off in 1993 (HIP Report, 2012).
} 
an environment where it was acceptable for the general public to follow suit; Tim explained one such example:

There are fans of rival teams who mock and taunt, but it's not so much them that I object to it is the complete failure of football authorities, particularly the FA, who don't do anything about it... should be allowed to be able to and support my team without hearing the greatest trauma of my life mocked and abused...you don't hear people mocking the London tube bombings, you don't hear mocking the Dunblane shootings, it just doesn't happen to those the survivors... Why is the football association allowing this abuse to occur unchallenged?

Such encounters created great pain, and they also put survivors in the position of continually having to defend themselves and others. These incidents demonstrate how the smear campaign against the fans created a social culture of mass victim-blaming that created many barriers to positive survival, as survivors had to also fight to be recognised as victims. Many survivors discussed the detrimental outcomes caused by the untreated emotional and psychological damage from Hillsborough and its official aftermath: people endured PTSD, survivor guilt, and took illicit drugs as an avoidance and coping mechanism. Two survivors had been arrested due to altercations with police officers, as Adrian explained, "it very nearly derailed my life at a number of junctures". Participants often explained they struggled with the internal conflict caused from being unable to reconcile their experiences with the police version of events and this caused them to suffer panic attacks, nightmares and breakdowns for years afterwards.

For some people, this sense of blame has been too much to bear. Many survivors from Hillsborough have self-harmed or taken their own lives. As Dan and Peter recounted:

Many have taken their own lives...there was one fairly high profile [case]...he's been called the 97th victim, but that could apply to any number of people. He wasn't actually there, but he sold his ticket to someone who died, and obviously was wrapped with grief for years and years and years (Dan). 
...I'd met this fella... he had me in tears, everything that he said was dead right. Why isn't the Labour movement demanding that heads roll over this? Nobody ever lost their job over Hillsborough, no-one...there was a documentary on the telly and he couldn't handle the way that the documentary was done and he took his own life in the garden shed (Peter).

Aside from the suicides known to be related to people's experiences of Hillsborough, participants said there have been premature deaths from the stress of fighting the establishment in the campaign for truth and justice. After the 2016 verdict, a survivor told Dan that the experience of Hillsborough destroyed his life and the verdict meant nothing to him. Many participants suggested why they felt the lack of recognition, misrepresentation, denial and victim-blaming had been directed towards them; they felt it was intrinsically linked to the political climate of the 1980's, Sheila explained:

...Liverpool was viewed negatively, but football supporters were viewed through the lens of hooliganism, and so when...Hillsborough happened it was just that combination. It just meant this is easy to cover up, not only are they football supporters who are given to violence, they're Liverpool supporters. Heysel comes into it, ticketlessness, drunkenness, and this kind of anarchy of working class people.

People acknowledged the power those 'in charge' have in dictating people's social status in society. Dan explained the wide-reaching consequences of the cover-up: "everybody from Liverpool...[has] had to bear the weight of those lies, those smears for all this time". All participants spoke of being regarded with suspicion by authorities and wider society over the years. Adrian explained "to be blamed for killing people, which is what we were, it's a terrible stigma to have to live".

In short, official victim-blaming has severely affected the quality of life of people trying to survive within that climate. Participants identified that many have not survived the mass stigmatisation they experienced as a result of the political climate at the time of disaster. Officials negatively stereotyped football fans, by framing survivors as a mass group of 'problematic' working class hooligans. This idea is developed in the following section, which 
gives examples of the relevance of the wider political response in preventing 'survival' at an individual level, and the harms that ensue.

\section{Damaging Official Responses}

The social injustices of Hillsborough, involving many official agencies and institutions, has significantly impacted the quality of 'survival' for those affected by Hillsborough. As an example, Dan explained: "M... in particular, often uses a word about other family people who have died before seeing justice: 'they died tormented'". The cost of surviving Hillsborough described here is that surviving in a climate of denial has devastating social consequences that due to the longevity of the cover-up can never be rectified. Paul expresses this when explaining the premature death of bereaved parents:

...they never saw justice and that's hellish for me, they didn't get to sit in that court room and have everything vindicated and that's the...third tragedy, the cover ups the second, the third one is that sitting here 27 years later not everyone is able to see it. And, I think that shames this country for me.

Interviewees highlighted that the deliberate actions by authorities have created major barriers to positive survival. Nick raised a widespread concern:

I think most people now recognise that our police... when they do things wrong they will lie and cover it up. There's a lack of accountability in our police force...because their default is to protect themselves rather than try and seek the truth, cos they're afraid the truth will be critical of them.

Participants commonly saw the conduct of the police (in causing the disaster and instigating the cover-up) as producing an unquantifiable pain for them. Paul explained from the initial time of the disaster:

Football fans in the 80's were treated like animals, they call them pens for a reason, to the police's eyes they were sub-human people, they were people that just had to be 
herded, treated like crap and basically no human rights whatsoever - we're football fans, we're lower than that.

Commenting on the dishonest approach from the police over the entire 27 years since Hillsborough, Dan said: "for that to happen, in a social civilised society, in a democratic country, raises massive questions and should induce an enormous amount of soul searching". Many participants had ensured they remained well informed on the SYP and WMP involvement in other miscarriages of justice, such as Orgreave and the Birmingham 6. Participants also brought up the entire British police culture. As Tim explained:

The fact that it was the establishment defines everything, but from a personal point of view it sets you apart...from society. You know...these organisations, when they mess up, when they make mistakes, there is no depths that they will not sink to in order to get out of being blamed. Jean Charles de Menezes, the man who was executed by the police and on the tube train... how low do you have to actually sink before you're gonna hold your hands up and admit that you killed a man in cold blood through incompetence? So this is what we're up against here.

Many participants brought up the past failures of the legal systems with the rulings and outcomes from previous inquests, scrutiny, civil litigation and private prosecutions. There was a very strong assertion that the inadequacies from the past legal proceedings were a deliberate "stitch-up" (Adrian) as part of the sustained collusion and cover-up. This was not a historic situation, but an ongoing occurrence. Even participants who were not directly involved in legal proceedings explained they would still follow them and saw them as an important means to gain some resolution. People almost had no choice but to "put their faith in the system" (Sheila), they had to rely on 'legitimate' systems and they were deeply affected by the decisions made within those systems for decades after.

Every participant stressed the damage caused by the adversarial nature of the recent 20142016 inquest. Nick explained the controversial handling by those in charge of running this process: 
You could be labelled a murderer...the conduct of the police in the last two years has put the fans back on trial...25 million quid to put a load more innocent people on trial and regurgitate the old lies, but that's our legal system for you.

Participants emphasised the significant re-traumatisation caused by the fresh inquest. Dan explained "people were in a terrible, terrible way". All participants noted that had question sevent gone against the fans there would have been more suicides, a few participants personally knew someone at risk.

Interviewees saw an unavoidable 'chain-reaction' of negative consequences from official proceedings. Official decisions had a huge impact on people, even those who were not overtly involved. Many, for example, felt the inquest put their lives on hold which created problems in day-to-day life. Steve, for example, explained the difficulties of emotionally needing to attend court and the problems that created:

...the unseen things you gave up: time with your family, time at home, because don't forget you still had to go home and do your washing, your cleaning, your cooking, your life still went on. Trying to get work, I virtually gave up work so you couldn't claim benefits, so you were living off your life savings and that's what l've done for the last three years. But none of that mattered, the fight mattered.

Like other interviewees, Steve expressed the internal conflict between doing what they needed and doing what they felt was right, understanding that those choices often stood in direct opposition. Tony, a rescuer on the day, said "it's really hard to actually listen to people's stories... sometimes I'm glad I'm away from it and that's probably a way of coping". Many other participants pointed out the strain that the constant battle against the authorities had on all involved; some said it took up most of their lives. They explained that because "the

\footnotetext{
7 Question 7: Behaviour of the supporters: A) was there any behaviour on the part of football supporters which caused or contributed to the dangerous situation at the Leppings Lane turnstiles? B) Was there any behaviour on the part of football supporters which may have caused or contributed to the dangerous situation at the Leppings Lane turnstiles? (RIV, 2016)
} 
police, the media, the government turned against you" (Dan), they felt they had a responsibility to challenge the official version of events. This could have dramatic impacts on their closest relationships:

My sister had three daughters. They suffered because we were always going to court, we were going to meet police, it was a constant source of conversation. At home, we lived and breathed it. We became what I would sort of call 'Hillsborough bores', cos it's all we ever talked about. We lost our own identities and so our siblings and children and grandchildren they lost out, because instead of us being two family members we were part-time and that must have been difficult for them (Steve).

Participants also recognised that they had become distrustful of people, especially authority figures and agencies. A few participants raised the issue that since uncovering the lengths those involved went to cover-up the truth, they are now paranoid of being at risk of being targeted by officers. As Dan said: "what's to say just cos you're paranoid doesn't mean they're not out to get you?" Many participants explained as a consequence of the cover-up they have lost all faith in politics, because as Nick explained "why would I have any interest in people who don't understand justice when it hits them in the face, so l've been put right off politics for that reason". Further, they all spoke about the lack of credibility state institutions now have due to the lack of accountability for their actions.

Overall, participants identified the inner-conflict in having to constantly negotiate their personal/private survival needs with the collective struggle to fight against the official responses and representations of Hillsborough. They acknowledged the immense detrimental effect that official responses have had on their attempts to gain a positive quality of life. The following section builds from this by providing examples of how the initial trauma from survival and the official proceedings have impacted on their personal lives.

Impact on Personal Lives and Relationships

The personal legacy of Hillsborough has been significant: families have split up, there has been absent family members, the generational costs of children growing up knowing nothing but 
the fight for Hillsborough, people lost friends, and people lost jobs; all are consequences from the trauma they suffered or from the legal proceedings taking up so many years of their lives. Adrian explained: "the trauma is so, so terrible you can't do anything for years". People spoke about the impact of the trauma and personal sacrifices made by Hillsborough campaigners, and reflected on the toll and strain that drove many to an early grave. This connects with the cost of feeling a moral obligation to challenge the establishment, as Sheila explained:

You make personal sacrifices, but you do it because you you're a political animal, not in a party political sense, but you have a sense of right and wrong and it's your value system.

Participants spoke about the irreparable damage caused to them, and the 'unsung heroes' of Hillsborough, from the personal sacrifices they made to establish the true facts of the disaster. Examples included a police constable whose evidence of holding Kevin Williams and hearing him speak 'mum' past $3.15 \mathrm{pm}$ remained a constant challenge for the establishment version of events. Tony spoke about her evidence at the fresh inquest:

She turned round and said to them: 'was you there? I was there, I know what that kid said and I had that kid in my arms', and she stood up for herself. But it absolutely ruined her in the years, she had a fiancé in the police and she never got married, she stayed single and they ruined her.

Sheila gave an example of an ambulance driver on the day:

He is a survivor, he is a victim of Hillsborough if ever l've seen one in terms of his life, how it altered, the trauma, nothing physical, but the trauma of that day will never leave T....

By continuing to speak the truth of their experiences, this officer and ambulance driver's quality of life was diminished by their treatment by the authorities. This situation has been endured by countless others. 
How people dealt with their trauma from Hillsborough affected how they interacted with those closest to them. Over the years, people's 'survival' trajectories altered and mechanisms used to cope changed, and this affected the level of inclusion or exclusion of family and friends. Many survivors never spoke to family or friends about Hillsborough. A few said they feared being blamed and they thought others wouldn't understand. Many worried about the impact their story would have on others and they didn't want to burden those closest to them with their pain or anger. Part of the smear campaign was the 'self-pity' city allegations, and this prevented survivors from seeking help because they wanted to resist those labels. Participants acknowledged this was counterproductive for survival as struggling victims required help. The negative impact the disaster had on relationships took many different, serious forms. Paul explained if we looked at bereaved and survivors personal relationships we would see:

...pretty high divorce rate, high separation rate. I think they'd be issues like in our family where you just go separate ways... because it has taken so long. People have given up, they've given up the fight and gone their separate ways. And, if you talk to S... she will say that she's' pretty sure that Hillsborough killed her mum and dad.

Interviewees discussed the damage caused to the outer layer of relationships in people's lives. For example, people lost their jobs and so lost contact with a work-based network, and they saw their friend circle diminish. Participants repeatedly stressed that 'Hillsborough' took up their whole life; many said that it was all they could talk about at times, and that was very draining for listeners. The outcomes of the strain put on relationships from the trauma of surviving Hillsborough has, in some cases, created isolation, pushing those suffering further towards the fringes of society. This is something that can change, or take different forms, but it is continually present. As Adrian noted:

...the idea of 'closure', for me it's a completely false idea... The best you can do is...just accommodate it into your life as best you can. You'll never beat it and that's a problem in itself, because in the early years there was this idea that 'oh you know you'll get over it, just keep going couple of years, maybe longer, but you'll get there'. So what you do is you presume that one day you're gonna get over the line and...you can put it all 
behind you. And that becomes part of the problem in itself, when you're trying to recover, because it's a false idea... it's not a straight track trauma...you're on a circular track all the time, you just keep going round and round in circles. Things get easier, definitely, but you always return to it and it's always part of your life.

The trauma of surviving disaster, and the official response, has had a multi-dimensional and diverse impact on the personal lives of those who were 'surviving'. Many interviewees have actively tried to challenge and resist, but trauma is deep and far-reaching, bringing many other individuals into its wake. In the long-term aftermath of the disaster, as campaigns grew, and elements of the realities of the disaster began to gain wider attention, the smear campaign against the fans evolved into demands for them to 'move on'. The following section explains how concepts of 'moving on' and 'closure' do not reflect the lived journey of survival and demonstrates the impacts the persistence of these ideas can have on survivors' lives.

\section{Expectations from Others to 'Get Over It'}

A final major barrier to survival is the persistent demands from mainstream media, public officials and wider society that those affected should 'move on' from Hillsborough. Participants explained that the notion of 'getting over it' did not reflect their lived experiences of survival. Many explained they had continued with their lives, that they were resilient and were constantly moving forward, however, they all expressed that Hillsborough never left them. Paul articulated this situation:

I think the moving on argument is hard for us to understand, it's very easy for the outside world to say 'move on', unless you're part of it, unless you feel a massive burning sense of injustice it's hard to move on.

Participants highlighted two key issues that prevented them from moving on from Hillsborough: "the massive scale both of the trauma...and the mendacity of the cover-up" (Tim). Interviewees explained they never received what they needed in order to be able to move forward: they never had the full facts officially admitted and recognised, there was no accountability, and no justice. The lack of understanding at all levels has been damaging, 
because it isolated survivors. Tony said people criticised his support for the truth and justice campaign, right up until the recent inquest verdict, as they asked him "What are you trying to do, what are you trying to achieve?".

Participants recognised that, in the climate of intolerance towards 'Hillsborough', survivors were reticent to voice their experiences, or articulate how they felt. Some observed that those suffering severe trauma struggled to express their feelings in socially acceptable ways, and their expression of suffering made others uncomfortable. Sheila explained:

Some people are very articulate in how they can explain their experiences of that day. Other people, they can articulate it, but in a totally different way, and in a way that not everyone's prepared to listen, so they might swear, they might use slang.

The common response from participants was that because survivors were not seen as victims and because there was a generalised expectation to move on, what accompanied that was an expectation of how they 'should' behave. Their attempts to challenge the state were met with official responses that they were being difficult or troublesome, once more. The application of the label 'self-pity-city' is one example of how the inability to overcome trauma was reconstructed as evidence of problematic behaviour. Further, these challenges to authority could also be regarded as overt attempts to refuse to 'move on'. 


\section{Conclusion}

Participants have highlighted many structural processes that have created barriers to survival, including: official processes, legal proceedings, and media representations of the disaster and survivors. This section also uncovered that societal opinions and (mis)understandings of survival experiences created struggles for survival at a personal level in daily life. The lack of recognition as victims and lack of recognition of the long-term impacts of trauma influenced expectations to 'get over it'. Further official and societal misrepresentations continued to blame and stigmatise fans, and question their survival trajectories. These barriers to survival have proved fatal for some, however participants identified pathways which assisted and supported positive survival in the long-term aftermath of the disaster. The following chapter presents accounts of these pathways and discusses the diverse factors that have affected these trajectories. 


\section{Chapter Five: Paths to Survival}

I survived Hillsborough so I can survive anything, it changes your attitude to life when you have an experience like Hillsborough (Paul).

This chapter outlines the personal pathways to survival, including the ways in which those affected by Hillsborough accessed certain types of supports. It examines how the shift in responses from the wider community, over the years, has proved significantly beneficial to overall survival experiences. The chapter discusses six survival trajectories, raised by participants including: personal distancing from others to opening up to others; building supports via social media; getting involved in official campaigns; connecting to a 'survivor community'; following and engaging in legal proceedings; and experiencing empathy and solidarity from others unconnected to Hillsborough. The chapter argues that although there continues to be many barriers to survival, factors which support and encourage survival coexist. Survivors may be traumatised and suffering, but they also experience positive impacts from other factors that foster and develop survival trajectories. The co-existence of these contradictory experiences is a good illustration of the continuum of survival.

While, as previously shown, participants stressed the trauma, suffering, torment, and damage that experiencing Hillsborough and its aftermath has caused to them, many also recognised that they could draw some positives in how they managed to survive. People acknowledged experiencing Hillsborough changed their perspective on life in a positive way; a few used the phrase "I survived Hillsborough so I can survive anything" (Paul). Adrian explained "it's not an entirely negative thing, I think you develop an empathy and a compassion as well, a humanity for other people". Others corroborated this idea; Nick and Tim said they have since reached out to help others dealing with trauma, sharing advice and knowledge they felt they gained only through experiencing Hillsborough.

Participants explained that even in the "very dark years" or "wilderness years" the tenacious attitude of the collective struggle created a shared perspective that they were not going to give up (Tim). This idea sometimes manifested itself in a very literal way, as Peter described 
"the other thing that really drove me on was that I wasn't gonna kill meself". Some participants sought out 'survival'; Dan said over the years "you have to take whatever joy you can from wherever you find it". All took solace from the fact that what they were doing was morally right. This perspective was extended to the beliefs concerning the 96 people that died; participants conveyed they continued the quest for truth and justice because of the severe miscarriage of justice the 96 suffered, as Peter said: "I didn't know any of them, but they were mates". Often the wider issues of Hillsborough were connected to individual's personal survival journeys and in turn this often connected the different groups affected by Hillsborough. The following section starts with initial personal reactions to the disaster and develops how those survival trajectories have twisted and turned and evolved over the following sections.

\section{From Distancing to Opening Up}

Probably five-six years I couldn't even talk about it, I couldn't, I couldn't get my head round the fact that people were asking me questions about it...I changed jobs, moved into a head of another company and didn't tell anybody I was there until they saw me on a documentary, so you know there's different types of survival...it was a horrific day, horrific experience, but we all cope with it differently (Paul).

Participants explained that there will be survivors who will never talk about Hillsborough and will never come forward; as Steve observed "the biggest majority is the silent majority". Many people have hidden themselves as a means to protect themselves from stigmatising associations. Sheila told many stories of survivors who would not overtly come forward, but would linger at events or at the HJC shop and observed that they were "dipping their toe in the water". Sheila told one story of a young homeless lad who she recognised from footage in the immediate aftermath of the disaster and made contact with him and had started to organise help for him:

...then he went off the radar and I never knew what happened to him, that's a really sad story... What it raises the question... how many others went off the rails like that, got into crime, got into all sorts of things, but would never use Hillsborough, because 
they had that survivor guilt, they were 'lucky to be alive' - and I think that's vast, I really think that's vast.

Interviewees explained, however, that their survival journey changed over the years and because of that their coping mechanisms also changed. Some initially could not deal with Hillsborough and employed distancing techniques. They spoke about throwing themselves into work, and not even being able to tell people they were actually there. Paul explained that, a few years, ago he found out his brother couldn't face the idea that he very nearly died in the pens, and put his struggling to breathe in the crush down to an imagined allergic reaction to a bee sting he had on the way in to the ground. Participants used avoidance tactics, some even moved to New Zealand as a direct result from the trauma of Hillsborough. As Adrian explained:

...about four years afterwards I just thought I can't, I didn't even wanna be in this country, I hated it and that's why I wanted to literally get as far away in the world as I could and that's why I went to New Zealand and for me that was the first time I actually found any peace in my head.

For many, this distancing could not be maintained, and most participants felt that they got to the point where they needed to open up and share their experiences. For some participants it has taken many years to be able to speak about Hillsborough and even now Paul spoke about the continual pain, "you know clearly its 27 years later it's still difficult to talk about". Participants identified how their personal feelings and reactions to Hillsborough and the way it affected them had developed over time. This illustrated how diverse survival trajectories can be accessed at different junctures in time and in this way people are able to access supports they may have previously been denied. Nick provides an example of this:

Of the survivors I have spoken to, I'd say less than half have never had any counselling at all...l've only spoken to about 15 or 20, but assuming they are typical, that means an awful lot of people have slipped through the net and again when it's 27 years ago it's much harder for them to go and ask for help. So I do what I can to try and encourage those who I think need it, without saying 'you need counselling'. I just say I found it 
very beneficial, share what happened with me...I don't sugar-coat it, it's hard but I quote it as the best thing I ever did. Before I had it I was in a low place you know, I was on the phone to the Samaritans a couple of times, so I daren't think what might have happened if I hadn't got help.

The majority of participants have never received any professional help, but the few who had said it was the best decision they made in terms of their survival. There was an understanding that, because many people had such negative responses during their first points of contact with help services, this prevented seeking further help. People sidestepped services by speaking to other survivors and bereaved, who might understand them. Participants explained they needed to share their experiences to confirm their own experience, make sense of it all and work out the mechanisms of the cover-up.

Many participants identified even if they were unable or unwilling to access professional supports, they were able to utilise personal support from other survivors, finding the shared experience brought a unique understanding to their situation and the ways of coping with it. The following section develops this idea of informal supports and the impacts these have had on their personal journeys of survival.

\section{Building Supports through Social Media}

She was very active on Facebook A..., she always used to do these little updates every morning every night, 'good morning my red family, good evening my red family' and it's lovely...It's been an incredible support network for people that, particularly people from further afield, or even people that are local but haven't got the strength or the confidence to come and meet someone... To be able to talk to each other and unburden yourself with it, three in the morning or three in the afternoon, has been hugely important for people (Dan).

Every participant spoke about the importance of social media in assisting survival and supporting people affected by Hillsborough. People explained that the advent of social media allowed people to create an instant online community of support. Not all survivors were from 
Liverpool and over the decades people have relocated, so being able to find others online has allowed people to connect with others who understand what they'd been through. People were also able to control their involvement using social media, so they could manage their contact and inclusion. Social media could also usefully challenge the false smears against survivors, as it allowed participants to directly confront the SYP and link them to existing evidence.

One of the many stories raised in this area was of a survivor, JH. Dan explained that JH severely struggled with his trauma for many years, he led an isolated existence and was not 'surviving'. $\mathrm{JH}$ found out that the young boy he tried to save in the pen had died. Eventually JH contacted the boy's mother, via Facebook, and they became very close. JH said "she saved my soul". Dan explained:

He basically couldn't deal with what had happened to him, couldn't move on, was stuck in this kind of nightmarish never ending circle of pain and misery and she helped bring him out of that.

On another level, social media can alleviate some of the pain. Paul told a story of a survivor who organises charitable walks through Facebook. Paul explained people from both the HJC and HFSG attend the organised walks and they are hugely beneficial to the survivor, who needs that tangible support, but also they are important to everyone that attends. This survivor has created a place where people can support one another on a very personal level. Unofficial supports proved to be the most valuable in terms of satisfying the need to have consistent, positive help. In a climate of denial those affected by Hillsborough created their own community and formed their own unofficial support networks. This could happen in online networks, but also in offline communities. Often these two supports integrated and strengthened each other. The following section discusses another trajectory which functioned in a similar capacity: campaigning. 


\section{Getting Involved in Campaigns}

People were beginning to see it as a social justice issue... we were with the stickers, the banners, more people were coming into the shop by the time we had a base then. Probably what kept us going most was the regular meetings, weekly meetings can you believe that? I can't believe we went every week...and we'd say the same thing over and over again...but then something would happen and we'd go 'ooh' and there'd be a bit of a crisis...So it was like a support group in that sense, we thrived you know we bounced off each other (Sheila).

All those involved in campaigning for truth and justice explained that being politically active helped in satisfying their need 'to do something' and it also comforted them by showing they were not alone. Participants drew strength from the solidarity, community and shared identity with people involved in the campaign - although they were stigmatised by the state and wider society, they were able to create a community out of that 'othered' population. Sheila explained "it gave them an identity 'we're the HJC, this is my story". Campaigning also allowed the survivors and bereaved to share experiences, collectivise and organise to create change in what many considered was a meaningful way. For example, some participants said the grassroots organisation of charity fundraisers over the years were a positive because it brought people together. Tony recounted:

...it was the charity nights and things like that to carry on the fight, there was always something going on...to get some money to carry on fighting against the government, that's what made them carry on because they weren't ever gonna give up.

Despite their suffering, people had fun and enjoyed the camaraderie, whilst raising money they desperately needed. Sheila said "we had a laugh because more than anything if you didn't laugh through all this you'd of gone under years ago".

Nonetheless, some participants expressed a continuous struggle to balance their personal needs with the needs of the collective. Some survivors wanted to deal with it privately but felt a responsibility to get involved in the campaign because they could see the damage 
caused from the cover-up. Those who were actively involved in the campaign often took on other roles: they became researchers, public figureheads of the fight for justice, or counsellors to other survivors. Participants did not express that this negatively affected their personal survival. However, it does highlight one of the problems generated from the cover-up, as victims and survivors had to process and cope with their own trauma alongside that of others.

Despite this, participants explained the HJC and the HFSG provided a beneficial 'space' where people were listened to and responded to appropriately. For example, participants who accessed or were a part of the HJC said it played a major role in their support. They saw the HJC as a physical, recognisable base for tangible support, at a time where survivors were largely outcast by mainstream society.

One of the most important moments in the story of Hillsborough is 1998 the HJC being formed... up till that point no one had ever really spoken about the survivors, they were the forgotten victims, they were living daily with the torment of what they witnessed and of being blamed, the HJC was born for a reason (Dan).

Now and again you will get someone drift in, just wanting a chat. So we might just have a cup of tea, they might feel a bit down so we'll close the door, go upstairs, we'll have a laugh, have a cry and we'll get to the bottom of what's going on (Steve).

Even prior to the formation of official support groups, informal support networks were a source of strength. Sheila told of her experiences, prior to the HJC, when her flat had been broken into and Hillsborough papers and her address book were stolen and people's phones were being tapped:

I had a network then of people I was working with and that made me strong and made me realise you're onto something here... we were an informal group but we were hardcore in terms of the communication... we were always in touch with each other.

For those living outside of Liverpool who had survived on their own for many years, they spoke of the positive role their informal networks still have on them. Nick gave an example of 
this: "more recently in terms of support I've got to know Ade, Tim and R..., we'll meet regularly now, we'll have a drink once a month which is invaluable".

Those interviewed who did not identify with being 'actively' involved in campaigning still supported the campaigns over the years. For example, every single interviewee has continued to boycott 'The Sun' newspaper. Many gained strength from seeing the HJC stickers around Liverpool and overseas - these signs of solidarity had a hugely positive impact on them. People admired the justice banners at football grounds, the thousands of supporters chanting 'justice for the 96 ' at games, and the thousands who boycotted one major game as it was held at Hillsborough and sponsored by the Suns. As Steve reflected:

It's quite easy for a government to deal with the fact that 96 families will go down to number 10 Downing Street banging on the door saying "can we have justice for the 96?", but when every other Saturday at Anfield 50,000 are chanting "justice for the 96" and they don't stop, well then someone listens. And, that's exactly what happened when Andy Burnham got up on the 20th anniversary, people started chanting and that was the changing point and again it was that community base that group of people that forced the hand of the government.

These acts showed that, no matter what was legally happening at the time, they were not on their own and others believed them. In this incident the persistence of the chants brought about tangible, meaningful change. As detailed previously, Burnham, after being emotionally moved by the crowd, filed a Freedom of Information request for the privately held documents relating to the disaster to be released. This initiated a chain of events, which resulted in the publication of the HIP report, the quashing of 'accidental death' verdicts, the opening of the recent inquest and subsequently the RIV which has unequivocally cleared fans of any blame.

${ }_{8}$ Only $14 \%$ of tickets were taken up for the May $8^{\text {th }} 1989$ match between Sheffield Wednesday Football Club and LFC (http://www.contrast.org/hillsborough/boycott.shtm) 
In sum, survivors found many benefits in accessing the support of groups like the HJC and the HFSG, engaging with online networks, and creating friendship circles through gradually meeting others in daily life. Individuals could be struggling with their survival, but still 'wanted' to survive and they accessed and created various informal supports. The following section broadens out the notions of solidarity and connecting to others, as previously discussed in this chapter, to understanding how connecting to a wider 'survivor community' functioned as a major support which encouraged and maintained positive survival trajectories for many.

\section{Connecting to a Survivor Community}

Since the HIP report I've met quite a few survivors... and the instant bond that you feel with them is unique...If you've shared an experience like that you become fast friends...l've introduced new Hillsborough friends to old Hillsborough friends and just seen...the same instant bond apply with them, and it really does warm the heart (Tim).

Official language refers to the different categories of people affected by Hillsborough, such as 'rescuer', 'campaigner', 'survivor' or 'bereaved' in separate ways. Often, their experiences are segregated in media accounts. This could give the impression that people involved in those various groups remain in opposition to one another, but in reality this is often not the case. Tony said over the years he had come to know a lot of family members and survivors and:

...like a community you get involved with people and you think'I never thought that'd happen'. You could be speaking with someone you mightn't really know till 4 o'clock in the morning and go and stay in someone's house.

Participants shared similar stories, of people coming together in solidarity to help one another survive. Nick explained the valued friendships and close bonds he had formed with some family members and explained that "by listening to us and hearing from us they can learn about what happened". Steve had a very personal reason for his survival and campaigning which could have become isolating, however he dedicated years to helping survivors through 
the HJC, "going into their homes...spending hours and hours during the night on phones with people". He is still supporting survivors, in the absence of adequate professional help.

Participants often felt that connecting with a 'survivor' community was a vital requirement on their journey of survival. Those interviewed who did not live in Liverpool stressed that their lack of access to other survivors was a significant barrier for them. People highlighted the difficulties of not being able to easily attend vigils, memorials, and not being in close proximity to supports like the HJC shop. Stories were told of others who lived outside Liverpool who felt isolated and who were more likely to be confronted with misinformation. Many spoke of the protective atmosphere that came from the "solidarity throughout the city" (Dan) which helped uplift those who were struggling; those living outside the city said they felt excluded from this united support.

Interviewees attributed meeting other survivors, and forming friendships within the survivor community, as significantly beneficial. They all explained the positive impact of knowing you're not alone and having someone you can talk to who truly knows and understands what you're going through. Peter said:

Besides family for me, it was other survivors, they were the greatest help...to listen to other survivors and hear about the struggles that they went through, it was swap and share, you tell me what you're going through and I'll tell you what I'm going through. And in the mix each one of us will find a benefit or a use for that and that was massive.

Many participants illustrated that, given the damage from the cover-up, the survivor communities were vital in monitoring people at risk. Steve shared a story of a survivor TT, a deeply traumatised survivor who years after Hillsborough had moved back in with his mother and had a strict routine of only leaving the house to collect his benefit, go to the shop and then back home - the "eternal triangle" (Steve). TT's sickness benefit was suddenly taken off him and "after his traumas of Hillsborough he caved in on himself" (Steve), but because the Hillsborough community had kept an eye on him, Steve was notified and with the help of others they managed to get TT's assistance back. Steve continues to emotionally support TT to this day. 
Survivors have also gained strength from the outpouring of support for them, when they attended or watched the televised memorial, because "you've got the city coming out in numbers, 10, 20, 30 thousand people" (Paul). However, people noted the difficulties of maintaining the public face for the Hillsborough campaign, as remembering the 96 and their experiences of Hillsborough became a collective pursuit. Participants explained their grief was very public and "to keep continuing, having to show your soul, it takes something out of you every time" (Steve). They felt dissonance between how they personally wanted to mark anniversaries with what the collective movement for truth and justice required.

Finally, here, participants involved with the HJC spoke about the positive impact from other campaigns and clubs. People connected with the Birmingham 6, the Guilford 4, bereaved family members of people who died in police custody and Celtic football club which has very publicly supported the HJC. Connecting with others who had fought the British establishment gave them strength during the times when they felt like the tide was against them. The support networks were widely established as survivors attempted to have their experiences validated, to receive acceptable help, and to sustain informal and official campaign efforts. Over the decades there have been many individuals who have had the opportunity to make a significant impact on Hillsborough. The following section addresses some of those who have had powers to cause a positive or detrimental effect on survivors.

\section{Following, and Being Involved in, Legal Cases}

Participants acknowledged that most dealings with the legal arena have created barriers in the process of finding information and getting the truth recognised. An early example given was of lawyers for the Hillsborough Steering Committee, who took fundraised money and then advised there was nothing more they could do. There was a strong opinion that, notwithstanding recent action, the legal world had not been active in challenging the lies against the survivors and bereaved.

Every participant brought up their disappointment at how the fresh inquests were carried out. Participants spoke about the damaging adversarial stance of authorities who chose to 
"regurgitate the [same] old lies" from the cover-up (Nick). They spoke about survivors who were re-traumatised and the many prematurely aged family members who had to sit through another inquest. Dan explained the emotional toll it took on people's lives because: "all of this was already known and that's one of the most egregious, frustrating, heart-breaking things". However, every participant stressed the importance of the RIV and identified that when official proceedings function as they are intended, they can have a massively positive impact on survivor's quality of life. Tim explained:

I'd like to pay tribute to the six women and three men on the jury who bore one hell of a burden for two years, two years of their life, imagine the burden of responsibility...I will be forever grateful to those nine people...it bolsters my faith in the jury system...these were ordinary people who realised that the powerful were trying to stitch ordinary people up again, and they emphatically rejected that and I and many others will be forever in their debt.

Participants also spoke about the long delays and breaks on court days, and how that provided time for people to share stories and get to know one another, and experience further support. Specific examples of this were brought up by two participants, Tony and Steve, who told two versions of a similar scenario. After giving evidence at the inquest on a person Tony had attempted to save, he was approached by the victim's brother as he was leaving court. Tony explained:

He was one of the brothers that survived and he gave me a big hug and he said 'thanks for trying to look after our kid, our brother'. I said 'yeah but I didn't *big sigh* I didn't save him'. He said 'yeah but you were there and that was a massive thing'.

Some of the people who carried Steve's brother on the hoardings were identified in court and afterwards Steve approached them:

I was really pleased to go up and chase after them when they'd given evidence in court, speak to them, and I did with every one of them and it meant so much to them. They 
said 'oh Steve you didn't have to' I said 'no I did have to, I had to do it for me, I had to do it from our Mike'.

Twenty seven years later people are still finding each other and connecting over their experiences. They learn what happened to their loved ones and to each other. Many participants acknowledged this could have all be done at the initial inquests if they had been conducted properly. Undertaken with proper consideration of victims and bereaved, official legal mechanisms can provide a source of resolution. They can build a sense of 'survivor solidarity', and increase supports for all those victimised. Participants acknowledged that their 'survival' would be ongoing, but that support from the wider community in various forms, significantly helped them to positively survive. The following section further develops this idea, by discussing various 'outsiders' who have supported those affected by Hillsborough.

\section{Empathy and Solidarity from Others}

A recurring theme was that survival is often contingent on the actions of others. Therefore this section illustrates a range of examples where 'outsiders' to the 'Hillsborough community' have made a positive impact on personal survival journeys.

Previous sections have discussed how the overall response from various police forces had undermined survival in many ways. However, acts of individual officers could also foster positive survival trajectories. For example, the second time Adrian was arrested for verbally abusing the police, he had such a positive experience with one officer it completely altered the trajectory of his survival:

I just said 'oh I was at Hillsborough in '89 and I hate coppers' and he said to me 'I can understand that' he said 'but you can't go on like this cos you'll ruin your life'...and it was a 2 minute conversation nothing more and it was just life changing, because to have someone listen to you and say they understand and actually show some concern...I've never been in trouble with the police since and that was a significant moment. 
Participants also acknowledged the beneficial impact of those who have worked tirelessly, seeking no recognition, in solidarity with the Hillsborough campaign over many years. Participants spoke of individuals who had no direct link to Hillsborough, in the sense that they weren't there or didn't know anyone that was there, but who gave up many years to help support the justice campaign; and the individual acts of courage and resistance towards the official cover-up. Tony was 'advised' by his employers at the fire service not to wear his uniform to court and not to appear on documentaries criticising the police, because it would affect the relationship between the fire service and the police force. However, Tony said he would wear his uniform to court and he would give interviews purely because bereaved mother A... asked him to, as over the years she had become his close friend. Well known public faces of the campaign were mentioned, people like Phil Scraton and Sheila Coleman, as being essential to fighting the official issues around Hillsborough.

People like Sheila, Phil and many others who became involved in a professional capacity were able to share information, explain legal rulings to bereaved and survivors, and produce work. For example, one participant said the work produced from the Hillsborough Project was a valuable confirmation of their experiences. During interviews there were countless individuals recognised and praised for their support who were often described as "ordinary working class" people who had a "sense of right and wrong" (Sheila). Sheila described one such person: "Gerry the old guy in the shop, day in day out, talked to people, helped people, saved lives, saved lives of quite a few people" (Gerry passed away August 2016).

As well as campaigners and community support, interviewees warmly acknowledged the individual professionals who had worked to assist survivors and the bereaved - of solicitors that worked pro-bono or MP's who officially supported the campaign. Participants perceived that it was only the individuals who got to know them on a personal level that would break away from the official attribution of blame and cover-up. The only time participants felt this situation with authority had changed was in the recent inquests, where they praised the support and representation from their legal teams. 


\section{Conclusion}

From the previous discussion it is clear that there are various diverse pathways to survival and that each pathway is continuously affected by multi-dimensional factors. In this sense 'survival' has been demonstrated as existing along an continuum where individuals are always going through processes of negotiating their 'state' of survival, depending upon the factors affecting them at any given point in time. Some of the survival trajectories identified by participants involved: distancing from others; opening up to others, building supports via informal networks such as online communities, engaging in active campaigning and creating an informal 'Hillsborough community'; being involved in legal proceedings; and engaging with a wider 'outside' community who rejects the official cover-up. In the next chapter, the potential outcomes from the various positive and negative trajectories are considered, in an examination of what is required to 'survive'. 


\section{Chapter Six: Moving Beyond Hillsborough}

As the previous chapters have demonstrated, 'survival' presents a highly complicated situation, particularly in a context of multiple victimisations. There are contradictory states of survival whereby survivors can be engaged in positive coping strategies and supports whilst struggling to cope in other arenas of their lives. It shows survival as a constant struggle and something highly dependent on others - family, friends, support workers, legal teams, among others. What is required by those affected by Hillsborough to 'survive' cannot be generalised and so responses to survivors should remain accommodating, flexible and capable of addressing long-term issues of survival. This chapter develops the concept of 'survival' as a continuum via specific examples, which illustrates the diverse states of survival. It proposes what may be required to support those affected by Hillsborough in long-term positive survival trajectories and discusses the roles of official and personal supports in this. In short, it considers what is required to continue a life beyond 'Hillsborough'.

\section{Survival as a Constant Struggle}

Survival is a varied experience, it comes and goes in different shapes and forms. I used to say 'Hillsborough turned me upside down, inside out, and back to front', and it still does that to a certain extent (Peter).

All interviewees saw survival as a constant struggle. Some acknowledged there were milestones in understanding their survival. Peter said he focused on the birth of his first child and just tried to make it to that point: "it was as if once the baby's born 'oh I'll be happy then' and it wasn't like that, it was nowhere near like that". He explained that although it was a momentous time of joy it did not alleviate his pain and trauma from Hillsborough, as if that was a separate part of him. Many participants brought up the joy from relationships, the birth of their children, and successful careers but everyone explained that they still struggled with aspects of Hillsborough. 
'Surviving' Hillsborough was, for many people, attributed to consequences from the official cover-up. For example, the bereaved could not accept the 'accidental death' certificates they had for their loved ones and that had an immobilising impact in many ways. Steve explained:

I feel as though he dies every year and I have to rebury him, so he's had all these masses of funerals and you cannot live your life like that, you can't grieve like that, you can't manage to be an eternal mourner. That's what we are.

Survivors explained that the way they were consistently treated and misrepresented has continuously affected them, but they also spoke of being mentally strong, not giving up, and being able to continue after being knocked back. Essentially, they described their ability to endure. They were resourceful in developing their survival techniques, drawing on what Dan described as: "inner reserves of strength that we didn't know we had till we needed them". The way participants described their fortitude was as though it was something that could be literally shared, given and enhanced by others and, because of this, the support from others was significantly beneficial. Many people, actively involved or not, expressed a sense of pride that they had not given up.

At the same time, the overwhelming response from participants was that the trauma will never leave them and they have to learn to live with it forever. Peter described this situation as: "it's a living experience, it's an ongoing dynamic, it's a social dynamic, and that's the best way you can understand it, so it doesn't stop". A few participants used the word "accommodate" to explain how they cope - because Hillsborough never leaves them they try to "accommodate" that experience to survive. Everyone acknowledged that the repercussions of surviving Hillsborough can change, and become more or less prominent at different times, however everyone said that there is no closure.

Those affected by Hillsborough bear an ongoing vulnerability, and some individuals will always be at risk of not surviving Hillsborough. Many explained that because of the continuous miscarriages of justice over the years and the negative consequences (such as the misrepresentation or lack of recognition for survivors), some people will always be emotionally vulnerable. Dan explained this situation: 
...people will always be suffering...I think to some extent all we can do is try and minimise that...it was living hell for people at the time, on the day, and obviously what happened afterwards as well, that's left a deep deep mark on many.

Even after receiving some form of official truth and justice via the recent inquest verdict, the damage caused from not receiving that for 27 years will, for many people, be irreparable, as Steve explained:

I went to visit a family member this week and I seen the devastation, he's quite an elderly man now, but it was just hard looking at him, cos I could see behind his eyes what was in him and it was just pain and that's hard to look at.

This highlights the issue that the 'stories' of Hillsborough, the ramifications from the coverup, the consequences from the longevity, are still to be uncovered. It will take time for their survival stories to emerge and become known in the public domain. The following section presents some examples of these stories involving examples of what survivors have sacrificed or lost as they continue on their journey forward.

\section{The Unseen Costs of Survival}

I deal with people who are poor, in dreadful poverty and I see millions being spent [in legal fees for Hillsborough]...but there's no winners in it in terms of the cost because...[for] survivors it's 27 years too late for them to have a decent quality of life...The cost is irreparable... and I think for a lot they will never get over it (Sheila).

Interviewees acknowledged the 'unseen' costs of experiencing Hillsborough and its aftermath. People discussed the lost futures, the limited possibilities, and the lack of quality of life for so many survivors, Sheila explained: "I think some people feel cheated of their lives and rightly so, cheated of careers, of a future". Some said they don't know who they would have been and what trajectory their life would have taken if they hadn't suffered the trauma of Hillsborough. 
People referred to the ongoing psychological costs of surviving when others didn't; the very fact that they survived made them painfully aware of the 96 that didn't and the many others who have subsequently died. Speaking of the future he should have had with his brother, Steve said:

To this day I miss him.... we should be going for a pint now me and him, instead of sitting here with a nice young lady *laughs, I should be going out with some old guy, you know what I mean, I miss that.

Many people brought up the costs incurred from the longevity of the cover-up; Adrian said:

Twenty seven years we've been dealing with this and it hasn't sunk in, to kind of think that you've been involved in the biggest cover-up in the last century and the biggest miscarriage of justice probably of the last century as well, you can't really take that in.

People spoke about others they know who will always be deeply traumatised from the experience of Hillsborough and the way it was officially responded to. Adrian relayed a conversation he had with a bereaved family member:

I was speaking to S...great bloke and he said to me on the day of the verdict, we're having a beer, and he said to me 'you know I'm too old now, I'm never gonna drive a Winnebago to Rock River, my life is I've spent too long doing this'.

Many identified that they, or others they knew, had spent the most part of their lives fighting for truth and justice and because of that the need for support will be forever ongoing. This demonstrates the irreparable costs from being forced to endure injustice; there are now thousands of people who have no faith in the official systems in place in British society and little investment in the way society is run. Participants acknowledged a positive shift in the societal perception towards Hillsborough since the HIP report and the recent inquest verdicts. The realities of the state coordinated cover-up have been officially recognised and publicly recorded and this now raises questions of what the wider implications of that are, particularly 
in terms of responding to survivors' needs in the wake of a major disaster and subsequent impunity.

\section{What Do Survivors Need?}

I'd say each survivor needs their own space for it, and it's a very subtle understanding that will help them to get through it...[we] need to be sensitive to what the survivors need to have and that's multifaceted... I don't think there is a single formula for that, because we're all such different beings aren't we? (Peter).

A common understanding from participants was that because there are many years and layers of experiences, survivors' needs cannot be generalised. Steve explained: "I think there will be resolution for some, we all want something out of it, that's the trouble with this event". Like many others, Steve acknowledged that different outcomes have different meanings to different groups. The longevity of the cover-up has complicated the situation further. Because of the very specific injustices that occurred in the aftermath, people will seek multiple types of reparation.

Professional and Relational Supports

...it does knock you outta ya stride, it stops you from working, it stops you from focusing on anything other than the event itself and the strain it has on you personally and your families and your friends it's horrendous... We've got so much to learn from Hillsborough...one of the biggest lessons we need to have is support for people, it's not been given...there's been nothing there so hopefully we can try to put that right (Steve).

Everyone identified that the need for active and specialised support will continue and will never really cease because of the damage caused from the cover-up and the propaganda campaign. In terms of generating supports, people spoke about evolving the HJC, establishing a social hub in Liverpoo,I for anyone suffering severe trauma, and creating a permanent support centre or online network. All of these initiatives are coming from a grassroots 
mobilisation, nothing official has been developed and there has been no formal input or financial assistance from the state. The historic lack of official support has influenced those affected by Hillsborough to remain proactive in fulfilling their own survival needs.

All the participants explained that the informal support networks would continue regardless of what form they took. Tim said:

The good thing that's come from this is meeting so many wonderful people, made so many strong friendships, and in order to preserve that and also make it into something concrete we've had the idea, it's still very much in its early stages I must emphasise that, of forming a survivors' association.

People still require a 'space' to be able to 'be' with others who understand exactly what they've suffered over the last 27 years; it was also clear that they see no value in waiting for any type of authority to assist them, but will be creating these 'spaces' themselves.

Official Recognition and Redress

...the local BBC insideout program basically followed S... for two years while the inquests were on ...there's a line in that where she says... "our life is in their hands" and it really was and it's only now afterwards that I kind of really truly appreciate that (Dan).

Every participant spoke about the importance of gaining official recognition and the immediate positive difference it made to all their lives. Paul explained the only time he felt his feelings had changed for the positive was after the HIP report and speaking about the immediate positive effects from the verdict he said:

These guys have aged with a weight on their shoulders, they're smaller, shrunken people, even in the weeks afterwards they've changed, S... is smiling, people are smiling, people that I've never seen smile are laughing and joking...they've been to hell and back really. 
Participants also acknowledged they needed the 'legitimate stamp' from the HIP report to gain wider public support and many felt they gained a swell of support post-HIP. People also needed the content of the HIP report to be publicly recorded and they needed a legal ruling that established the true facts of the disaster. Adrian explained:

The panel coming out in 2012 was massive, because we won the argument then, that was the end of the debate and now the inquest verdict that is life changing, because it's a historical fact now it can never be overturned.

Those affected by Hillsborough needed to know that their lived experiences of the day and in the aftermath had been adequately recognised. Many spoke about how they know some people would no longer be at risk of committing suicide because they had gained that official recognition and vindication from the HIP and recent verdict. However, as Dan explained people will feel "probably a never ending anger that many of their friends and fellow survivors have died before seeing it". In terms of having experienced some form of redress for the many injustices against them, Adrian noted: "people think that you know truth, justice are just a legal instrument, it's not, it has massive impact on people's mental health". This indicates that for some survivors seeing criminal sanctions for those who are responsible for the disaster and subsequent cover-up is still an important part of their survival journey.

\section{Criminal justice}

We haven't got justice...how many dead bodies do you need to see on a stretcher before you go and help? I would suggest one would be sufficient. Most of them police were standing doing nothing, body after body after body was taken past them and they did nothing, none of them have been held to account. The police on the terracing, who were pushing people back over the fences, none of them have been held to account. The policeman, who I personally begged for my life, who was on the gate, who I had to physically push the gate against, he was pushing it shut, I pushed it open, I fought my way out he put it shut again, he's not been held to account. The policeman who tried to put me back in to pen three, a guy picked me up and tried to put me back 
in, he's not been held to account. All the police who lied, all the West Midlands who changed statements, changed my statement, they've not been held to account. So we've not even got close to justice, we've just got the truth and that's all we got (Nick).

Some participants said the HIP report and recent verdict was all they needed to be able to move forward from 'Hillsborough'. However, many interviewees spoke passionately about requiring 'criminal justice'. The common opinion was that those responsible for the disaster and cover-up should receive the same treatment as people who are not authoritative figures in society; as Paul explains:

I want them held to book. I don't want a pound of flesh, I want the full force of the law. You lied, you committed perjury on this occasion, on that occasion, and right up until last month...I want them prosecuted to the full extent of the law.

Many participants understood what happened at Hillsborough and in the aftermath were criminal offences and because of that they needed to be responded to and dealt with in such a way. People expressed the, at times, unbearable pain they suffered over the years and felt a moral obligation to try to change society for the better and prevent others suffering as they have. Peter described this view:

If this is the way the State carries on, what hope is there for any of us? Well the hope is within yourself, if you've had this done to you, then you have a responsibility to the next person who's gonna find themselves in the position that you're in to challenge that... Whatever that suffering is that you're going through you don't want somebody else behind you to go through it.

Many participants brought up the introduction of "Hillsborough Law", Peter explained:

...there would be a law that would force them [authorities] to truthfully co-operate with inquires and inquests. And I think there's got to be something like that taken on board so...there's a code of ethics *laughs*. So I mean the thing is: do you trust those in power? 
From experiencing the cover-up participants felt an initiative such as the 'Hillsborough Law' was required to restore public faith and credibility in the official institutions in society. Similarly when speaking about the importance of the petitions, advocating for Hillsborough to be taught in schools as part of the national curriculum, Dan explained: "to have any credibility going forward, the scale of this, of what's happened here and the volume of people that's been affected, they know they have to make it right". The essence from these discussions was concerned with the legacy of Hillsborough, the lessons that need to be learnt, the systems that need to be amended, Sheila described this as: "the legacy of Hillsborough needs to be a positive one of how we move forward and that has to be around treating people differently and this never happening again". This indicates the survivors need positive transformative change in society to allow those affected by Hillsborough to move forward knowing they have created protections against future miscarriages of justice.

\section{Want to Move Beyond Hillsborough}

I'd like to go back to having conversations other than Hillsborough with S...the weight's been lifted off people, it has, they're a foot taller than they used to be. So I think a lot of people will just want to get on with living their lives and Hillsborough will always be there, it will always be at the back of our minds (Paul).

'Hillsborough' would always be with people, but people did want and need to move forward from it. People expressed they needed to continue onto the next stage of their life without everything being in relation to Hillsborough. Steve explained the frustration he felt at the loss of his personal identity: "I've got no identity now, I'm 'Steve Kelly Hillsborough campaigner' you know, no-one ever talks to me about me". Similarly, people spoke about reclaiming the personal agency in their lives, making decisions they have chosen, based on who they are and not have to be constantly dealing with another aspect of Hillsborough. Dan spoke about the importance of the HIP report and recent verdict in allowing some people to move forward: "I've seen a lot of positive changes in people in the last four weeks, in the last two years, I think it's maybe, it's restored people's faith in human nature, it's certainly restored mine...to a degree". And although for others there is still a long road to go concerning the potential 
criminal prosecutions to come from the IPCC investigation and Operation Resolve, Nick explained: "people are getting on with their lives and remarkably so actually considering what they've gone through".

\section{Conclusion}

I think the positive legacy has to be friendships made and a sense of camaraderie amongst many, an identification of being a 'survivor' in the positive sense of the word as almost a badge of honour, because not only did they survive the disaster, they survived the smears and the lies and the cover up and the conspiracy and a lot came out the other end to see them be vindicated on that...but the damage done is immense and a lot fell by the way along the way, there're others who'll never get over, there will be others who will now move on with their life (Sheila)

This chapter has demonstrated that survival is not an individualised pursuit, rather it requires supportive actions from various groups. In particular this chapter illustrated that official agencies (health, counselling, political actors, legal personnel, criminal justice agencies and so on) play a vital role in the process of supporting people to move forward from victimisation. This knowledge impacts how we might view resiliency and PTG, in the context of survival from a major disaster. Participants demonstrated they were resilient against impacts from the disaster and the victimisation in the aftermath, as Steve explained: "God, I think 27 years of fighting, I think we've proved how resilient we are". However, as a stand-alone response being resilient was consistently identified as insufficient to support long-term positive survival. Similarly, participants disclosed points in time where they identified with aspects of PTG and felt like they were thriving. However, they acknowledged that a multitude of other factors affected their feelings of PTG and could place them back in a heightened traumatic state. In this way conceptualising survival as a continuum enables the degrees of impacts to be considered on a continuum. Therefore, this acknowledges the various survival trajectories that can be followed and the multi-dimensional nature of the requirements for survival according to each distinct trajectory. 


\section{Chapter Seven: Reflecting on Survival}

You have to survive somehow (Coleman, 2016).

Long-term survival from disasters remains an under researched area, and research project designs often employ a narrowed focus, concentrating on one aspect of survival. By critically analysing the experiences of Hillsborough 'survivors' and campaigners, this thesis has demonstrated that there are various pathways to survival and all are impacted by the wider official and collective response to 'survivors'. These findings illustrate the common situation of survivors being forced to navigate their personal survival in a context where their needs "are subordinated to the professional priorities of" official institutions in the aftermath of disaster (David and Scraton, 1999: 86). This marginalises the realities of survival trajectories, and presents a mythical view of what 'surviving' exactly entails. Given that the dominant representation of survival has ignored or denied the perspectives of survivors themselves, 'survival' is also regularly framed within limiting classifications (Davis and Scraton, 1999). This has subsequently obscured the needs of survivors (Davis, 2013; Davis and Scraton, 1999). The representations of survival in this thesis have challenged mainstream survival myths and approaches which, too often, do not accurately reflect the dynamic and varied experience of survival.

\section{Representations of Survivors}

Thesis findings demonstrate that conventional understandings of victims and survivors do not accurately represent the various 'types' of victimising experiences. It shows that applying a categorical model, where 'victim' status is based on prescribed characteristics, acts as a process of exclusion. As discussed in chapter two, victims who possess or 'perform' certain traits (such as being victims of conventional crime or displaying signs of helplessness) are granted a higher status on the victim hierarchy and therefore are more 'visible' in society and are granted greater access to official and societal supports (Christie, 1986). Lesser-status victims, those lower down the hierarchy, can be excluded from these positive responses. The societal representation and treatment of victims are important to survival trajectories, as 
these two identities are often seen to be a natural progression: from victim to survivor (Kelly, 1998).

Being misrepresented can create an ongoing chain-reaction of marginalisation, denial and revictimisation, all of which undermine personal attempts at survival (Stanley, 2009). Those who react or express their trauma in ways that are not 'silent', or who challenge official responses, may be perceived by officials as problematic or a 'threat'. In the case of Hillsborough, the media colluded with officials to construct negative images which stigmatised some survivors' reactions over others (Eyre, 2006; Scraton, 2009). These findings challenge the traditional representations of victims/survivors by acknowledging that these identities are not embodied at clear distinct times but, in reality, 'survivors' will identify as victims throughout their 'survival' or at certain junctures in their survival journey.

Misrepresentation also acts as a catalyst, creating opportunities for multiple mechanisms to 'legitimately' obscure the realities of survival. As previously discussed, the traditional conceptions of victimisation generate a misrepresentation of victims/survivors and this hides their victimisation experiences. This denies certain 'types' of victims and masks certain survival trajectories (Stanley, 2009). This thesis demonstrates that, in reality, there are many 'types' of victims, even from the same event, and therefore many 'types' of survival trajectories. Victims do not exist as one 'group', but they exist in a ripple-effect situation (Newburn, 1993). For those victimised from Hillsborough, the 'ripple effect' starts with the 96 victims who were killed, then the net widens to the survivors from the pens, the bereaved family members, the rescuers on the day, the long-time campaigners, the children of those affected, LFC fans, and so on. Each of these 'groups' have been victimised in very different ways. By understanding the diverse nature of their survival trajectories, we might develop understandings of their diverse needs.

The lack of accurate representation of survival also causes "misguided expectations" regarding the behaviour, reactions and trajectories of survivors (Eyre, 2006: 14). It hides their 'roller coaster' reality. The findings illustrate the damaging expectation that survival exists as a process towards closure. The social expectation of a linear survival trajectory creates unhelpful judgments regarding how survivors should be surviving, and can even pressure 
survivors to not be seen as 'failing' at survival (Kelly, 1998; Newburn, 1993). It can clearly be detrimental to anticipate particular reactions or pathways for particular cohorts of survivors. For example, a 'rescuer' might have a more difficult survival trajectory than a survivor from the pens, if they develop 'survivor guilt' (Eyre, 2006). Newburn (1993: 51) identified this as a "hierarchy of worthiness" where some survivors feel they are underserving as they perceive others to be "much worse off". This thesis demonstrates that these situations create barriers for survivors to access supports, as they often feel undeserving or fear being blamed. The mainstream expectation that survival and 'recovery' will be a linear process means that we are even less likely "to know the full extent of the ripple effect" (Eyre, 2006: 15). Ideally, official supports would be flexible enough to respond to reactions that have not been preempted (Eyre, 2006).

Finally, in line with critical disaster literature, it is clear that traditional identities of victims/survivors can be intentionally manipulated. It was in the interests of officials to immediately classify Hillsborough survivors as one homogenous group, and as a group separated from the 'victims'. Ultimately, this created a situation in which survivors did not receive responses, treatments and supports which would be appropriate for 'victims'.

\section{The Management of Survival}

This research shows that official responses are highly political, and that pre-existing social and structural inequalities can be worsened as a result of government responses to survivors (Eyre, 2006; Green, 2005). The findings confirm the 'socialisation of disaster' theory, outlined in chapter two, as they show how certain groups suffered disproportionately due to their social status as predominantly working class football fans (Verchick, 2012). Further, it illustrates how powerful actors can exploit discriminatory and prejudicial structures to marginalise survivors who challenge the official narrative, and to 'manage' survival (Spring, 2011).

Authorities possess discretionary powers which allow them to handle post-disaster issues in ways which mask political agendas (Green, 2005). Employing a neo-liberal model of resilience, which encourages individuals to support their own survival, is one mechanism that enabled 
agencies to deflect responsibility and avoid accountability in the aftermath of the disaster (Manyena et al., 2011; Shaw, 2012). Eyre's (2006: 83) research on official responses in the aftermath of Hillsborough identified that "a stoic acceptance and strong belief about being able to cope" was emphasised. Constructing this societal expectation of self-help and resilience strengthened the pre-existing traditional understandings of survival. The social and official demand for 'resiliency' actually prevented survival in many instances, as it made survivors feel less comfortable or less worthy to ask for help. The discourse of resiliency acted as a barrier to survivors disclosing their struggles.

The findings also confirm the use of 'victim-blaming' as a mechanism or tactic of the state and official institutions to avoid accountability for their own failures. This persistent victimblaming impacted on interviewees' attempts to enhance their personal survival, especially as it constructed Hillsborough victims/survivors as 'undeserving'. In the context of disaster, this can exacerbate other negative outcomes, such as survivor guilt, trauma and re-victimisation (Eyre, 2006; Newburn, 1993). This thesis therefore confirms research which demonstrates the significant harms generated by victim-blaming (Leisenring, 2006; Olson, 2000), but it also develops this body of knowledge by discussing the impact of persecution on Hillsborough survivors' attempts to survive. The findings illustrate the impacts such as, loss of personal identity, generational costs, and loss of futures are generated as a direct result from the continuous persecution. This thesis argues that state victim-blaming responses create survival myths, such as survivors do not need support services and they will move on, which further mask the realities of survival.

\section{The Trajectory of Survival}

There is a vast literature concerning disaster preparedness and official welfare interventions post-disaster (see Eyre, 2006; Newburn, 1993), but there is minimal information regarding how survivors cope and react to these official strategies (Newburn, 1993). This thesis contributes to existing knowledge by demonstrating how individuals navigate their personal survival trajectories in different ways. It shows the complexities of survival and the implications of survival in a disaster context. 
The fact that different survival trajectories exist is noted in the disaster literature (Hobfoll et al., 2007; Norris, Friedman and Watson, 2002), however specifics are rarely discussed. Often survival trajectories are simplified and represented in a way that has an underlying presumption of what 'survival' involves and these assumptions usually relate to conventional understandings of survival. For example, survival trajectories are often defined via the polarisation of 'coping versus not coping' or 'being resilient versus remaining traumatised' (Manyena et al., 2011). These narrow representations tend to ignore or exclude different survival trajectories.

The findings reflect feminist literature which conceptualises survival as a continual process. The concept of a 'continuum' was specifically designed to expose the range of victimising experiences, acknowledging that many forms of victimisation are not officially recognised (Kelly, 1988; Profitt, 1996). Kelly (1998) developed the concept of a continuum by stressing that survival does not exist in a linear progression or in a hierarchical format. Instead, a continuum can more accurately explain "a wider range of possible experiences" of survival, and this can help survivors to identify and make sense of their own survival responses (Kelly, 1988: 77). Employing a perspective that survival exists on a continuum captures the "extent and range" of diverse trajectories and experiences (Kelly, 1988: 74). It acknowledges the multi-dimensional elements of survival.

A continuum perspective can also assist understanding of the complex implications of survival, such as the 'trauma' of survival. One impact of experiencing trauma is that, at different times, existing trauma can be exacerbated (Eyre, 2006; Newburn, 1993). Framing survival as a continuum acknowledges the co-existence of multiple dimensions of survival (Kelly, 1998). A continuum of survival accommodates a vast range of survival trajectories as it acknowledges individuals can be resilient and endure adversity but they can simultaneously feel traumatised and struggle to cope (Profitt, 1996). At different points in time, they can revert from surviving to thriving and vice versa. This thesis shows that 'surviving' does not mean the end of victimisation or the attainment of 'closure'. Rather, victim/survivor identities occur as a dual-identity which constantly fluctuates between each state, depending on the contextual factors at the time. This perspective rejects that survival is a linear process which inevitably involves 'moving on' from the victim identity to achieving the survivor identity. 
Recognising trajectories of survival, whatever they may be, grants survivors the freedom to not have to limit their survival to the traditional classifications and expectations associated with survivorship (Kelly, 1988).

Using the concept of a continuum of survival also challenges the mainstream view of resiliency as a means to secure post-disaster wellbeing and positive quality of life. The thesis shows that, in reality, notions of resiliency and well-being can only present a superficial understanding of survival. The dominant representation of resiliency as a survival pathway to wellbeing does not encompass the intricate complexities that this process entails (Prilleltensky and Prilleltensky, 2005). It assumes a linear process - from victimisation to survival - that does not exist. Moreover, this dominant representation places all the burden on individuals to survive and 'be well' (Spring, 2011; Taylor, 2011). As demonstrated earlier, this has placed significant strain on Hillsborough survivors to cope by themselves.

This thesis provides evidence of diverse survival trajectories, and some of their outcomes. In doing so, it rejects mainstream understandings of post-disaster survival as an individualised process that will reach a point of 'resolution'. Individuals need more than encouragement to be 'resilient', and they need more than a 'blanket' response to have a positive survival trajectory. Thesis findings indicate the need to move beyond generalised views of survivors and their expected trajectories, and to dismiss the view that survivors are a "homogeneous" group (Eyre, 2006: 29). This thesis therefore supports the critical and feminist survival literature which acknowledges that survival is not a continual process of 'improvement' that concludes in closure (Kelly, 1998; Profitt, 1996). Instead, it recognises that there are no set pathways to survival and that people will experience and express survival in a myriad of ways which cannot always be predicted. In order to have effective official supports for diverse survivors' needs, these findings are important to take into account.

\section{Survival as a Social and Political Process}

For Hillsborough survivors, official mechanisms contributed to further layers of victimisation, and subsequently of survival (Davis, 2013; Scraton, 2009). That is, survivors not only have their personal survival on a continuum, but they also have to navigate survival against official 
mechanisms and social structures that disadvantage them (Davis, 2013). In this way, survivors have to navigate victimisation that occurs at a macro-level in society, as well as trying to cope with the personal micro implications of surviving major trauma. This thesis has presented evidence of the macro level of survival, especially via the HJC and HFSG campaigns for truth and justice in the aftermath of the disaster. It is in this context that the concept of 'conscientization' in a post-disaster setting is necessary, as it exposes how survival trajectories encompass acts of resistance as a direct response to official corruption (Tedeschi, 1999).

When individuals experience 'conscientization' they are able to challenge discriminatory societal systems instead of adjusting to cope within those systems (Prilleltensky and Prilleltensky, 2005). Therefore, conscientization is the process of survivors realising or becoming aware of the pre-existing structures in society which act to oppress them in a postdisaster setting (Tedeschi, 1999). In this research, conscientization developed personal trajectories of survival by galvanising individuals into grassroots campaigning. Survivors built a collective trajectory of survival, in order to create meaningful change and to improve their personal opportunities to receive support and human connection. Campaign groups grew over the years as more people became aware of the realities of the cover-up. The level of conscientization had a deep social and political impact and created the formation of online communities of care and support. In this way conscientization brought benefits, generated from collective acts of resistance to adversity. One major example would be the organisation of chants for 'Truth and Justice for the $96^{\prime}$ at the $20^{\text {th }}$ anniversary of the disaster, which influenced MP Andy Burnham to commit to filing a FOI request that subsequently led to the Hillsborough Independent Panel Report and the recent inquest verdict.

\section{The Role of Official Recognition to Survival}

The HIP and RIV have officially rectified the misinformation and misinterpretations of Hillsborough, and have now legally registered the 'known' realities surrounding the causes and responses in the immediate aftermath. They have also legally recognised the individuals, agencies and institutions that were responsible for the disaster and the damaging responses to victims/survivors. This represents a significant change in the official approach towards Hillsborough. However, the HIP and RIV have been described by many as 'bitter-sweet'. 
Although the HIP and RIV granted official recognition, a crucial element in helping so many to 'move on' from 'Hillsborough', it was also an anti-climax as participant's knowledge had essentially just been given the 'official' 'seal of approval'.

The recent inquest was heavily criticised for taking an extraordinarily long time, and for causing re-victimisation to those involved (Tempany, 2016). Further, despite official assurances that court proceedings would not be adversarial, defensive agencies continued to regurgitate the same lies and denials employed at the original inquests (Coleman, 2016; Tempany, 2016). The inquest was only a 'success' as the jury saw through the lies and deceptions. Beyond that, the inquests have proved an inadequate means to address survivors' issues. The Coroners Court cannot address the long-term implications of survival, it does not have the remit to provide official redress. 'The survivors' as a unanimous group have had official recognition for their heroic acts of rescue on the day of disaster and have legally been cleared of any causation in the disaster - and that is it. The long-term impact of being misrepresented, blamed and having experiences of victimisation and survival denied has not been rectified in any meaningful or practical way. There has been no processes developed to resolve the injustices and trauma that survivors have faced. Mirroring the situation on the day of the Hillsborough disaster, after the RIV the survivors have been left to continue on with their lives without official supports.

\section{What Is Required for Survival?}

Superficial understandings of survival can stereotypically assume a homogeneous survival response. Therefore, when responding to the needs of survivors, those in power must prioritise the "voices from below" and allow their actions to be informed by those who have experienced the disaster (Davis and Scraton, 1999: 94; Eyre, 2006). This thesis demonstrates that officials cannot pre-empt categorised responses from individuals. Like other disaster literature (Friedman and Thompson, 2003; Newburn, 1993), it acknowledges that human reactions to disaster are diverse, that they change over time in their severity, and will fluctuate along the continuum of survival. 
A proactive response is required from officials. The findings highlight that responding agencies must adopt an inclusive approach informed by the survivor's understanding of what they need, at specific points, during their survival journey. Survivors require official responses that will not further cause distress, trauma or re-victimisation. In order to avoid damaging and 'out-of-touch' responses, officials need to recognise the diverse needs which arise from the distinct trajectories of survival (Davis, 2013). A "polycentric response", in which institutions co-ordinate to construct and implement useful supports, is required to effectively address the complex, multi-dimensional needs of survivors (Davis and Scraton, 1999). Official responses can only be effective in supporting personal survival if they are informed with the knowledge of survival outcomes and experiences by the very group they are trying to help (Davis and Scraton, 1999).

These findings indicate a need for official responses to take a humanitarian focus on survivor welfare, rather than "an impetus towards control" (Davis, 2013: 514; Eyre, 2006). An effective response to survivors cannot be bureaucratised, stemming from a neo-liberal individualised focus, as this prevents empathetic crisis support and does not acknowledge the wide-ranging experiences of victimisation (Davis, 2013; Eyre, 2006). Ongoing communications between survivors and 'helping' agencies are necessary to ensure processes are transparent; their aims and outcomes can then be reviewed, and this will make it easier to hold individuals and agencies to account for their actions (Davis, 2013). This can also challenge the culture of denial and the normalisation of state collusion, corruption and cover-up in the aftermath of disasters. Committing to a humanitarian response is oriented towards accommodating and addressing the diverse and ongoing needs of survivors from disaster (Davis, 2013; Eyre, 2006).

Developing a progressive concept or model of survival will ensure that those in positions of power, in responding to disasters, will be educated on the realities of survival and its various trajectories. As previously discussed, multi-agency responses are politically influenced and can be applied in a way which protects the vested interests of the state and officials (Scraton, 2007; Stanley, 2012). Therefore, responding processes need to be guided by the ethos of prioritising the needs of those affected by disaster. This did not happen for Hillsborough survivors. As one example: in the aftermath of the disaster, a group of survivors wanted to use the safe space at the 'Hillsborough Centre' but did not want an authoritative presence of 
social workers. Their attempt to navigate their survival in a 'different' way was met with hostility and negative judgments from some social workers, which fostered tensions and a negative environment. At a point where official processes might have acted to support survival, the limits of worker's understanding on diverse survival trajectories acted to undermine survival. This 'out-of-touch' application of support emphasised that professionals 'knew best'. If officials adjusted according to the needs of survivors, they could have progressed positive survival trajectories and built survivor-official trust along the way (Davis, 2013).

Writing 20 years after he experienced the Hillsborough disaster, Tempany (2009: para 21) acknowledged that it is obvious "that the very act of surviving a major tragedy changes people's lives and personalities" but what is less obvious is the fact that survivors constantly navigate and negotiate their own survival. This means that there cannot be an assumed 'type' or set of prescribed processes that are automatically enacted as a response. Officials will have to be flexible, will have to be prepared to tailor and adapt their responses as survivors' journeys progress and their needs change and develop. Some requirements for survival appear to be common. For example, this thesis shows that official recognition, professional and personal supports and accurate representation of experiences, are all important elements. However, the importance attached to these common needs will also differ and so again they will need to be addressed on a case-by-case basis (Eyre, 2006). "An approach that is responsive to the needs of individuals rather than being overly prescriptive" is required to assist in supporting long-term survival (Eyre, 2006: 7). These findings illustrate that it is the willingness to accommodate multi-dimensional needs that is an essential requirement in supporting personal survival.

\section{Conclusion}

The term 'survivor' reflects assumptions based in deeply-rooted social stereotypes and therefore will remain inadequate to understand the diverse issues that survivors face. In terms of terminology, the 96 are victims, the bereaved were by their own admissions made victims by official responses (Scraton, 2009; Steve), but the survivors were also victimised and re-victimised in the long-term aftermath. And so although individuals physically survived the 
disaster, the term 'survivor' does not encompass the diverse complexities involved in surviving.

It may be useful, therefore, to consider survival in terms of the 'continuum' (Kelly, 1998). Widening the definition of survival in this way enables victimising incidents to be identified across longer periods of time. The survival continuum deepens the conceptual understandings of the relationship between victim and survivor identities. It develops a critical recognition of diverse forms of victimisation that includes how victims are responded to, why victims are treated in certain ways and what victims need in order to 'survive' (Kelly, 1998; Profitt, 1996). This conception of survival also avoids the mass labelling of individuals as an anonymous 'survivor' group. It prepares for a more 'messy' version of survival trajectories that will require diverse responses from those in a position to provide support and care.

There are established systems and institutional structures which respond to disasters. These were not effectively applied in the Hillsborough case. Here, post-disaster interventions were activated in accordance with a political climate that stigmatised all those who attended football matches and prioritised the interests of the police and other control organisations (HIP Report, 2012). In turn, response systems were not humanitarian or empathetic. Given the reconstruction of the events which placed the blame onto the fans, and perpetuated myths, survivors did not receive long-term assistance or supports (Eyre, 2006). For some, the difficulties of dealing with their trauma alone has been devastating. This thesis points to a requirement, then, for official supports to be actioned in a way which prioritises the needs of survivors and is independent of the concerns of political agendas.

There is no one way to respond to survival and there should be no single prescribed, standardised response to survivors. This thesis has reinforced the importance of moving beyond traditional conceptions of survivors towards a more progressive understanding of the diverse and fluctuating experiences of navigating personal 'survival' (Eyre, 2006). 


\section{Chapter Eight: Conclusion}

State authorities, particularly the police force, used their social status to construct knowledge regarding Hillsborough and its aftermath. Those responsible for the failures before, during and after the disaster used legitimate systems to deflect blame and register a false narrative in the public domain. Various institutions colluded to control responses and to 'manage' survival trajectories in a way which secured impunity for their failures and the subsequent cover-up.

The political climate of the time, which sanctioned a vendetta against working class football fans, created an environment where discrimination against survivors was constructed as necessary actions to control a 'problematic' group. Consequently, wider society was more receptive to accept unjust treatment towards the survivors under the guise of security measures. This laid the ideological foundations for misrepresentations of Hillsborough, and enabled further acts of persecution that were not seen or identified as victimisation.

Accurate representation is essential in delivering an appropriate and effective response. To not represent people as victims, to not identify their experiences as a form of victimisation, has devastating consequences for survival. Hillsborough survivors were denied societal empathy and compassion as they, LFC fans, and even the city of Liverpool were stigmatised via victim-blaming. Hillsborough survivors were never labelled as victims and this exacerbated their suffering and created barriers to survival. It led to denial of their trauma and needs, which proved fatally detrimental for some. Further, being labelled as 'survivors' generated a social expectation that they would be resilient and 'move on'. This placed the entire burden of survival on individuals, and it removed official responsibilities to supply adequate supports. The misrepresentation, lack of recognition and victim-blaming concealed the wider social and political structures that created the climate for ongoing maltreatment.

This thesis proposes that conceptions of survival need to be broadened - they must be flexible, accommodating and informed by the lived experiences of victimisation. The theory of survival existing on a continuum is a more accurate representation of the various 'types' of 
survival. Conceptualising survival in this way gives victims/survivors the power to identify and articulate the multi-dimensional aspects of survival they experience. There are common pathways to survival and common barriers; however the extent and degree to which they are experienced is not the same. Survival cannot be generalised as, in reality 'the survivors' are not a homogenous group. Survival is a highly complicated varied experience, it is constantly affected by outside factors at official and personal levels, and survivors continuously navigate their way through their survival.

Survivors can embody 'victim' and 'survivor' identities at different points in time or may identify characteristics of both identities simultaneously. This thesis illustrates it is essential that responses to survivors are receptive to all possible trajectories and reactions. Acknowledging the changeable nature of survival existing as a continuum allows respondents to retain a level of preparedness to address the complex implications of survival. This thesis demonstrates that survivors want to move forward in continuing a life after 'Hillsborough'. However, they require responses which will not cause further trauma, re-victimisation, or undermine personal efforts at survival. Therefore, survivors should be involved in developing official and professional responses to ensure they are relevant, appropriate and effective.

This thesis also illustrates that when official responses do not meet requirements for survival, people will often endeavour to resist them. In many official and unofficial, personal and collective ways, individuals surviving the experience of 'Hillsborough' have resisted against their unjust treatment. A collective survival trajectory formed where people who experienced Hillsborough came together, creating numerous networks of solidarity and support for one another. United dissatisfaction concerning official responses led to a grassroots oppositional campaign that exposed the wider social and political implications of the disaster and coverup. These networks and campaigns grew mass support over the years and consistently challenged official responses and rulings, and their efforts proved successful with the Hillsborough Independent Panel Report (2012) and the recent inquest verdicts (2016). Following these events, at the very least, it would be reasonable for survivors to be given appropriate recognition and necessary supports to deal with their past victimisation. 
This research has demonstrated that those affected by the injustices and traumas of Hillsborough are still waiting for an appropriate and meaningful response from state authorities. As Nick explained, "we haven't got justice, we've got the truth, that's all we've got, and we haven't even got the truth, we've got one verdict in one court". Justice means different things to different people, however, a unanimous concern is that 'Hillsborough' must not happen again. The criminal investigations are ongoing, the creation of a 'Hillsborough Law' has been suggested - however, as of yet, official responses attempting to rectify the impacts of the systemic cover-up have not materialised. Steve indicated the current situation for the 'Hillsborough community': "don't forget in a few years there'll be more papers to come out from Margaret Thatcher...this is not the end...so we'll have to brace ourselves for even more". The 'Hillsborough community' has struggled tirelessly against immeasurable adversity. To ensure future generations are not embroiled in a never-ending fight for 'justice', official responses must now be deeply rooted in the principles of care and social justice and committed to preventing state collusion and cover-up. 


\section{References}

Alatartseva, E., \& Barysheva, G. (2015). Well-being. Procedia: Social and Behavioral Sciences, 166(7), 36-42. DOI: 10.1016/j.sbspro.2014.12.479

Armstrong, L. (2012). Reflections on a research process. Women's Studies Journal, 26(1), 210.

Aspinall, M. (2013, April 15). Thousands attend Hillsborough memorial at Anfield. The Scotsman. Retrieved from: http://www.scotsman.com/news/uk/thousands-attendhillsborough-memorial-at-anfield-1-2896057

Barlow, E. (2016, July 14). Andy Burnham: We won't have full truth on Hillsborough until we know what happened at Orgreave. Echo. Retrieved from: http://www.liverpoolecho.co.uk/news/liverpool-news/andy-burnham-wont-fulltruth-11615019

Becker, H. S. (1963). Outsiders. New York: The Free Press, a division of Simon \& Schuster Inc.

Becker, H. S. (1967). Whose side are we on?. Social Problems, 14(3), 239-247.

Belknap, J. (2015). Activist Criminology: Criminologists' Responsibility to Advocate for Social and Legal Justice. Criminology, 53(1), 1-22.

Berger, R. (2015). Now I see it, now I don't: researcher's position and reflexivity in qualitative research. Qualitative Research, 15(2), 219-234.

Brown, C., \& Alcoe, J. (2010). The heart of wellbeing: A self-help approach to recovering, sustaining and improving wellbeing. Journal of holistic healthcare, 7(1), 24-28.

Chesshyre, R. (2012, September 15). Thatcher's "boot boys": When the unholy trinity of police, press and government took root. Independent. Retrieved from: http://www.independent.co.uk/voices/comment/thatchers-boot-boys-when-theunholy-trinity-of-police-press-and-government-took-root-8139816.html

Christie, N. (1986). The Ideal Victim. In E.A. Fattah (Ed.), From Crime Policy to Victim Policy: Reorientating the Justice System. 17-47. London: The Macmillan Press Ltd.

Christie, N. (1986a). Suitable Enemies. In Herman Bianchi and Rene von Swaaningen (Eds.), Abolitionism: toward a non-repressive approach to crime. Amsterdam: Free University Press. 
Cohen, S. (1993). Human Rights and crimes of the state: the culture of denial. Australia \& New Zealand Journal of Criminology, 26(2), 97-115.

Coleman, S. (2009). Hillsborough - 20 years and still no justice. Nerve. Retrieved from: http://www.catalystmedia.org.uk/archive/issues/nerve14/hillsborough_20years.php

Coleman, S. (2009a, April 14). In M. Bracken, This is my Hillsborough. The Guardian. Retrieved from: https://www.theguardian.com/lifeandstyle/2009/apr/14/hillsborough-posttraumatic-stress-disorder

Coleman, S. (2012, October 26). Critical Research Seminar Series: Hillsborough Collusion \& Cover up [Video file]. The Centre for the study of Crime, Criminalisation and Social Exclusion. Liverpool John Moores University. Retrieved from: https://www.youtube.com/watch?v=ekc4tDL5jtM

Coleman, S. (2015). Hillsborough: The Long Struggle to Expose Police Corruption. In D. Whyte (Ed.), How Corrupt is Britain?. 85-93. London: Pluto Books. Retrieved from http://www.jstor.org/stable/j.ctt183p7g4.10

Coleman, S. (2016). Hillsborough, Orgreave and the lessons for the fight for justice [Video file]. Marxism Festival. Retrieved from: https://www.youtube.com/watch?v=iSS1s7pB1Bg

Copp, M.A. (2008). Emotions in Qualitative Research. In L. M. Given (Ed.), The SAGE Encyclopedia of Qualitative Research Methods. 1-6. Sage Knowledge. Retrieved from: http://sk.sagepub.com/reference/download/research/n131.pdf

Croall, H. (2007). Social Class, Social Exclusion, Victims and Crime. In P. Davis., P. Francis \& C. Greer (Eds.), Victims, Crime and Society. 50-78. UK: Sage Publications Ltd.

Crotty, M. (1998). The Foundation of Social Research: Meaning and Perspective in the Research Process. Australia: Allen \& Unwin.

Davis, H. (2013). Contextual Challenges for Crisis Support in the Immediate Aftermath of Major Incidents in the UK. British Journal of Social Work, 43(3), 504-521.

Davis, H., \& Scraton, P. (1999). Institutionalised Conflict and the Subordination of 'Loss' in the Immediate Aftermath of UK Mass Fatality Disasters. Journal of Contingencies and Crisis Management, 7(2), 86-97.

Derbyshire, K. (2012, September 12). 'Hillsborough took away my life'- a survivor's story of the 1989 disaster. By J. Brown. Independent. Retrieved from: http://www.independent.co.uk/news/uk/crime/hillsborough-took-away-my-life-asurvivors-story-of-the-1989-disaster-8129860.html 
Dickson-Swift, V., James, E.L., Kippen, S., \& Liamputtong, P. (2009). Researching sensitive topics: qualitative research as emotion work. Sage Publications. Qualitative Research, 9(1), 61-79.

Dignan, J. (2005). Victims, victimization and victimology. In M. Maguire (Ed.), Understanding victims and restorative justice. 13-40. New York: Open University Press.

Edwards, C., \& Imrie, R. (2008). Disability and the Implications of the Wellbeing Agenda: Some Reflections from the United Kingdom. Journal of Social Policy, 37(3), 337-355.

Faust, K.L. \& Kauzlarich, D. (2008). Hurricane Katrina Victimization as a State Crime of Omission. Critical Criminology, 16(2), 85-103.

Fetterman, D. (2008). Key Informant. In L.M. Given (Ed.), The Sage Encyclopedia of Qualitative Research Methods. Thousand Oaks: Sage Publications Inc. 477-478. Retrieved from: http://methods.sagepub.com/base/download/ReferenceEntry/sage-encycqualitative-research-methods/n243.xml

Foucault, M. (1982). The Subject and Power. Critical Inquiry, 8(4), 777-795.

Freire, P. (2005). Pedagogy of the Oppressed. (Translated by M. Bergman Ramos with an introduction by D. Macedo). 30th anniversary edition. New York: The Continuum International Publishing Group Inc.

Friedman, L.M. \& Thompson, J. (2003). Total Disaster and Total Justice: Responses to ManMade Tragedy. DePaul Law Review, 53(2), 251-287.

Friedrichs, D. O. (2009). Critical Criminology. In M.J. Miller (Eds.), 21st Century Critical Criminology: A Reference Handbook Vol 1. 210-219. USA: Sage Publications Inc.

Grbich, C. (2013). Qualitative Data Analysis (2nd Ed.). London, UK: Sage Publications Ltd.

Green, P. (2005). Disaster by Design: Corruption, Construction and Catastrophe. The British Journal of Criminology, 45(4), 528-546.

Green, P. (2008). Women and Natural Disasters: State Crime and Discourses in Vulnerability. In M. Cain \& A. Howe (Eds.), Women, Crime and Social Harm. 161-179. North America: Hart Publishing.

Hartley, H.J. (2002). A Part on the River: The 1989 Marchioness disaster-regulation of safety on the River Thames and the 'political economy' of risk. World Leisure Journal, 44(4), 30-43.

Hicks, T. (2016, April 26). 'I was calling their names in the hope they'd know we were there': The harrowing inquest evidence of father whose two daughters were crushed to death 
at Hillsborough. By S. Cockroft \& R. Spillit. MailOnline. Retrieved from: http://www.dailymail.co.uk/news/article-3557885/Harrowing-evidence-givenfamilies-told-tragedy-96-victims.html

Hillsborough Independent Panel (2012). Hillsborough: The Report of the Hillsborough Independent Panel, House of Commons. HC581. London: The Stationery Office Ltd. ISBN 9780102980356.

Hillsborough Inquest Verdict, (2016). Retrieved from: https://hillsboroughinquests.independent.gov.uk/

Hobfoll, S.E., Watson, P., Bell, C.C., Bryant, R.A., Brymer, M.J., Friedman, M.J., Friedman, M., Gersons, B.P., de Jong, J.T., Layne, C.M., Maguen, S., Neria, Y., Norwood, A.E., Pynoos, R.S., Reissman, D., Ruzek, J.I., Shalev, A.Y., Solomon, Z., Steinberg, A.M. \& Ursano, R.J. (2007). Five Essential Elemenets of Immediate and Mid-Term Mass Trauma Intervention: Empirical Evidence. Psychiatry, 70(4), 283-315.

Hooks, J. P. \& Miller, T. B. (2006). The Continuing Storm: How Disaster Recovery Excludes Those Most in Need. California Western Law Review, 43(1), 21-74.

Howarth, G. \& Rock, P. (2000). Aftermath and the Construction of Victimisation: 'The Other Victims of Crime'. The Howard Journal, 39(1), 58-78.

Hughson, J. \& Spaaij, R. (2011). 'You are always on our mind': The Hillsborough tragedy as cultural trauma. Acta Sociologica, 54(3), 283-295.

Hull, A.M., Alexander, D.A. \& Klein, S. (2002). Survivors of the Piper Alpha oil platform disaster: long-term follow-up study. British Journal of Psychiatry, 181(5), 433-438.

Hume, M. (2016, May 3). Hillsborough: A few truths they still want to hide. Spiked. Retrieved from: http://www.spiked-online.com/newsite/article/hillsborough-a-few-truthsthey-still-want-to-hide/18318\#.V-3kEYh96Uk

Johnson, N. (2009). The role of self and emotion within qualitative sensitive research: a reflective account. Enquire 2(2), 191-214.

Jones, D. \& Fallon, L. (Interviewees), \& Gordon, D. (director). (2014). ESPN 30 for 30: Soccer Stories: Hillsborough [Video file]. Retrieved from: https://www.youtube.com/watch?v=qBbifoVdyGM

Jordan, J. (2013). From Victim to Survivor- and from Survivor to Victim: Reconceptualising the Survivor Journey. Sexual Abuse in Australia and New Zealand, 5(2), 48-56. 
Kavanagh, D. (2005, September 11). 'God, please get me out': As Hillsborough documents set to be released, one survivor recalls football's darkest day. Mirror. Retrieved from: http://www.mirror.co.uk/news/uk-news/hillsborough-documents-released-survivordamian-1317380

Kelly, L. (1988). Surviving Sexual Violence. UK: Polity Press in Association with Basil Blackwell. Lamont, M. \& White, P. (2005). Workshop on Interdisciplinary Standards for Systematic Qualitative Research: Cultural Anthropology, Law and Social Science, Political Science, and Sociology Programs. National Science Foundation. 1-180. Retrieved from: http://www.nsf.gov/sbe/ses/soc/ISSQR_rpt.pdf\#page $=70$

Leichenko, R., McDermott, M., \& Bezborodko, E. (2015). Barriers, Limits and Limitations of Resilience. Journal or Extreme Events, 2(1), 1-27.

Lindy, J.D. \& Tichener, J. (1983). "Acts of God and Man":* Long-term Character Change in Survivors of Disasters and the Law. Behavioral Sciences \& The Law, 1(3), 85-96.

Macintyre, D. (2014, June 16). How the miners' strike of 1984-85 changed Britain for ever. NewStatesman. Retrieved from: http://www.newstatesman.com/politics/2014/06/how-miners-strike-1984-85changed-britain-ever

Manyena, S. B., O’Brian, G., O’Keefe, P., \& Rose, J. (2011). Disaster resilience: a bounce back or bounce forward ability?. Local Environment: The International Journal of Justice and Sustainability, 16(5), 417-424.

McArdle, H. (2016, January 14). Ibrox disaster Sheriff, Irvine Smith QC, dies aged 89. Herald Scotland. Retrieved from: http://www.heraldscotland.com/news/14202350.Ibrox_disaster_Sheriff_Irvine_Sm ith_QC_dies_aged_89/

McCabe, J. \& Holmes, D. (2009). Reflexivity, critical qualitative research and emancipation: a Foucauldian perspective. Journal of advanced nursing, 65(7), 1518-1526.

McDougall, N. (2015, July 9). Interview: A Hillsborough survivor speaks. By W. Duncan. The Point. Retrieved from: http://www.thepointhowever.org/index.php/issues/117interview-a-hillsborough-survivor-speaks

McGreavy, B. (2015). Resilience as Discourse. Environmental Communication: A Journal of Nature and Culture, 10(1), 104-121. 
McLaughlin, E. (2010). Critical Criminology. In E. McLaughlin \& T. Newburn (Eds.), The Sage handbook of Criminological Theory. 153-174. London: Sage Publications Ltd.

McMillan, N. (2009). The Hillsborough Football Disaster: Context \& Consequences. UK: EM Project Lt. Retrieved from: www.hfdinfo.com

Moore, S. (2016, April 27). The Hillsborough verdict shatters the fantasy that class war doesn't exist. The Guardian. Retrieved from: https://www.theguardian.com/commentisfree/2016/apr/27/the-hillsboroughverdict-shatters-the-fantasty-that-class-war-doesnt-exist

Morgan, L., Scourfield, J., Williams, D., Jasper, A. \& Lewis, G. (2003). The Aberfan disaster: 33year follow-up of survivors. British Journal of Psychiatry, 182(6), 532-536.

Muncie, J. (2000). Decriminalising Criminology. In G. Mair \& R. Tarling (Eds.), The British Criminology Conference: Selected Proceedings Volume 3. Liverpool: British Society of Criminology.

Nelson, M. (accessed 2016). Hillsborough Survivors. LFChistory. Retrieved from: http://www.Ifchistory.net/Articles/Article/2890

Newburn, T. (1993). Working with Disaster: Social welfare interventions during and after tragedy. UK: Longman Group UK Ltd.

Nicol, P. in Scraton, P. (2004). Death on the Terraces: The Contexts and Injustices of the 1989 Hillsborough Disaster. Soccer and Society, 5(2), 183-2000.

Nissim-Sabat, M. (2009). Neither Victim nor Survivor: Thinking Toward a New Humanity. UK: Lexington Books.

Norris, F.H., Friedman, M.J. \& Watson, P.J. (2002). 60,000 Disaster Victims Speak: Part II. Summary and Implications of the Disaster Mental Health Research. Psychiatry, 65(3), 240-260.

NSW Health. (2012). Disaster Mental Health: Handbook 1- Resilience \& Disaster Adaptations. Collaboration with Disaster Response \& Resilience Research Group, University of Western Sydney. 2-58. Australia: Disaster Response \& Resilience Research Group, University of Western Sydney.

Olson, R.S. (2000). Toward a Politics of Disaster: Losses, Values, Agendas, and Blame. International Journal of Mass Emergencies and Disasters, 18(2), 265-287.

Orgad, S. (2009). The Survivor in Contemporary Culture and Public Discourse: A Genealogy. The Communication Review, 12(2), 132-161. 
Peirce, G. (2010). Gareth Peirce: Why I Still Fight for Human Rights. The Guardian. Article by S. Jeffries. Retrieved from: https://www.theguardian.com/law/2010/oct/12/garethpeirce-fight-human-rights

Pillow, W. (2003). Confession, catharsis, or cure? Rethinking the uses of reflexivity as methodological power in qualitative research. International Journal of Qualitative Studies in Education, 16(2), 175-196.

Prilleltensky, I. (2008). The role of power in wellness, oppression, and liberation: the promise of psychopolitical validity. Journal of Community Psychology, 36(2), 116-136.

Prilleltensky, I., \& Prilleltensky, O. (2005). Beyond Resilience: Blending Wellness and Liberation in the Helping Professions. In M. Ungar (Ed.), Handbook for working with children and youth: Pathways to resilience across cultures and contexts. 89-105. Thousand Oaks, CA: Sage Publications.

Profitt, N.J. (1996). "Battered Women" as "Victims" and "Survivors": Creating Space for Resistance. Canadian Social Work Review, 13(1), 23-38.

Quinney, R. (1972). Who is the Victim?. Criminology, 10(3), 314-323.

Rager, K.B. (2005). Compassion Stress and the Qualitative Researcher. Qualitative Health Research, 15(3), 423-430. Sage Publications.

Rangers Football Club. (accessed 2016). Ibrox Disasters. Website by Blue2. Retrieved from: http://rangers.co.uk/club/history/ibrox-disasters/

Reade, B. (2012, September 14). Brian Reade on Hillsborough: The police have been allowed to believe they have a right to operate above the law. Mirror. Retrieved from: http://www.mirror.co.uk/news/uk-news/brian-reade-hillsborough-police-havebeen-1323332

Schwendinger, H., \& Schwendinger, J. (1970). Defenders of Order or Guardians of Human Rights?. Issues in Criminology, 5(2), 123-157.

Scraton, P. (1999). Policing with Contempt: The Degrading of Truth and Denial of Justice in the Aftermath of the Hillsborough Disaster. Journal of Law and Society, 26(3), 273297.

Scraton, P. (2002). Defining 'power' and challenging 'knowledge': critical analysis as resistance in the UK. In K. Carrington \& R. Hogg (Eds.), Critical Criminology: Issues, debates, challenges. 15-40. Devon: Willan Publishing. 
Scraton, P. (2004). Death on the Terraces: The Contexts and Injustices of the 1989 Hillsborough Disaster. Soccer and Society, 5(2), 183-2000.

Scraton, P. (2007). Power, Conflict and Criminalisation. Oxon: Routledge.

Scraton, P. (2009). Hillsborough: The Truth. UK: Mainstream Publishing Company (Edinburgh) Ltd.

Scraton, P. (2009a). "Hearing Voices, Bearing Witness": Reflections on Critical Analysis in Criminology. In C. Powell (Ed.), Critical Voices in Criminology: Critical Perspectives on Crime and Inequality. 143-183. Plymouth UK: Lexington Books a division of Rowman \& Littlefield Publishers Inc.

Scraton, P., Jemphrey, A., \& Coleman, S. (1995). No Last Rights: The Denial of Justice and Promotion of Myth in the Aftermath of the Hillsborough Disaster. Liverpool: Liverpool City Council.

Shaw, K. (2012). The Rise of the Resilient Local Authority?. Local Government Studies, 38(3), 281-300.

Shennan, P. (2012, September 11). Hillsborough: Andy Burnham MP on a major turning point in the campaign for justice - the day he was barracked at Anfield. Echo. Retrieved from: http://www.liverpoolecho.co.uk/news/liverpool-news/hillsborough-andyburnham-mp-major-3334516

Solomon, M.J. \& Thompson, J. (1995). Anger and blame in three technological disasters. Stress Medicine, 11(1), 199-206.

Spring, U. O. (2011). Social Vulnerability, Discrimination, and Resilience-building in Disaster Risk Reduction. In H. G. Brauch., U. O. Spring., C. Mesjasz., Grin, J., P. Kameri-Mbote., B. Chourou., P. Dunay., \& J. Birkmann (Eds.), Coping with Global Environmental Change, Disasters and Security: Threats, Challenges, Vulnerabilities and Risks. 11691188. Springer. DOI: 10.1007/978-3-642-17776-7.

Stanley, E. (2009). Torture, Truth and Justice, London: Routledge Taylor \& Francis Group.

Stanley, E. (2012). Interviewing Victims of State Violence. In D. Gadd., S. Karstedt., \& S.F. Messner (Eds.), The Sage Handbook of Criminological Research Methods. 231-243. London: Sage Publications Ltd. ISBN: 978-184920-175-9

Taylor, D. (2011). Wellbeing and Welfare: A Psychosocial Analysis of Being Well and Doing Well Enough. Journal of Social Policy, 40(4), 777-794. 
Taylor, LJ. RT Hon. (1990). The Hillsborough Stadium Disaster Interim Report. London: Her Majesty's Stationary Office.

Tedeschi, R. G. (1999). Violence Transformed: Posttraumatic Growth in Survivors and their Societies. Aggression and Violent Behavior, 4(3), 319-341.

Tempany, A. (2009, March 15). Twenty years after Britain's worst stadium disaster, Adrian Tempany and five other survivors describe the impact Hillsborough has had on their lives. The Guardian. Retrieved from: https://www.theguardian.com/football/2009/mar/15/hillsborough-disastersurvivors

Tempany, A. (2016). And the Sun Shines Now: How Hillsborough and the Premier League Changed Britain. London: Faber \& Faber.

Ugwudike, P. (2015). An Introduction to Critical Criminology. Policy Press: Bristol.

United Nations Development Programme. (2014). Human development report 2014: Sustaining human progress: Reducing vulnerabilities and building resilience. Retrieved from: http://hdr.undp.org/sites/default/files/hdr14-report-en-1.pdf

Urbatsch, R. (2016). Judgement days: moral attitudes in the wake of local disasters. Disasters, 40(1), 26-44.

van der Velden, P.G., Wong, A., Boshuizen, H.C. \& Grievink, L. (2013). Persistent mental health disturbances during the 10 years after a disaster: Four-wave longitudinal comparative study. Psychiatry and Clinical Neurosciences, 67(2), 110-118.

Verchick, R. R. M. (2012). Disaster Justice: The Geography of Human Capability. Duke Environmental Law \& Policy Forum, 23(1), 23-71.

Walker, G. (2005). 'The Ibrox Stadium Disaster of 1971' In P. Darby, M. Johnes., \& G, Mellor (Eds.), Soccer and Disaster: International Perspectives. 45-59. New York: Routledge, an imprint of the Taylor \& Francis Group.

Walklate, S. (2007). Imagining the victim of crime. New York: Open University Press.

Walklate, S. (2015). Jock Young, Left Realism and Critical Victimology. Critical Criminology, 23:179-190. DOI 10.1007/s10612-015-9274-7.

Watts, J.H. (2008). Emotion, empathy and exit: reflections on doing ethnographic qualitative research on sensitive topics. Medical Sociology Online, 3(2), 3-14.

White, J. (2009, April 15). Liverpool fans turn on Andy Burnham at Hillsborough memorial. The Telegraph. 
http://www.telegraph.co.uk/sport/football/teams/liverpool/5160448/Liverpoolfans-turn-on-Andy-Burnham-at-Hillsborough-memorial.html

White, M. (2011, October 18). Hillsborough disaster: a case of class injustice?. The Guardian. Retrieved from: https://www.theguardian.com/football/blog/2011/oct/18/hillsborough-disasterclass-injustice 


\section{Appendix One: Ethics Materials}

\section{Surviving Hillsborough}

Research Information Sheet

Hello, my name is Sally Day. I am a Criminology Master's student at Victoria University of Wellington. I moved to New Zealand from the UK in 2004 with my family, and we all strongly support the Hillsborough campaign for truth and justice.

Please read the following information about my research project. If you decide to take part you will be given a consent form to sign. Victoria University requires, and has granted, approval from the Human Ethics Committee for this research to proceed (0000022632).

\section{THE RESEARCH}

This research is led by the question: What factors have enabled Hillsborough survivors to "survive"? The study will chart survivors' experiences in the years after the disaster, and identify the factors that have helped survivors to 'survive' or gain a sense of well-being.

\section{THE INTERVIEW}

If you agree to be interviewed, you will take part in an interview of between 1-2 hours, in a location of your choosing. During this time, we will talk about your experiences after the Hillsborough disaster. I am keen to hear your thoughts on how you, and others, have come to build positive lives after Hillsborough. I also want to know what words or actions by others have particularly helped you during this time.

At any time during the interview process you can take a break or stop the interview. You do not have to answer any questions that you do not want to. You are welcome to have a support person present and I can also advise you of available support services.

\section{FEEDBACK AND FINDINGS}

If you agree, I will digitally record the interview, and a transcript of the interview will be sent to you for checking. A summary of the research findings, and a copy of the Master's thesis, will also be available to you, once completed. 
All material collected will be kept confidential, and will be viewed only by myself and my supervisor, Dr Elizabeth Stanley at the Institute of Criminology. The thesis will be submitted for marking to the School of Social and Cultural Studies. Aside from the MA thesis, findings may be published in other sources, such as academic journals or conference collections.

\section{PARTICIPATION AND PROTECTION}

Unless you choose to, you will not be identified personally in any written output. You may choose a pseudonym.

Should you wish to withdraw from the project, you may do so until 1st May 2016. All relevant data (digital recording; transcripts) will be destroyed. Regardless, all data will be destroyed within two years of thesis completion. I may wish to use the data for academic purposes within the two years and I will contact you to ask your permission first.

\section{FURTHER INFORMATION}

If you have any questions or would like to receive further information about the project, please contact me at daysall@myvuw.ac.nz or call/text 0064-277466283. You may also contact my supervisor, Dr Elizabeth Stanley at elizabeth.stanley@vuw.ac.nz or telephone 0064-4-463 5228 (landline). If you have any queries regarding the ethics process and approval please contact Associate Professor Susan Corbett at susan.corbett@vuw.ac.nz or telephone 0064-4-463 5480 (landline).

Thank you for your time and understanding.

sally Day 


\section{Surviving Hillsborough}

\section{Key Informant Information Sheet}

Hello, my name is Sally Day. I am a Criminology Master's student at Victoria University of Wellington. I moved to New Zealand from the UK in 2004 with my family, and we all strongly support the Hillsborough campaign for truth and justice.

Please read the following information about my research project. If you decide to take part you will be given a consent form to sign. Victoria University requires, and has granted, approval from the Human Ethics Committee for this research to proceed (0000022632).

\section{THE RESEARCH}

This research is led by the question: What factors have enabled Hillsborough survivors to "survive"? The study will chart survivors' experiences in the years after the disaster, and identify the factors that have helped survivors to 'survive' or gain a sense of well-being.

\section{THE INTERVIEW}

If you agree, you will take part in an interview of between 1-2 hours, in a location of your choice. We will talk about what experiences have affected your journey of living with 'Hillsborough'. We will also discuss what you have learnt is required for people to gain a sense of wellbeing in this context. At any time during the interview you can take a break or stop the interview. You do not have to answer any questions that you do not want to.

\section{FEEDBACK AND FINDINGS}

If you agree, I will digitally record the interview, and a transcript of the interview will be sent to you for checking. A summary of the research findings, and a copy of the Master's thesis, will also be available to you, once completed. Throughout the research process only myself and my supervisor will have access to the data. The thesis will be submitted for marking to the School of Social and Cultural Studies. Aside from the MA thesis, findings may be published in other sources, such as academic journals or conference collections. 
Unless you request otherwise, your name will be used within outputs. Should you wish to withdraw from the project, you may do so until 1st May 2016, at which point all relevant data (digital recording; transcripts) will be destroyed. Regardless, all data will be destroyed within two years of thesis completion. I may wish to use the data for academic purposes within the two years and I will contact you to ask your permission first.

\section{FURTHER INFORMATION}

If you have any questions or would like to receive further information about the project, please contact me at daysall@myvuw.ac.nz or call/text 0064-277466283. You may also contact my supervisor, Dr Elizabeth Stanley at elizabeth.stanley@vuw.ac.nz or telephone 0064-4-463 5228 (landline). If you have any queries regarding the ethics process and approval please contact Associate Professor Susan Corbett at susan.corbett@vuw.ac.nz or telephone 0064-4-463 5480 (landline).

Thank you for your time

sally Day 


\section{Surviving Hillsborough \\ Participant Consent Form}

\section{Researcher: Sally Day, VUW Criminology Master's Student}

If you are willing to be interviewed, please read and tick the following statements:

I have been provided with adequate information relating to the nature and objectives of this research project. I have understood that information and been given the opportunity to seek further clarification, or ask any questions.

I voluntarily consent to participate in the study as outlined to me.

I understand I have the right to decline to answer any question or to end the interview at any time.

I understand that I have the right to use a pseudonym.

I understand that any information or opinions I provide will be kept confidential to the researcher and her supervisor.

I understand that the information and opinions I provide will be used only for this research thesis, and related academic outputs such as journal articles or conference presentations. I understand that I may withdraw from this study until $1^{\text {st }}$ May 2016, without providing reasons and without prejudice.

I understand that if I withdraw from the project, any data I have provided will be destroyed. I understand that when this research is completed, all data will be destroyed within two years and the researcher will request permission of any further use within those two years.

Please circle preference:

I would/would not like a copy of the transcript of my interview.

I would/would not like to receive a copy of the summary/final thesis and have added my email address below.

Name:

Preferred Pseudonym:

Email/Postal Address:

Sign:

Date: 


\section{Surviving Hillsborough}

\section{Key Informant Consent Form}

\section{Researcher: Sally Day, VUW Criminology Master's Student}

If you are willing to be interviewed, please read and tick the following statements:

I have been provided with adequate information relating to the nature and objectives of this research project, I have understood that information and have been given the opportunity to seek further clarification, or ask any questions.

I voluntarily consent to participate in the study as outlined to me.

I understand I have the right to decline to answer any question or to end the interview at any time.

I understand that any information or opinions I provide will be kept confidential to the researcher and her supervisor.

I understand that the information and opinions I provide will be used only for this research thesis, and related academic outputs such as journal articles or conference presentations.

I understand that I may withdraw from this study until $1^{\text {st }}$ May 2016, without providing reasons and without prejudice.

I understand that if I withdraw from the project, any data I have provided will be destroyed. I understand that when this research is completed, all data will be destroyed within two years and the researcher will request permission of any further use within those two years.

Please circle preference:

I would/would not like a copy of the transcript of my interview.

I would/would not like to receive a copy of the summary/final thesis and have added my email address below.

I would/would not like to use a pseudonym: Preferred Pseudonym:

Name:

Email/Postal Address:

Sign:

Date: 


\section{Appendix Two: Interview Schedule}

\section{Participant Interview Schedule}

Each interview had specific questions informed by my understanding of participants' individual experiences of Hillsborough. However, each interview was framed with a generic focus on issues of survival, these included: survivor identity, survival processes/actions, representations, wider barriers, and positive changes, to name a few. This appendix provides an indication of generic questions.

\section{Questions to Survivors}

Do you identify as being either a 'victim' or 'survivor' of Hillsborough? (Would you say you have 'survived' Hillsborough? Does neither term apply?).

Are there different stages to survival?

Do you feel there could be an ending/resolution to your 'survival' journey?

There is an emphasis in disaster literature on victims being encouraged to be 'resilient' and 'move on', what is your view on that?

There are other factors that can provide healing/outlets for people such as job security, engagement in the local community and positive levels of health. What role have these dimensions played in your journey of coping with Hillsborough?

Up until just recently, survivors have often been publicly blamed for the disaster. What did you make of this?

Those responsible for the disaster and cover up have been members of official institutions, how do you think those unique circumstances have affected your survival journey?

What things have been detrimental to your coping in the aftermath? 
What do you believe is required for survivors to be able to move forward and gain a sense of wellbeing?

Key Informant Questions

There are many different definitions of what it means to 'survive'. Following Hillsborough, how have you witnessed survivors try to 'survive' their experiences?

In the media the survivors were very quickly grouped together and branded 'survivors'; what was the impact on survivors not receiving the same treatment as if they were considered victims?

Do survivors need particular forms of support or specialised care? What would be best? And why do you think survivors have not had such supports?

Do you think it is important for people to understand the wider political context of Hillsborough, in terms of understanding survival journeys?

What has been the impact of campaigning on processes of survival? Has it made survival easier / more difficult? 